LBNL-44869

\title{
Estimates of the Achievable Potential for Electricity Efficiency Improvements in U.S. Residences
}

by

\author{
Richard Brown
}

\begin{abstract}
Masters Project
Submitted in Partial Satisfaction of the Requirements for the Degree

Master of Arts

in the

Energy and Resources Group

of the

University of California, Berkeley

May 18, 1993
\end{abstract}

http://enduse.lbl.gov/

This work was supported by the Assistant Secretary for Conservation and Renewable Energy, Office of Planning and Analysis and Office of Building Technologies, and the Deputy Undersecretary of the Office of Policy, Planning, and Analysis of the U.S. Department of Energy under Contract No. DE-AC03-76SF00098. 



\begin{abstract}
This paper investigates the potential for public policies to achieve electricity efficiency improvements in U.S. residences. This estimate of achievable potential builds upon a database of energy-efficient technologies developed for a previous study estimating the technical potential for electricity savings. The savings potential and cost for each efficiency measure in the database is modified to reflect the expected results of policies implemented between 1990 and 2010. Factors included in these modifications are: the market penetration of efficiency measures, the costs of administering policies, and adjustments to the technical potential measures to reflect the actual energy savings and cost experienced in the past. When all adjustment factors are considered, this study estimates that policies can achieve approximately $45 \%$ of the technical potential savings during the period from 1990 to 2010 . Thus, policies can potentially avoid $18 \%$ of the annual frozen-efficiency baseline electricity consumption forecast for the year 2010. This study also investigates the uncertainty in best estimate of achievable potential by estimating two alternative scenarios -- a "higher penetration, lower cost" scenario and a "lower penetration, higher cost" scenario. These are intended to encompass a range of possibilities for future energy-efficiency policies. The scenarios suggest that policies can achieve between $36 \%$ and $58 \%$ of the technical potential electricity savings during the 1990 to 2010 period.
\end{abstract}




\section{Acknowledgements}

This work was supported by the Assistant Secretary for Conservation and Renewable Energy, Office of Planning and Analysis and Office of Building Technologies, and the Deputy Undersecretary of the Office of Policy, Planning, and Analysis of the U.S. Department of Energy under Contract No. DE-AC03-76SF00098.

I would also like to thank my two readers, Dr. Jonathan Koomey and Professor Mark Christensen, for helpful comments and guidance.

\section{Disclaimer}

This document was prepared as an account of work sponsored by the United States Government. While this document is believed to contain correct information, neither the United States Government nor any agency thereof, nor the Regents of the University of California, nor any of their employees, makes any warranty, express or implied, or assumes any legal responsibility for the accuracy, completeness, or usefulness of any information, apparatus, product, or process disclosed, or represents that its use would not infringe privately owned rights. Reference herein to any specific commercial product, process, or service by its trade name, trademark, manufacturer, or otherwise, does not necessarily constitute or imply its endorsement, recommendation, or favoring by the United States Government or any agency thereof, or The Regents of the University of California. The views and opinions of authors expressed herein do not necessarily state or reflect those of the United States Government or any agency thereof or The Regents of the University of California. 


\section{Table of Contents}

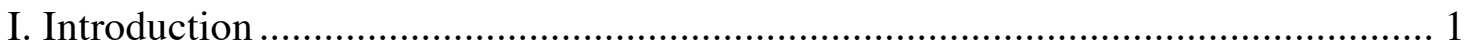

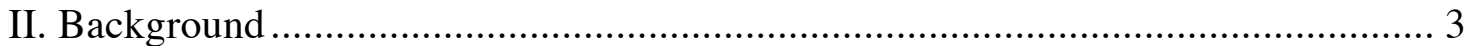

A. Supply Curves of Conserved Energy ......................................................... 3

B. Supply Curve Methods.......................................................................... 3

C. U.S. Residential Technical Potential ........................................................ 6

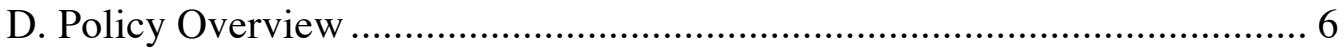

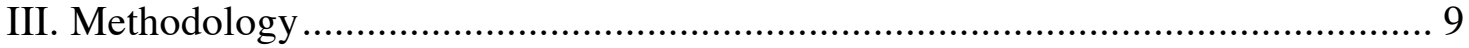

IV. Market Penetration Analysis .......................................................................... 10

A. Market Penetration Background............................................................... 10

B. Market Penetration Example …………………………............................ 11

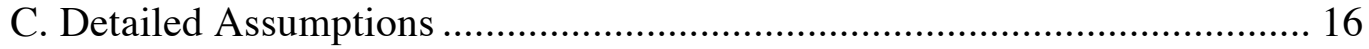

1. Thermal Shell …………......................................................... 16

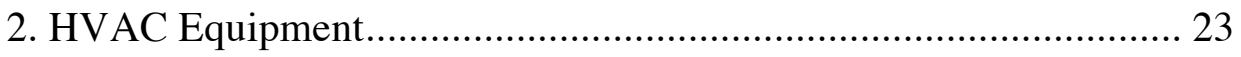

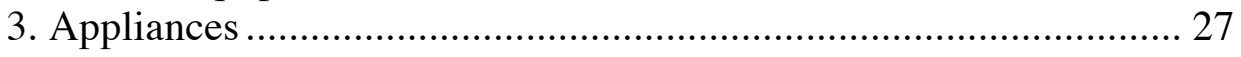

4. Policy Enforcement ....................................................................... 32

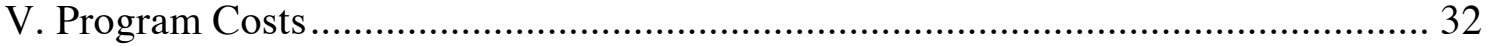

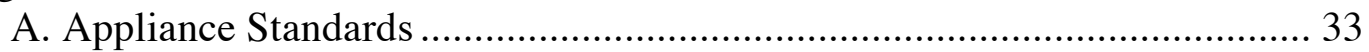

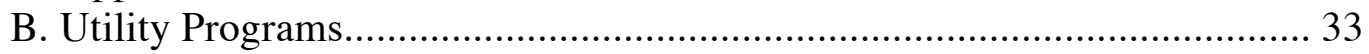

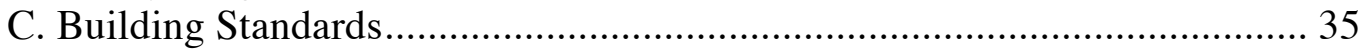

VI. Adjustments to Technical Potential ................................................................ 35

A. Engineering Estimate Adjustments ......................................................... 37

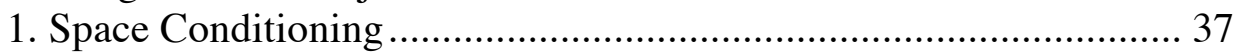

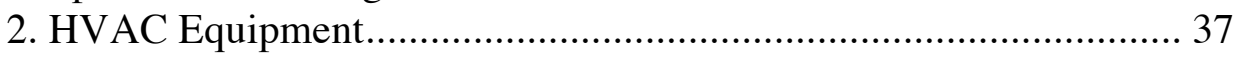

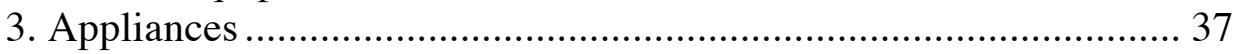

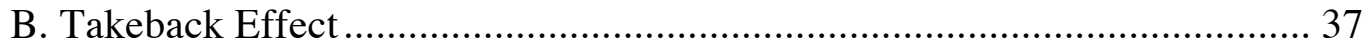

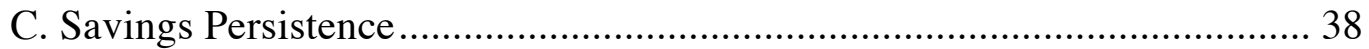

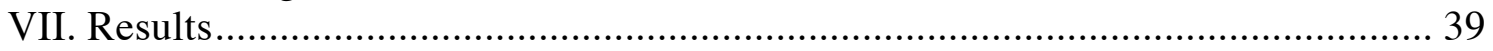

VIII. Uncertainty Analysis ................................................................................. 49

A. Factors Contributing to Uncertainty ......................................................... 49

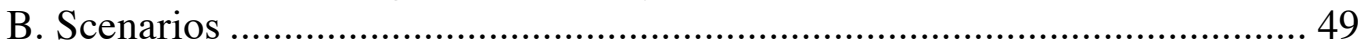

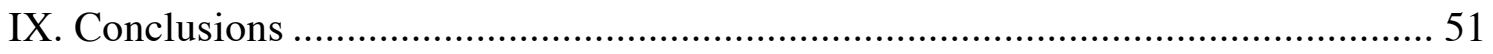

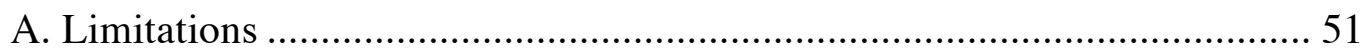

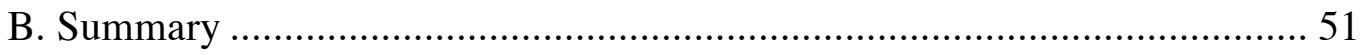

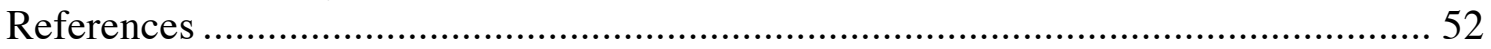

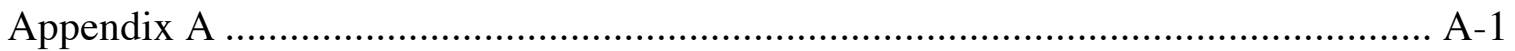




\section{Glossary}

$\begin{array}{ll}A S H R A E & \text { American Society of Heating, Refrigeration, and Air-conditioning Engineers } \\ C A B O & \text { Council of American Building Officials } \\ C A C & \text { Central Air Conditioner } \\ C C E & \text { Cost of Conserved Energy } \\ E E R & \text { Energy-Efficiency Rating (room air conditioners) } \\ E P A C T & \text { Energy Policy Act of 1992 } \\ E M F & \text { Existing Multifamily houses } \\ E M H & \text { Existing Mobile Homes } \\ E R & \text { Electric Resistance (heating) } \\ E S F & \text { Existing Single-Family houses } \\ E W H & \text { Electric Water Heater } \\ H P & \text { Heat Pump } \\ H S P F & \text { Heating Seasonal Performance Factor (heat pumps) } \\ N A E C A & \text { National Appliance Energy Conservation Act (1987) } \\ N M F & \text { New Multifamily houses } \\ N M H & \text { New Mobile Homes } \\ N S F & \text { New Single Family } \\ R A C & \text { Room Air Conditioner } \\ S E E R & \text { Residential Energy Conservation Ordinance } \\ & \end{array}$




\section{Introduction}

The literature on climate change mitigation often cites energy efficiency as having a significant potential to reduce carbon emissions. Many analyses over the past two decades have shown that current technologies can save substantial amounts of energy at a cost less than producing that same energy. A recent review of these estimates for the buildings sector found cost-effective energy savings ranging from 30 to $70 \%$ of the consumption that would take place without efficient technologies (Rosenfeld et al. 1993). Moreover, a 1991 report by the National Academy of Sciences Climate Change Mitigation Panel found that energy efficiency in buildings was the most cost-effective of the fifteen mitigation measures investigated (Rubin et al. 1992). In theory, the potential to save energy is substantial. In practice, however, experience shows that market forces and public policies to promote energy efficiency will only bring about a fraction of this potential. The fundamental question this paper address is: given the mixed success of energy-efficiency policies and the real-world constraints on future efficiency improvements, how much of the savings potential can be realized?

Taking tastes, preferences, and behavior as fixed, future energy savings are largely determined by four factors: the efficiency of commercially-available products, their capital cost, the willingness of consumers to adopt these energy-efficient technologies (influenced by policies to encourage adoption), and the actual, in-situ performance and usage of efficient devices. Traditional efficiency potential studies examine the first two factors -- technical performance and capital cost -- in order to estimate the technical potential. To determine the role energy efficiency could actually play in the U.S.'s future energy system (the achievable potential) requires extending these analyses to include additional factors -- policy implementation and empirical experience with efficient technologies. Achievable potential studies address not only the energy-efficiency technologies being employed, but also the means of adoption for these technologies. The purpose of this study is to estimate the achievable potential for electricity efficiency improvements in U.S. residences, and examine the variability in factors determining this potential.

The work to date in estimating achievable potential has focused on limited geographical areas, such as utility service areas or individual states, primarily for the purpose of regulating utilities at the state level (Krause et al. 1988, Nadel and Tress 1990). Thus there is a need to quantify the achievable potential at the national level in order to inform national policy-makers (particularly in the U.S. Department of Energy) as to the relative effectiveness of alternative energy-efficiency policies under consideration.

The scope of this project is limited to electricity in U.S. residences; it builds on previous work estimating the technical potential for electricity efficiency improvements in the U.S. residential sector (Koomey et al. 1991). That study assembled a database containing cost and performance data for each measure. The current achievable potential study builds upon this same technology database by modifying the savings potential and cost for each measure to reflect expected policy results. Factors included in these modifications are: the market penetration of efficiency measures, the costs of administering policies, and adjustments to the technical potential savings estimates to reflect the actual experience of measures implemented in the past.

This study considers three general classes of policies: appliance efficiency standards, utility demand-side management (DSM) programs, and building energy-efficiency standards. The policies' impact on energy consumption depends a great deal on the type of technologies promoted and the vigor with which the policies are implemented and enforced. Despite the increasing experience with energy-efficiency policies over the last fifteen years, estimating the impacts of these policies still requires that judgments be made as to the future policy climate and the effectiveness of policies. For this reason a set of "guiding principles," shown in Table $\mathbf{1}$ below, were adopted for 
this study. Some of these principles are simply assumptions, while others are implicit in the methodology used for previous technical potential estimates. This study is not an attempt to quantify the achievable potential definitively, but rather to explore the factors that influence this potential and estimate the potential using representative values for those factors. Likewise, an achievable potential estimate is not intended to be a forecast of the likely level of energy consumption. Estimates of savings potential present a stylized view of the world; in the case of achievable potential, the main abstraction is the assumption that the U.S. makes a full commitment to energy efficiency and pursues this commitment with effective policies at the federal, state, and local level.

\section{Table 1: Guiding Principles in Estimating Achievable Potential for This Study}

1) Market failures exist in the energy services market, justifying public policies to encourage energy efficiency.

2) The adoption and implementation of policies is pushed by a national commitment to improve energy efficiency.

3) Future energy-efficiency policies are designed and administered similarly to the most effective policies of the past, thus achieving similar market penetrations and energy savings.

4) There is no feedback between electricity demand and price.

5) In the baseline scenario (without efficiency measures), there is no technological progress or shift to more efficient products beyond the average products sold in 1990. Stock replacement due to natural attrition serves to upgrade units to this average 1990 efficiency level.

6) Characteristics of the housing and equipment stock, such as appliance saturations and operating patterns, remain constant over time.

7) Measures costing less than the retail residential electricity price (1990 national average $=7.8$ $\phi / \mathrm{kWh}$ ) are included in the achievable potential. Measures costing more than this value are entirely excluded from the energy savings potential.

8) Diversity of equipment efficiency and usage is hidden. All units within a given segment of the population are assumed to be the "average" for that group.

The design and effectiveness of future policies are subject to substantial uncertainty. To investigate this uncertainty, this analysis estimates achievable potential under three alternative scenarios: a "best estimate" case, a "higher penetration, lower program cost" case, and a "lower penetration, higher program cost" case. For each scenario, the results of the analysis are presented in an achievable supply curve of conserved energy, and also disaggregated by end-use to identify the technologies and policies that merit further attention.

This paper first reviews the concepts and methods used in developing supply curves of conserved energy, and briefly summarizes the types of policies considered in this study. It then presents the general methodology and main data sources used in the study. Next, it presents the detailed assumptions and calculations used in estimating the key aspects of achievable potential - market penetration, program costs, and adjustments to engineering estimates. Finally, it examines the uncertainty in the parameters used to estimate achievable potential and presents alternative scenarios to examine this uncertainty. 


\section{Background}

\section{A. Supply Curves of Conserved Energy}

Supply curves of conserved energy are a method of estimating future energy consumption. While other methods attempt to simulate the functioning of energy service markets in order to forecast the likely level of consumption, supply curves focus on the technologies embodied in individual energyusing devices in order to estimate the minimum possible energy consumption. In this method, energy end-use efficiency improvements are viewed not as decreases in demand but rather as additional energy supply (hence the term supply curve). This type of estimate is referred to as the technical potential for efficiency improvement because it encompasses all improvements that are technically feasible. Additionally, one may screen the measures according to a cost-effectiveness criterion, producing a techno-economic potential for efficiency improvement. Throughout this paper, I refer to these two potentials collectively as the technical potential, because their calculation methods are essentially identical. While these estimates delineate the upper bound of future efficiency improvements, they are not an accurate estimate of the energy savings that will actually occur. In practice, market forces will bring about some of the energy-efficiency improvements identified in the technical potential. Due to various shortcomings in the operation of the energy services market, however, public policies are needed in order to realize a significant portion of the technical potential.

\section{B. Supply Curve Methods}

The supply curves of conserved energy method implements specific technologies (known as "measures") in order of cost-effectiveness. By sequencing the measures, this method has the advantage of not double-counting energy savings for multiple measures applied to the same building or appliance. For each end-use within the residential sector, the analyst determines a baseline energy consumption level resulting from the physical characteristics and operating patterns of the current house and appliance stock. The energy consumption for each end-use is then calculated assuming that energy-efficiency technologies (referred to as efficiency measures) have been substituted for the baseline stock. Typically, these calculations are performed for an average (or typical) unit from the stock in order to simplify the calculations. The difference between these two consumption levels is the unit energy savings (UES) for a particular measure, which is then multiplied by the number of units in the appropriate end-use stock to calculate the total, nationwide savings potential. To evaluate the cost-effectiveness of each measure, the supply curves method uses the cost of conserved energy (CCE). The CCE is an indicator of the "cost" to buy each unit of saved energy. It is calculated from the incremental cost of the efficiency measure over the baseline device, which is then levelized over the assumed lifetime of the measure (using a selected discount rate), and divided by the annual energy savings of the measure. The resulting CCE is in units of $\phi / \mathrm{kWh}$ (for electricity), and is often used in a cost-effectiveness comparison with electrical generation technologies. An advantage of the CCE method is that the price of electricity is exogenous to the calculation, thus allowing simple evaluation of measures under different energy price assumptions. Once the costs and savings have been estimated for each measure, the individual measures are then combined to yield a supply curve (analogous to supply curves in microeconomic theory) showing the quantity of conserved energy that can be "purchased" for a given price. ${ }^{1}$

\footnotetext{
${ }^{1}$ Meier and others (1983) present a comprehensive overview of the concepts and methods of constructing supply curves.
} 
One shortcoming of the supply curve method is that it represents the entire population with one, "average" member of that population. For example, in estimating space conditioning energy consumption, this study models all houses of a particular type in a particular region (single-family homes in the south, for instance) as having one thermal design corresponding to the average of all homes in that category for each building component. While there may be millions of houses in a category, they are all assumed to have the same floor area, level of ceiling insulation, etc.

This technique masks the underlying diversity in the population and can bias the results in some cases (this is referred to as aggregation bias). For instance, if a measure's CCE is greater than the cost-effectiveness threshold, no savings are credited to that measure in the overall conservation potential. In reality, a single measure represents many individual decision situations, comprising a distribution of CCEs, of which the supply curve CCE is simply the mean. Some portion of this distribution may fall below the cost-effectiveness threshold, but the supply curve analysis method cannot distinguish this sub-population. The converse of this situation applies to measures that do meet the cost-effectiveness threshold: a portion of the conservation potential may in reality not be cost-effective.

Cost-effectiveness is strongly influenced by the perspective from which benefits and costs are assessed. In other words, to whom do the benefits and costs of energy efficiency accrue? Most technical potential studies calculate CCEs using a societal perspective, but only include costs that are readily quantifiable. This measure of cost-effectiveness is known in the DSM program literature as the total resource cost (TRC) test. A true societal measure would include all benefits and costs incurred by society, but in practice many of these additional benefits and costs are impossible (or at least very difficult) to quantify, so the TRC is usually used as a proxy for the societal test. Table 2 illustrates the different perspectives and the benefits and costs included in each.

In assessing the cost-effectiveness of a technology, one is making a normative statement about the desirability of adopting that technology. The traditional tests take an engineering-economic view of the world by assuming that people will decide to purchase an efficient product as long as the direct monetary costs incurred are less than the energy benefits gained in return. In reality, many nontechnical and non-economic factors influence (or determine) purchase decisions, but are not incorporated into cost-effectiveness because they are difficult to quantify and include in a comprehensive assessment system. As an example, to make the TRC test a more comprehensive measure of societal welfare, it would need to include costs and benefits that are not assigned monetary values in markets. Two benefits of energy efficiency that are not normally considered in the TRC test are: a) decreases in environmental externalities (Krause and Eto 1988), and b) increases in consumer surplus from improved energy services (Brathwait et al. 1993), (Chamberlin 1993). 


\begin{tabular}{|c|c|c|c|c|c|c|c|}
\hline \multirow[b]{2}{*}{$\begin{array}{c}\text { Economic } \\
\text { Perspective }\end{array}$} & \multicolumn{3}{|c|}{ Benefit Components } & \multicolumn{4}{|c|}{ Cost Components } \\
\hline & $\begin{array}{l}\text { Energy } \\
\text { Savings }\end{array}$ & $\begin{array}{l}\text { Incentive } \\
\text { Payment }\end{array}$ & $\begin{array}{c}\text { Other } \\
\text { Benefits }\end{array}$ & $\begin{array}{l}\text { Incentive } \\
\text { Payment }\end{array}$ & $\begin{array}{c}\text { Program } \\
\text { Admin- } \\
\text { istration }\end{array}$ & $\begin{array}{c}\text { Customer } \\
\text { Direct } \\
\text { Costs } \\
\end{array}$ & $\begin{array}{l}\text { Other } \\
\text { Costs }\end{array}$ \\
\hline Consumer/Participant & $\mathbf{X}$ & $\mathbf{X}$ & & & & $\mathbf{X}$ & \\
\hline $\begin{array}{l}\text { Total Resource - } \\
\text { Technical Potential }\end{array}$ & $\mathbf{X}$ & & & $\mathbf{X}$ & & $\mathbf{X}$ & \\
\hline $\begin{array}{l}\text { Total Resource - } \\
\text { Achievable Potential }\end{array}$ & $\mathbf{X}$ & & & $\mathbf{X}$ & $\mathbf{X}$ & $\mathbf{X}$ & \\
\hline Societal & $\mathbf{X}$ & & $\mathbf{X}$ & $\mathbf{X}$ & $\mathbf{X}$ & $\mathbf{X}$ & $\mathbf{X}$ \\
\hline
\end{tabular}

Notes:

(1) Adapted from Krause and Eto (1988)

(2) The Non-Participant perspective is not included in this table because it is not used for estimating supply curves.

(3) Incentive Payments are rebates paid by utilities (or governments) to consumers to encourage purchase of efficient products.

(4) Incentive Payment + Customer Direct Cost = Incremental Capital Cost of Measure in Supply Curve

(5) "Other Benefits" include increased energy services from efficiency measures, reduced power plant emissions, etc.

(6) "Other Costs" include: indirect economic impacts, such as changes in manufacturer competitiveness;

hard-to-quantify economic impacts, such as the costs for manufacturers to comply with standards; and hard-to-quantify non-economic impacts, such as reduced energy services from efficiency measures. 


\section{U.S. Residential Technical Potential}

Researchers from Lawrence Berkeley Laboratory have estimated the technical potential for electricity efficiency improvements in the U.S. residential sector (Koomey et al. 1991). That study included all end-uses in residences and evaluated nearly 300 efficiency measures applied to residences in the time period from 1990 to 2010. The savings potential was measured relative to a frozen efficiency baseline, in which natural stock turnover still takes place but efficiencies do not improve beyond the average for new units purchased in 1990. The frozen efficiency baseline consumption in 2010 is 1019 TWh. $^{2}$ The study concluded that by 2010 , annual residential electricity consumption could be reduced by $404 \mathrm{TWh}$ ( $40 \%$ of baseline consumption) by fully implementing all measures that cost less than the 1990 national average residential retail price of electricity $(7.8 \phi / \mathrm{kWh})$. The electricity price is a rough measure of the cost-effectiveness criterion a homeowner would use in evaluating efficiency investments. Also, from a societal perspective, net welfare is increased by purchasing those measures that cost less than the electricity they avoid. ${ }^{3}$ Figure 1 plots the conservation supply curve resulting from the LBL technical potential measures. The study used the average investor-owned utility real cost of capital ( $7 \%$ real discount rate ${ }^{4}$ ) to calculate costs of conserved energy. The results incorporate physical constraints such as stock turnover rates and production phase-in limits for new technologies.

\section{Policy Overview}

This study evaluates three types of policies -- appliance standards, utility demand-side management programs, and building standards. These are the primary policies that have been enacted, or actively considered, to address failures on the demand-side of the residential energy market. Additional policies, such as information campaigns, are not explicitly treated in this study because their effects are difficult to quantify; rather, they are assumed to be an integral part of the policies discussed here. This study also does not consider policies, such as energy taxes, that address supply-side market failures by influencing the price of energy. I will now briefly describe the policies that are analyzed in this study.

Appliance standards are a policy in which the government bars manufacturers from selling new products that do not meet a minimum energy-efficiency level. They were first implemented in California in 1978. Due to their success in that state, the federal government adopted appliance standards in 1987. The first national standards became effective in 1990, with most household appliances and heating, ventilation, and air conditioning (HVAC) equipment subject to standards by 1992. The Energy Policy Act of 1992 (EPACT 1992) extends these standards to nearly all residential energy-using equipment and plumbing fixtures. The federal standards require that the U.S. Department of Energy (DOE) re-evaluate the standard efficiency level approximately every five years.

2 The end-uses in this study account for approximately $90 \%$ of 1990 electricity sales (US DOE 1991).

${ }^{3}$ The retail price of electricity is an imperfect measure of the cost to society of that electricity, although it is frequently used for this purpose because it is widely known and intuitively appealing. Electricity rates are generally set at the average cost of electricity service for all customers within a rate class, whereas cost-effectiveness comparisons should be based on marginal costs. Also, electricity rates usually do not account for externalities, which are of concern to society.

${ }^{4}$ The real discount rate is net of inflation. The study assumes constant real prices for both the electricity price and capital cost of measures, which implies that all factors will experience the same rate of cost escalation. 
Figure 1: Maximum Technical Potential Electricity Savings for U.S. Residences in 2010

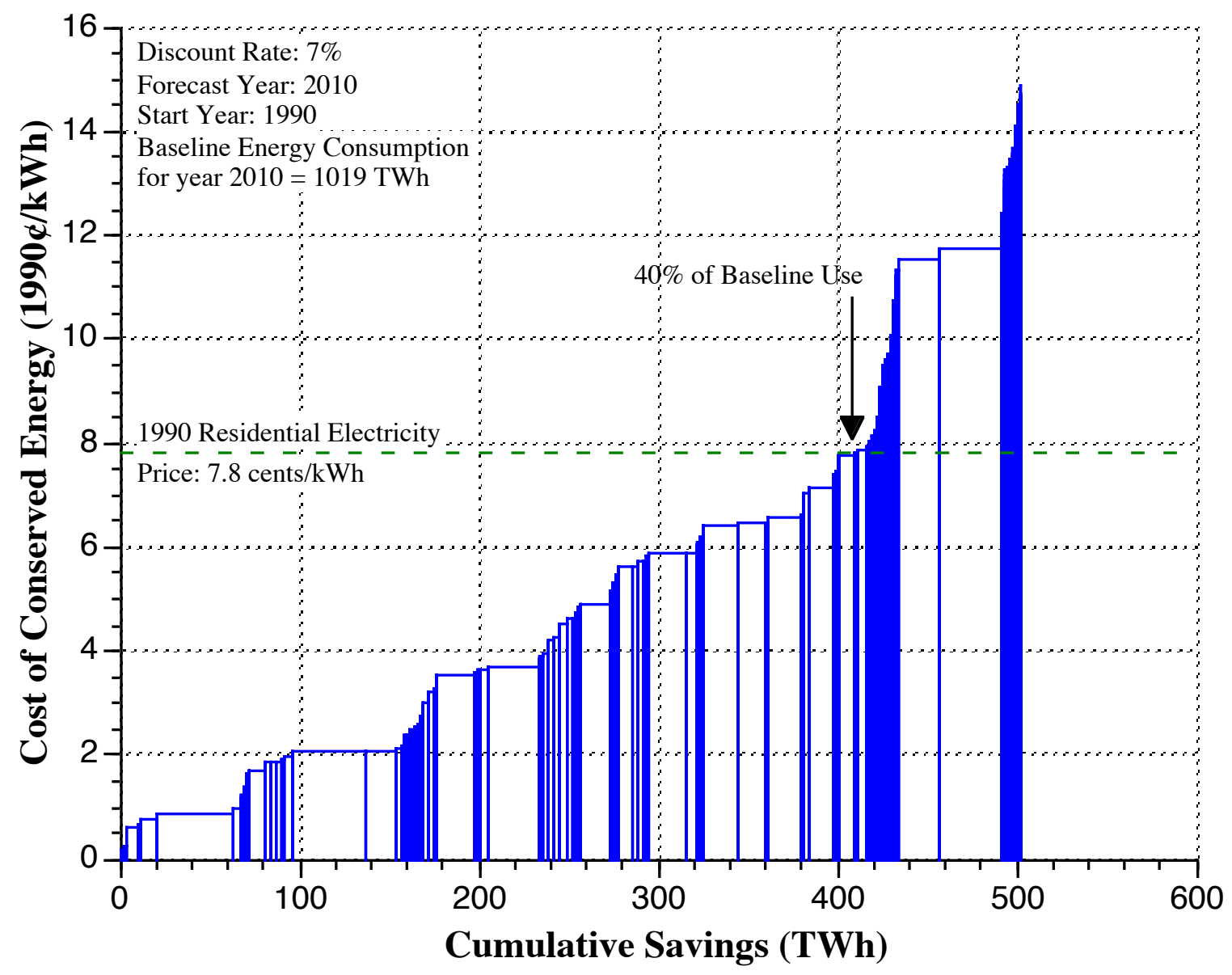

A supply curve of conserved electricity for the United States residential sector. Each step represents a conservation measure (or a package of measures). The width of the step indicates the nationwide electricity savings from the measure and the height of the step above the $\mathrm{x}$-axis indicates the cost of conserved electricity. The end-uses include space conditioning, water heating, refrigeration, lighting, and miscellaneous electricity uses. Source: Koomey et al. (1991) 
Utility demand-side management programs have been widely used since the early 1980s to encourage utility customers to improve the efficiency of their energy-using capital equipment. These programs have taken many different forms, but the most successful generally combine customer education or assistance with some form of economic incentive to defray the higher capital cost of high-efficiency products. ${ }^{5}$ The experience with utility programs has been very diverse, owing to the diversity of program designs, customer populations, and utility management. Over the last decade, utility programs have evolved from small-scale efforts to satisfy customers and appease regulators, to large-scale campaigns figuring prominently in the utility's electricity resource plan.

This increased reliance on utility programs has been made possible by the growing experience with programs and improved, standardized techniques for program evaluation, thus reducing uncertainty about program impacts and costs.

Building standards (or "codes") mandate specific building design and construction practices in new buildings. Originally, building standards were enacted for health and safety purposes, but since the 1970s energy-efficiency standards have been added to building codes. Due to variations in climate, materials, and building design, the construction industry has traditionally been very fragmented and heterogeneous. For this reason, building construction is usually controlled at the local level, although some states (such as California) have state-wide regulations for energy-efficiency. Energy standards for building construction have generally mirrored the structure of the industry they regulate and been very heterogeneous in the past. This situation is quite different from the situation of appliances, where a small number of companies manufacture products for a national market. From the standpoint of administrative simplicity, standards are most easily set at the national level. For this reason, several national organizations, principally ASHRAE and $\mathrm{CABO}^{6}$, develop model building codes that local jurisdictions can adopt as they choose. The EPACT of 1992 may serve to standardize building codes to some extent, because it contains provisions requiring states to adopt minimal energy-efficiency standards. While discretion as to the exact content and enforcement of standards will remain at the local level, the EPACT sets a strong precedent for national standardization of energy efficiency in newly-constructed buildings.

One shortcoming of building standards is that they only apply to new construction and major renovations, and therefore can have a significant impact only over long periods due to the slow turnover of the housing stock. A policy addressing this issue is the residential energy conservation ordinance (RECO), which mandates that all existing houses be upgraded to a minimum thermal integrity level at the time of sale (another possibility is that all houses must meet this level by a certain date). RECOs are most effective when combined with two additional policies: home energy rating systems (HERS) and energy-efficiency mortgages (EEMs). HERS are programs that measure a home's energy efficiency on a standardized rating scale (equivalent to the yellow energy labels on appliances) so home buyers can more easily consider energy efficiency in their buying decision. These rating systems simplify the administration of RECOs and establish an important precedent in the government regulation of existing-house thermal integrity. EEMs are standard mortgages with an additional provision for financing of energy-efficiency investments as part of the mortgage principal. This type of financing allows home buyers to more easily afford the upgrades required by RECOs. Although I do not separately analyze HERS or EEMs, they are assumed to be in place when analyzing the effectiveness of RECOs. The cost of rating homes at the time of sale is

\footnotetext{
${ }^{5}$ The size of the incentive varies as a fraction of incremental measure cost. Incentive size and program participation appear to be positively correlated, although the exact relationship depends on the measure being considered. The relationship also appears to be highly non-linear, as there is a threshold incentive (of non-trivial size) below which participation is almost zero.

${ }^{6}$ American Society of Heating, Refrigeration, and Air conditioning Engineers; Council of American Building Officials
} 
assumed to be a part of the normal RECO administrative cost (most RECOs have provisions for inspecting homes to verify compliance).

The interaction between policies can significantly change the magnitude and cost of energy savings. Quantifying the effects of this interaction is difficult, however, so this study explicitly treats interaction only in cases where the timing of one policy depends on another. In other cases where multiple policies may influence one another, I implicitly account for this effect when estimating the impact of each policy. There are many ways in which these interactions can occur; two specific interactions are considered in this study. First, utility programs often serve as vehicles for accelerating the development and adoption of new technologies, in turn accelerating the time at which those technologies can be incorporated into appliance standards. Second, appliance standards are often used as the basis from which incremental efficiency levels are given rebates in utility programs. For instance, refrigerator models that exceed the 1990 federal standard efficiency by 15, 20 , and $25 \%$ are eligible for increasing rebates, and manufacturers now design their high-efficiency products specifically to qualify for rebates (Morrill 1993). The existence of the appliance standard reduces the administrative cost of setting rebate levels and facilitates coordination of rebate programs among utilities.

\section{Methodology}

To assess the impact of energy-efficiency policies, one must take into account the economic and social constraints limiting the adoption of efficient energy-use technologies, as well as the costs to society of running the programs themselves. The policy impacts are modeled as modifications to the LBL technical potential study discussed in the last section. The modifications involve four steps applied to each measure in the database. The first step is to determine the type of policy(ies) that will be used to encourage adoption of the efficient technology. Second, by drawing on empirical data about the effectiveness of past and current policies, I assume an expected market penetration of the measure as a result of policies. Third, I recalculate the cost of the measure to include the assumed costs of implementing the policies. Fourth, I adjust the measure's expected energy savings to account for empirically observed conditions the measure will experience in actual use (such as post-measure changes in equipment usage). Estimating market penetration is the most complex part of this process because it requires data from diverse sources, which must then be synthesized into market penetration estimates at the national level. These estimates are very dependent on the type and timing of policies, and therefore largely determined by the assumptions made about policy implementation. For instance, market penetration is higher and program costs are lower for standards than for utility DSM programs.

The LBL technical potential supply curve presented previously contains some 300 efficiency measures. Before using these data in calculating achievable potential, I aggregated some of the measures to make the subsequent estimates less cumbersome. Measures were combined if they had a similar end-use, cost-effectiveness (CCE less or greater than the electricity price), technology type, and would be promoted with the same policies. Appendix A provides a detailed listing of the measures, showing which technical potential measures were combined. The aggregated measures contain a techno-economic potential of $410 \mathrm{TWh}$, which is $6 \mathrm{TWh}$ higher than the potential identified in the original study. The difference is due to updates in the measure database since the publication of that study. 


\section{Market Penetration Analysis}

This section begins with a general discussion of the theory, data sources, and modeling techniques to estimate market penetration. It then outlines the estimation method used in this study, and concludes by presenting the detailed assumptions made for each end-use.

\section{A. Market Penetration Background}

Market penetration describes the process by which a technology or innovation is adopted by (or "penetrates") a defined population (or "market"). As the terminology suggests, it is a concept originally developed by the product marketing community to forecast the acceptance of new products. The process of estimating market penetration can be broken into two stages. The first step is to estimate the cumulative market penetration (the fraction of eligible population adopting the innovation) that a product or policy can achieve in the long run. The second step is to determine the rate or trajectory at which this ultimate market penetration will be realized. Ideally, one would like to simulate the adoption decisions taking place in the market in order to estimate these penetration parameters. But do we know why people adopt or reject technologies? To simulate the functioning of the market requires knowledge about how decisions are made. As with the cost-effectiveness assessments discussed previously, consumers use both economic and non-economic criteria in evaluating possible courses of action. The relative importance of these criteria, however, depends on the specifics of the situation (such as the number of options from which to choose) and the characteristics of the decision-maker. While knowing this information may seem like an impossible task, theoretical models are being developed to realistically simulate market processes. The Electric Power Research Institute (EPRI) is developing an adoption process model for utilities to plan their DSM programs (Kendall and Cates 1991). The advantage of this model is that it can include noneconomic considerations in assessing the probability of adoption. The main drawback is that it requires a thorough segmentation of the population into categories of preferences, and it is therefore only practical in applications where extensive data have been collected on the population. Utility service territories are one such application because most utilities collect marketing data about their customers. On the other hand, national-level studies such as this one are not well-suited to dataintensive adoption process models.

The traditional approach to estimating market penetration is to model the outcomes of decisions at a macro level, rather than attempting to model the decisions themselves. These models are based on innovation diffusion theory, which assumes that the market share of a new technology increases over time as a function of the current market penetration. This method has the advantage that it requires estimation of only a few parameters, which can be derived from the experience of past programs. In practice, the parameters used in these models are often based on the analyst's judgment as to the adoption rate and ultimate penetration of a technology, and the model serves simply to formalize the judgment process.

This study dispenses with a formal model of diffusion processes and instead uses representative values for the rate of adoption and ultimate penetration of each policy (based on analogies to past policies, where possible). Generally, this study's "first principles" of market penetration are the assumed annual rate of penetration for a specific program, and the starting and ending dates of policies. These inputs, combined with information about the rate of turnover and additions to the stock (from the LBL technical potential study), permit estimation of the cumulative market penetration by the end of the study period (2010). In addition, certain empirical observations constrain the ultimate market penetrations. For instance, utility retrofit programs rarely reach over $50 \%$ of the eligible population. This information is used to limit the penetration of programs in cases where calculations based on annual rates would reach a higher penetration. 
For appliance and building standards, market penetrations are straightforward to estimate. I assume that once a standard has been passed, $100 \%$ of the eligible stock is converted in each year (because standards apply to new products, this implies that efficient products assume a $100 \%$ market share). The principal uncertainty for standards is the year in which the standards will be enacted and the level of technology required by the standard.

Market penetration for utility programs is more problematic. There are literally hundreds of DSM programs conducted every year, nearly all of which are summarized in evaluation reports published by utilities for regulatory review. Most of these data, however, are limited in their general applicability because they are valid only for a certain program design and population of customers. The last few years has seen attempts to synthesize the results of the DSM field. Nadel (1991) reviewed the experience of programs in the 1980s, and also detailed the experience of commercial and industrial DSM programs in New York state (Nadel 1990). The most useful sources of data for estimating market penetration are two previous achievable potential studies conducted for Michigan (Krause et al. 1988) and New York (Nadel and Tress 1990) These studies contain useful information about the potential market penetrations of well-run utility programs (which is conceptually different than the experience of average programs). Generally, I rely on these two studies for inputs and assumptions about utility program market penetration.

\section{B. Market Penetration Example}

To explain more concretely the process of estimating market penetration, I will show the details for one end-use. The end-use used in this example is heat pump-heated homes, although all measures in this study are analyzed in this way. Figure 2 shows the process of deciding which policies apply to each measure. The columns labeled "Baseline" and "Measures" are the technical potential measures from the earlier LBL study. To these measures -- as shown in the "Policies" column -- I apply both: a) the appropriate type of standard (either building or appliance, depending on the enduse), and b) a utility program lasting from 1990 until the standard becomes effective. In this particular end-use, however, the utility program for the Basic Measure is omitted because the standard becomes effective early enough in the study that a utility program would have a negligible impact. The beginning dates of appliance standards are based on information about the DOE appliance standard review cycle from the LBL Energy Conservation Policy Group. In the heat pump example, the 1992 standard was written into law as of 1990, and the 1999 standard is the expected update year for air conditioners and heat pumps. ${ }^{7}$ For the utility programs I assume an annual penetration rate, defined as the fraction of new purchases or existing stock that is upgraded to more efficient equipment in a given year. The $30 \%$ annual penetration for heat pump replacements (Figure 2) means that $30 \%$ of replacement equipment purchases are upgraded to efficient models. In addition to this steady-state penetration rate I also assume a ramp-up period of one to five years during which the program gradually becomes fully operational. For thermal shells and HVAC equipment, I treat the stock of existing (pre-1990) buildings and new construction separately because the policies and stock turnover are different.

\footnotetext{
${ }^{7}$ Note that the standard levels for advanced options are based on judgement and do not represent DOE policy as to what the future standards actually will be.
} 
When applied to an individual measure, these policy assumptions produce a market penetration trajectory like Figure 3. The utility program is implemented first and ramps-up to its steady-state annual market penetration of 30\%. ${ }^{8}$ In 1999 the standard becomes effective and the utility program stops. The cumulative effect of these annual penetrations is shown in Figure 4 (for the new construction program). By 2010 approximately $70 \%$ of the heat pumps in houses built since 1990 are high-efficiency models. This process is repeated for each measure in the study. When this paper cites a value for the 2010 cumulative market penetration, the value has been estimated using the technique just outlined.

${ }^{8}$ In this case, the utility program provides rebates for replacement purchases; the new construction program would appear similar but reach a steady-state penetration of $50 \%$. 
Figure 2: Policy Selection Process for Heat Pump Measures

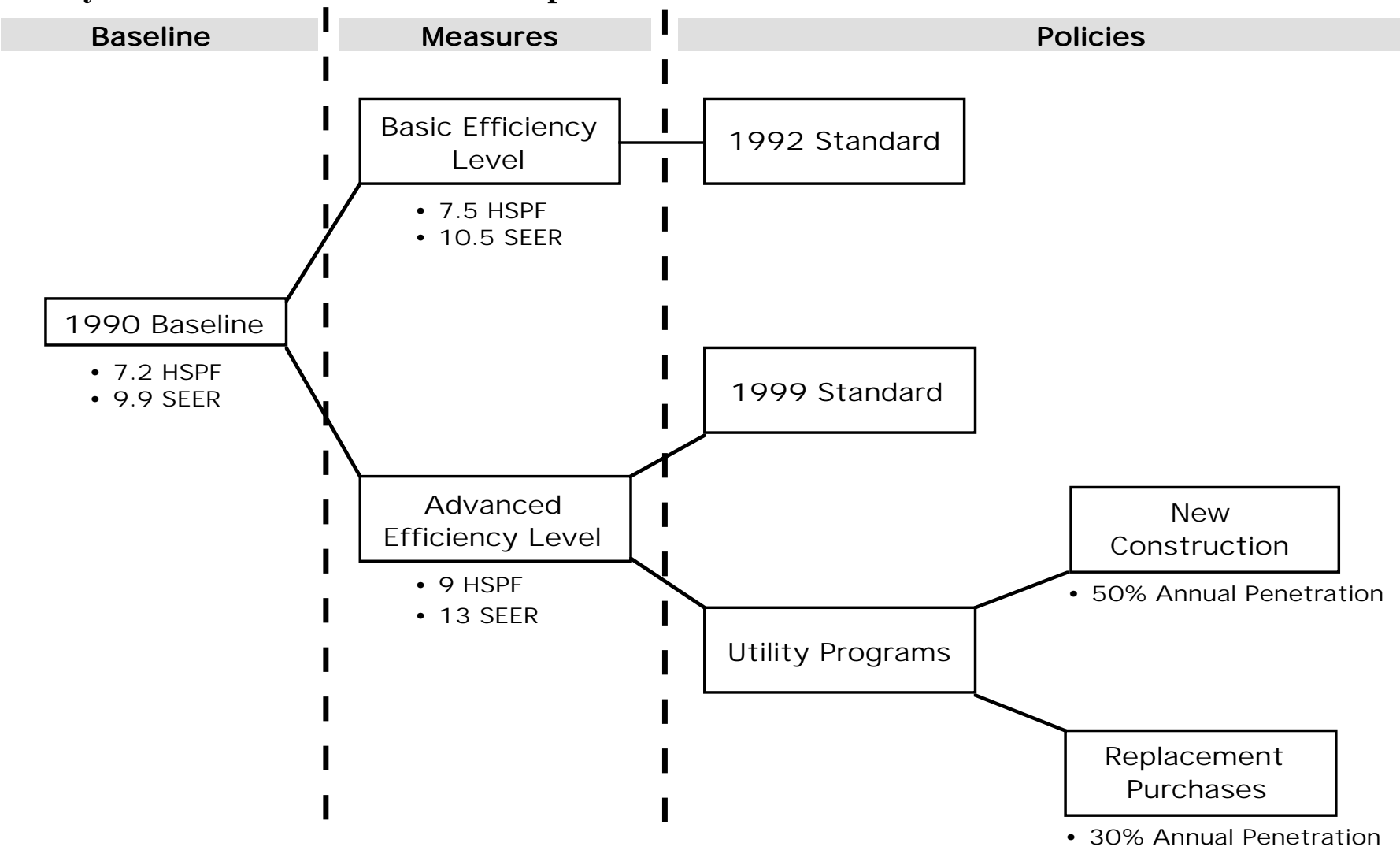

The first step in estimating market penetration is to decide which policies will be used to promote each measure. The "Baseline" and "Measures" columns are from the previous technical potential study. The basic efficiency level is currently on the books as a NAECA standard effective in 1992. I assume that the advanced efficiency level will be adopted as the standard when the updated NAECA heat pump standard becomes effective in 1999. Until that time, utilities promote the advanced efficiency heat pumps through rebate programs for both new construction and purchases to replace retired equipment in existing homes. The annual penetration rates shown for utility programs are the steady-state market share of high-efficiency equipment, after a program ramp-up period. This same process is used to decide the applicability of policies to all other measures in the achievable potential supply curve. 
Figure 3: Annual Penetration of Advanced-Efficiency Heat Pumps in New Construction

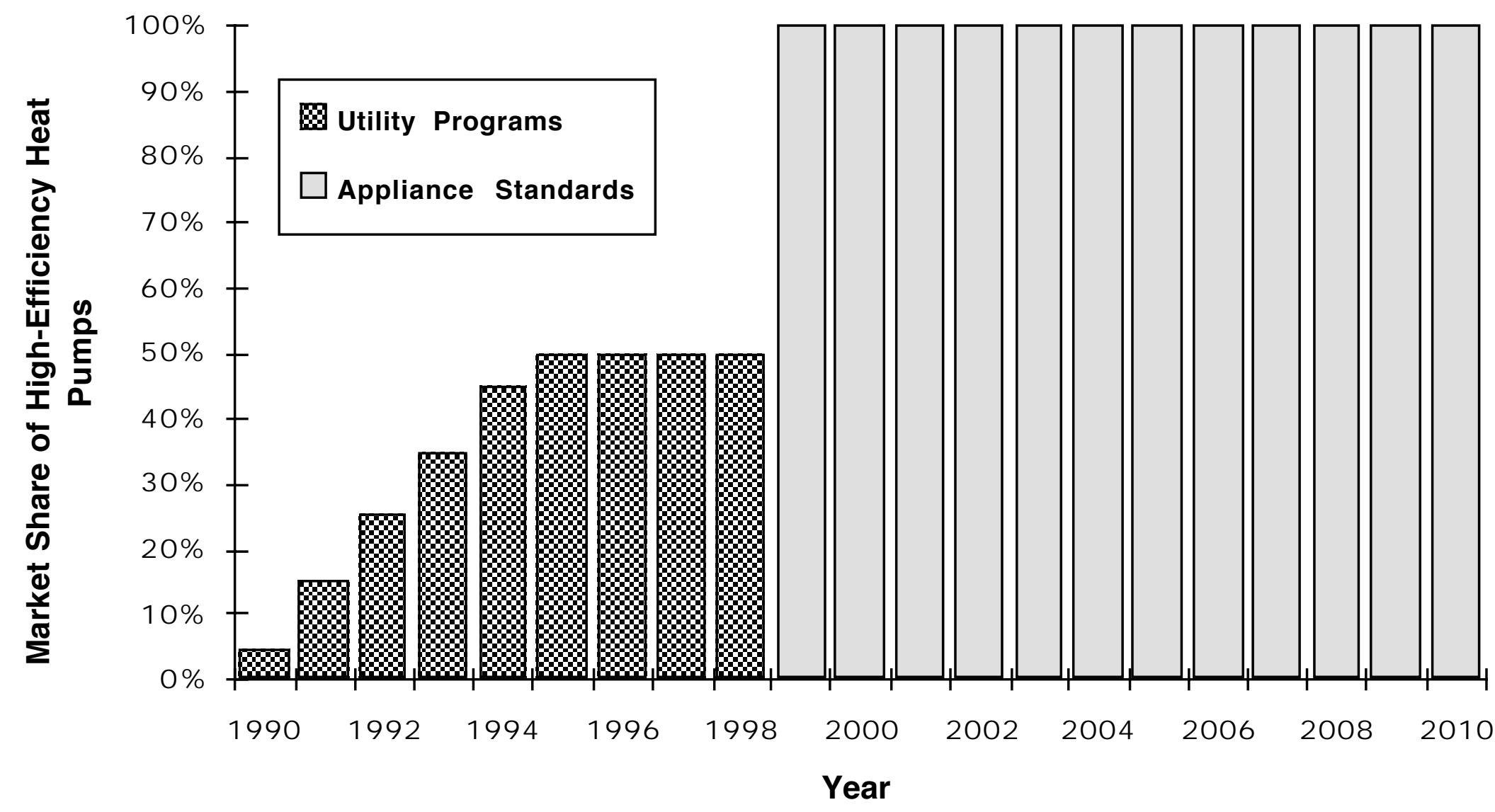

The year-by-year effect of the policies selected in Figure 2 is shown here. Market share is defined as the fraction of all new heat pumps sold in a given year which meet a minimum efficiency level. Through 1998 (including a five-year ramp-up period), the utility new construction programs shift $50 \%$ of the sales of equipment for installation in new homes to high-efficiency models. The 1999 appliance standards are assumed to apply to $100 \%$ of sales after they become effective. 
Figure 4: Cumulative Penetration of Advanced-Efficiency Heat Pumps in New Construction

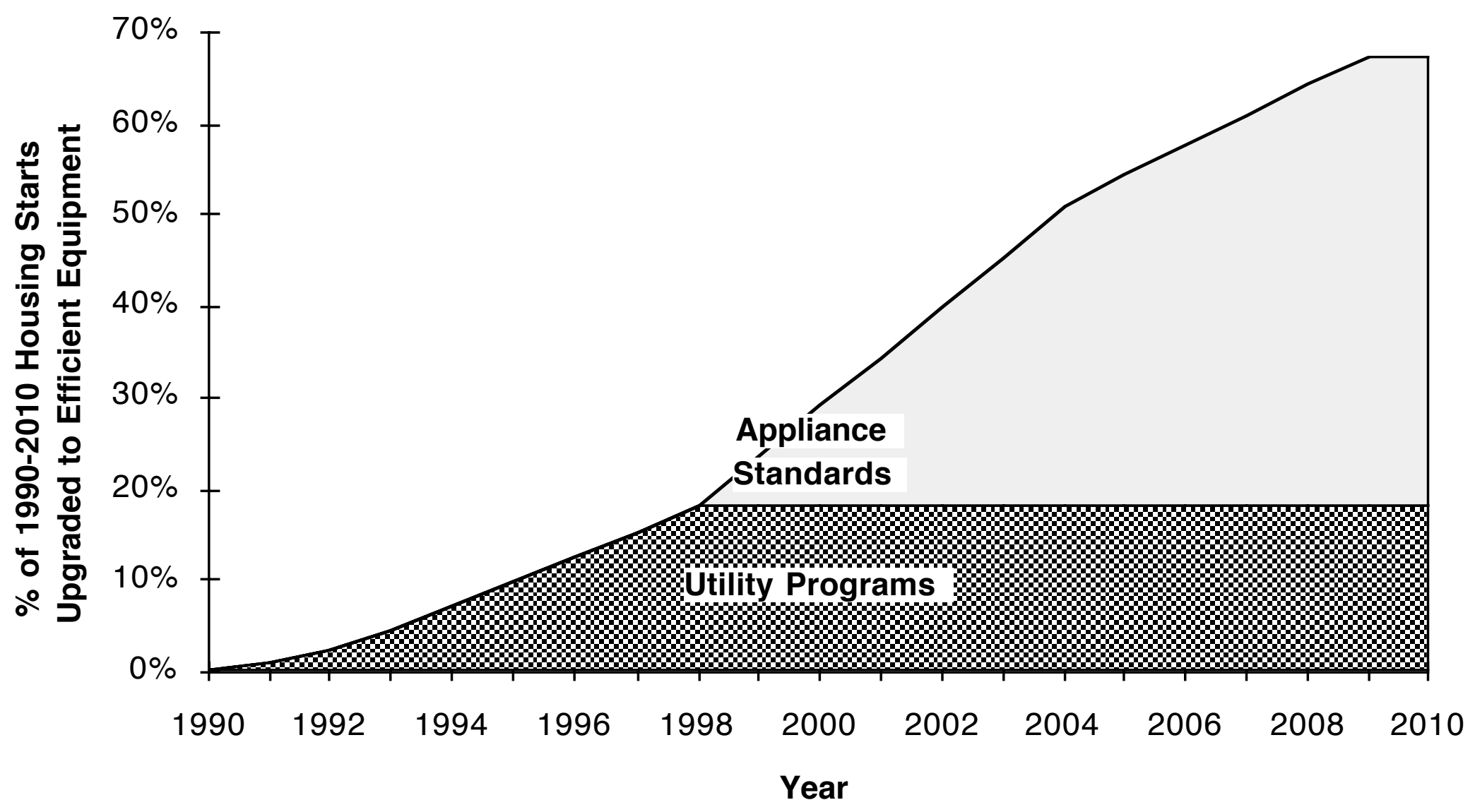

The annual market penetrations shown in Figure 3 result in the cumulative penetration trajectory illustrated here. Utility programs end in 1997, so no additional high-efficiency units are added to the stock as a result of these programs after that year. By 2010 , nearly $70 \%$ of the new homes built since 1990 were constructed with high-efficiency heat pumps. 


\section{Detailed Assumptions}

This section is organized by end-use. For each end-use, I describe the types of policies applied between 1990 and 2010: their timing, level of technology promoted, and their effect on cumulative market penetration.

\section{Thermal Shell}

The vast majority of past utility programs has been sponsored by electric utilities and targeted at electric end uses. For most of the end uses in this study, the utility programs I propose are analogous to these traditional programs. However, some of the thermal shell measures apply to gasor oil-heated homes, which would not be included in traditional electric utility programs. I assume that these measures are implemented under programs similar to the electric space conditioning programs. Achieving shell improvements in gas- and oil-heated homes will require that: gas utilities become more active in promoting the weatherization of gas-heated houses, government weatherization programs are expanded, or electric utilities extend their programs to more than just electric-heated houses. The thermal shell measures also take into account the fraction of the aggregated measures that will actually be part of the policies (See Appendix A).

\section{a. New Construction}

The thermal efficiency of newly-constructed houses is influenced by building codes and utility programs. I assume that: 1) ASHRAE standard 90.2P is finalized and approved by 1995, leading to its adoption by half the municipalities in that year. Over the next five years, adoption of this or a similar code leads to $100 \%$ adoption across the country. The provisions of this code are shown in Table 3. Over the 20 year study period, $63 \%$ of the new houses are built to the provisions of this code.

2) Beginning in 1990, utilities develop programs to improve the energy efficiency of newlyconstructed houses (these programs are actually continuations of programs begun in the 1980s). These programs cover most end uses, but one of the primary measures is a tight and well insulated thermal shell. The level of thermal integrity promoted in these programs goes beyond ASHRAE 90.2, and is shown in Table 3 under the "Next-Generation ASHRAE" column. The annual penetration of these programs is presented in the "New Construction" row in Table 4. The yearby-year penetration is shown in Table 5. Through 2005 (at which point an advanced building standard takes effect), these programs upgrade $35 \%$ of the total 2010 new housing stock (built after 1990).

3) After finalizing ASHRAE standard 90.2, ASHRAE develops an "advanced" building code, corresponding to the efficiency levels included in the utilities' new construction efficiency programs. The new standard is initially published in 2000 and approved by 2005, at which point $50 \%$ of municipalities adopt it. By 2010, 100\% of the municipalities use this advanced code. Its technical provisions are shown in Table 3 , in the column labeled "next-generation ASHRAE." Table 5 shows the adoption of the ASHRAE 90.2 and advanced ASHRAE standards over the course of the study period (in the "building standards" column). By the year 2010, 10\% of the houses built since 1990 have been constructed in accord with the advanced building standards. Taken together, the utility programs and next-generation ASHRAE standard upgrade $45 \%$ of all new construction between 1990 and 2010. 


\begin{tabular}{|c|c|c|c|c|c|c|}
\hline \multirow{3}{*}{$\begin{array}{c}\text { Shell } \\
\text { Component }\end{array}$} & \multirow{2}{*}{\multicolumn{2}{|c|}{$\begin{array}{c}\text { Supply Curve } \\
\text { Baseline }\end{array}$}} & \multicolumn{4}{|c|}{ Thermal Integrity Level Required In: } \\
\hline & & & \multicolumn{2}{|c|}{ ASHRAE 90.2P Code } & \multicolumn{2}{|c|}{$\begin{array}{c}\text { Next-Generation } \\
\text { ASHRAE }\end{array}$} \\
\hline & North & South & North & South & North & South \\
\hline Ceiling (R) & 28.2 & 26.4 & 30 & 28 & 38 & 30 \\
\hline Wall (R) & 14.2 & 11.3 & 16 & 16 & 19 & 19 \\
\hline Floor (R) & 12.6 & - & 19 & - & 30 & - \\
\hline Foundation & - & $\mathrm{R}-2.6,2 \mathrm{ft}$ & - & $\mathrm{R}-5,2 \mathrm{ft}$ & - & $\mathrm{R}-5,2 \mathrm{ft}$ \\
\hline Window U-value & 0.6 & 0.7 & 0.36 & 0.81 & 0.3 & 0.36 \\
\hline Window Shading Coefficient & - & 0.8 & - & 0.5 & - & 0.44 \\
\hline Infiltration $(\mathrm{ACH})$ & 0.51 & 0.63 & 0.59 & 0.63 & 0.40 & 0.40 \\
\hline
\end{tabular}

Sources: Supply Curve: Koomey et al (1991); ASHRAE 90.2: Ritschard, Hanford, Sezgen (1992)

Notes:

(1) Thermal integrity levels are presented for single-family homes because Koomey et al. considered shell measures for this house-type only.

(2) ASHRAE 90.2 is adopted by $50 \%$ of the U.S. municipalities in 1995, increasing to $100 \%$ by 2000 .

(3) Next-Generation ASHRAE is the thermal integrity level promoted by utility programs in this study, as well as an updated version of ASHRAE 90.2 to be adopted in 2005.

(4) North and South correspond to the regions defined in Koomey et al. (1991).

(5) $\mathrm{U}$-values are for the whole window: $0.36=2$-pane, low-e, wood frame; $0.81=2$-pane, alum.-frame;

$0.30=2$-pane, low-e, argon gas-filled, wood frame.

(6) Shading Coefficient (SC): Spectrally-selective $\mathrm{SC}=0.44$. I assume that spectrally-selective windows will be required in the south to meet the ASHRAE 90.2P shading coefficient requirements.

(7) Foundation insulation is slab-edge insulation to the R-value specified, to a depth of 2 feet.

(8) $\mathrm{ACH}=$ Air Changes per Hour 


\begin{tabular}{|c|c|c|c|}
\hline Table 4: Market Penetration of Utility Programs for Retrofitting Thermal Shells \\
\hline \multicolumn{1}{|c|}{ Program } & $\begin{array}{c}\text { Steady-State } \\
\text { Annual } \\
\text { Penetration Rate }\end{array}$ & $\begin{array}{c}\text { Program } \\
\text { Ramp-up }\end{array}$ & $\begin{array}{c}2010 \\
\text { Cumulative } \\
\text { Penetration }\end{array}$ \\
\hline - New Construction & $50 \%$ & $5,15,25,35,45,50 \%$ & $35 \%$ \\
- Existing Houses & & & $36 \%$ \\
- Weatherstripping Measures & $3 \%$ & & $48 \%$ \\
- Energy Fitness Retrofit & $4 \%$ & $2,2.5,3,4 \%$ & $38 \%$ \\
- House Doctor & $5 \%$ & $2,3,4,5 \%$ & $59 \%$ \\
- Home Insulation & $2 \%$ & $0.7,1.05,1.4,1.75 \%$ & $30 \%$ \\
- Window Rebates & $1 \%$ & & $20 \%$ \\
\hline
\end{tabular}

Notes:

(1) Penetration rates are from Nadel and Tress (1990)

(2) Penetrations are in addition to those achieved by appliance standards and building codes.

(3) Annual Rate is the fraction of eligible customers participating each year. For new construction, the eligible population is all new homes. For retrofits, the eligible population is all existing homes not already retrofit.

(4) New construction is treated as a "lost opportunity." If efficiency measures are not implemented at time of construction, retrofit does not occur later.

(5) Existing thermal shell retrofits are weighted between weatherstripping measures (1/3) and insulation measures (2/3), based on relative energy savings.

(6) Cumulative penetration for Energy Fitness Program from Nadel \& Tress (47.5\%) is reduced by $20 \%$ to account for rural customers unreachable by such programs (resulting in $38 \%$ nationwide penetration).

(7) Window rebate penetration rate is based on Berry (1990) average program annual penetration rate $(3 \%)$, multiplied by $1 / 3$ to account for fraction of total windows being replaced in each house. 


\begin{tabular}{|c|c|c|c|c|}
\hline \multirow[b]{3}{*}{ Year } & \multicolumn{4}{|c|}{ Efficiency Level } \\
\hline & \multicolumn{2}{|c|}{ ASHRAE 90.2} & \multicolumn{2}{|c|}{ Advanced ASHRAE } \\
\hline & $\begin{array}{c}\text { Utility } \\
\text { Programs }\end{array}$ & $\begin{array}{c}\text { Building } \\
\text { Standards }\end{array}$ & $\begin{array}{c}\text { Utility } \\
\text { Programs }\end{array}$ & $\begin{array}{c}\text { Building } \\
\text { Standards }\end{array}$ \\
\hline 1990 & $5 \%$ & $0 \%$ & $5 \%$ & $0 \%$ \\
\hline 1991 & $15 \%$ & $0 \%$ & $15 \%$ & $0 \%$ \\
\hline 1992 & $25 \%$ & $0 \%$ & $25 \%$ & $0 \%$ \\
\hline 1993 & $35 \%$ & $0 \%$ & $35 \%$ & $0 \%$ \\
\hline 1994 & $45 \%$ & $0 \%$ & $45 \%$ & $0 \%$ \\
\hline 1995 & $0 \%$ & $40 \%$ & $50 \%$ & $0 \%$ \\
\hline 1996 & $0 \%$ & $48 \%$ & $50 \%$ & $0 \%$ \\
\hline 1997 & $0 \%$ & $56 \%$ & $50 \%$ & $0 \%$ \\
\hline 1998 & $0 \%$ & $64 \%$ & $50 \%$ & $0 \%$ \\
\hline 1999 & $0 \%$ & $72 \%$ & $50 \%$ & $0 \%$ \\
\hline 2000 & $0 \%$ & $80 \%$ & $50 \%$ & $0 \%$ \\
\hline 2001 & $0 \%$ & $80 \%$ & $50 \%$ & $0 \%$ \\
\hline 2002 & $0 \%$ & $80 \%$ & $50 \%$ & $0 \%$ \\
\hline 2003 & $0 \%$ & $80 \%$ & $50 \%$ & $7 \%$ \\
\hline 2004 & $0 \%$ & $80 \%$ & $50 \%$ & $21 \%$ \\
\hline 2005 & $0 \%$ & $80 \%$ & $0 \%$ & $35 \%$ \\
\hline 2006 & $0 \%$ & $80 \%$ & $0 \%$ & $42 \%$ \\
\hline 2007 & $0 \%$ & $80 \%$ & $0 \%$ & $49 \%$ \\
\hline 2008 & $0 \%$ & $80 \%$ & $0 \%$ & $56 \%$ \\
\hline 2009 & $0 \%$ & $80 \%$ & $0 \%$ & $63 \%$ \\
\hline 2010 & $0 \%$ & $80 \%$ & $0 \%$ & $70 \%$ \\
\hline $\begin{array}{l}2010 \text { Cumulative } \\
\text { Penetration: }\end{array}$ & $7 \%$ & $50 \%$ & $35 \%$ & $10 \%$ \\
\hline
\end{tabular}

(1) Building standards penetration include the effect of incomplete enforcement $(80 \%$ enforcement for ASHRAE 90.2; 70\% enforcement for advanced building standards).

(2) Assumes that utility programs end when ASHRAE 90.2 is adopted. Annual penetration of building standards in 1995 is a result of 50\% of housing starts occuring in jurisdictions adopting ASHRAE 90.2, combined with $80 \%$ enforcement. 


\section{b. Retrofits}

The two policy options for retrofitting the thermal shells of houses are utility weatherization programs and residential energy conservation ordinances. I assume that utilities use a three-tiered approach to retrofitting existing buildings, as described by Nadel and Tress (1990). The first is an Energy Fitness program, using a neighborhood sweep approach to contact residents and install basic lighting, water heating, and weatherization measures. The thermal shell measures in this program are relatively simple -- weather-stripping is one common measure -- and thus expected energy savings are low. However, one of the main benefits of this program is to motivate the residents to take other actions on their own and to refer them to other utility programs for more elaborate measures. The next such program is a House Doctor retrofit, in which a team of technicians visits the house and spends several hours identifying leaks with a blower door and installing infiltration reduction measures. The House Doctor program also refers poorly insulated houses to the next program -- the Home Insulation program. This last program upgrades the shell's insulation where possible, usually with blown-in insulation. Additionally, I assume that the utility has a rebate program for energy-efficient windows in order to subsidize the incremental cost of purchasing improved windows at the regular time of window replacement (this program could be implemented in conjunction with one of the previously mentioned house visits, in order to identify the best windows for replacement). The thermal integrity levels promoted in these programs are shown in Table 6.

When implemented in the past, these programs have been able to retrofit on the order of a few percent of the existing housing stock per year. Berry (1990) found that the average annual penetration rate for utility audit programs was 3\% of the housing stock. Nadel and Tress (1990) estimate that weatherization programs can achieve annual penetration rates of 4 to $5 \%$. These results for past programs are summarized in Table 4, in the lower section labeled "Existing Houses." The cumulative penetration for the various thermal shell retrofit programs are derived using the annual penetration trajectories shown in Table 7 (showing three programs as examples). The average cumulative penetration for the simpler weatherization programs (involving weather-stripping, caulk, and a few storm windows) is approximately $50 \%$, while the home insulation programs retrofits $30 \%$ of the 2010 stock. To calculate a weighted average penetration for all shell retrofit measures, I use the relative energy savings attributable to each type of measure (two-thirds of the energy savings are from insulation measures). Thus the average penetration of all shell measures is $37 \%$. In addition, window replacement measures are treated separately in the supply curve, so I calculate a separate cumulative penetration for the window rebate program. Windows are replaced infrequently, partly because the total cost of buying new windows is quite high (the average cost of replacing windows, from a survey of major single-family additions and alterations, was \$1,933 in 1990 (NAHB 1990). For this reason, I assume that the window rebate program targets homes that are already replacing windows, thus increasing the likelihood of the consumer upgrading to more efficient windows. Nevertheless, the timing requirements of this program make it difficult to achieve participation levels as high as the other retrofit programs described previously. I assume that a program such as this could enroll up to $3 \%$ of the homes in the housing stock each year. Moreover, I assume that consumers will on average replace only one-third of the windows in the house at any one time, leading to a $1 \%$ retrofit rate for the window stock. This annual rate leads to a $20 \%$ cumulative penetration rate by 2010 . 


\begin{tabular}{|c|c|c|c|c|c|c|}
\hline \multicolumn{7}{|c|}{ 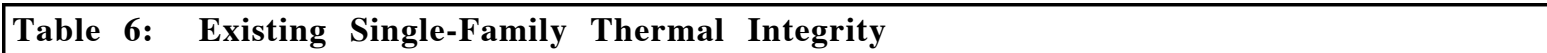 } \\
\hline \multirow{3}{*}{$\begin{array}{c}\text { Shell } \\
\text { Component }\end{array}$} & \multirow{2}{*}{\multicolumn{2}{|c|}{$\begin{array}{c}\text { Supply Curve } \\
\text { Baseline }\end{array}$}} & \multicolumn{4}{|c|}{ Thermal Integrity Level Included In: } \\
\hline & & & \multicolumn{2}{|c|}{ Utility Programs } & \multicolumn{2}{|c|}{ RECOs } \\
\hline & North & South & North & South & North & South \\
\hline Ceiling (R) & 21.0 & 17.8 & 30 & 30 & 30 & 30 \\
\hline Wall (R) & 2.4 & 2.6 & 11 & 11 & 11 & 11 \\
\hline Floor $(\mathrm{R})$ & 10.9 & - & 19 & - & 19 & - \\
\hline Foundation & - & $\mathrm{R}-0.9,2 \mathrm{ft}$ & $\mathrm{n} / \mathrm{a}$ & $\mathrm{n} / \mathrm{a}$ & $\mathrm{n} / \mathrm{a}$ & $\mathrm{n} / \mathrm{a}$ \\
\hline Window U-value & 0.6 & 1.0 & 0.3 & 0.36 & 0.6 & 0.81 \\
\hline Infiltration $(\mathrm{ACH})$ & 0.60 & 0.72 & 0.45 & 0.50 & 0.50 & 0.55 \\
\hline
\end{tabular}

Source: Supply Curve: Koomey et al. (1991)

Notes:

(1) Thermal integrity levels are presented for single-family homes because Koomey et al. (1991) considered shell measures for this house-type only.

(2) Thermal integrity levels for retrofit programs are approximate. Actual values promoted by the various policies are based on shell retrofit measures in Koomey et al. (1991). Thermal integrity levels depend on the climate, HVAC equipment, and baseline thermal shell quality. For example, where it is cost effective, a DSM program may upgrade ceiling insulation to R-37.

(3) RECO stands for residential energy conservation ordinance, a policy in which houses, upon sale, are upgraded to a minimum energy efficiency.

(4) I assume that RECOs require a lower level of thermal integrity than utility programs because the ordinances are involuntary and provide no financial incentive.

(5) North and South correspond to the regions defined in Koomey et al. (1991).

(6) U-values are for the whole window: $0.36=2$-pane, low-e, wood frame; $0.81=2$-pane, alum.-frame; Utility programs upgrade new windows during replacement; RECOs minor retrofit measures (e.g., sun-control coatings).

(7) Foundation insulation is slab-edge insulation to the R-value specified, to a depth of 2 feet. Foundation insulation retrofits are generally not cost-effective and therefore not considered in this study.

(8) $\mathrm{ACH}=$ Air Changes per Hour 


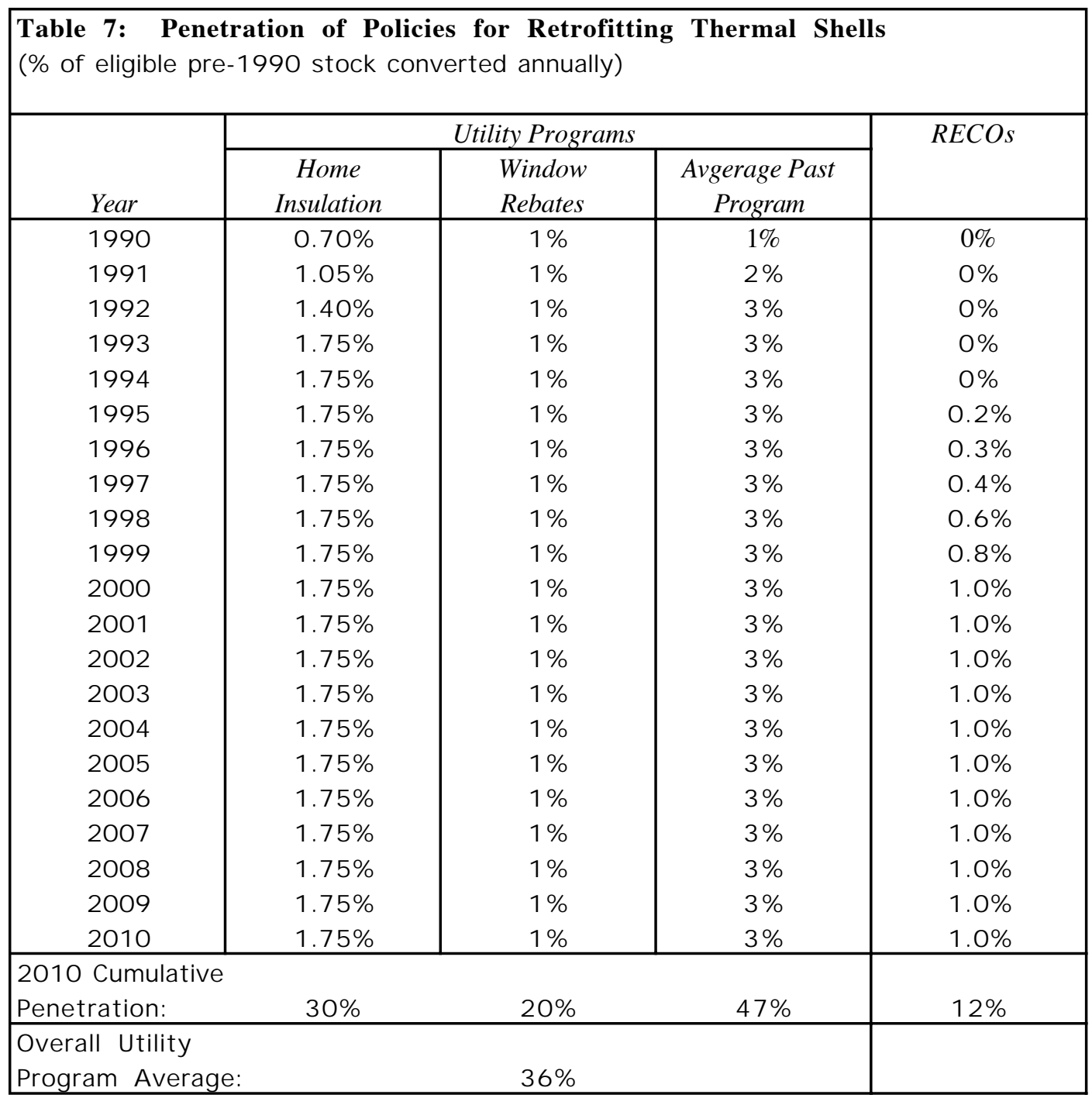

Notes:

(1) Utility-program eligible stock is all pre-1990 homes not yet retrofitted.

(2) Annual penetrations for Home Insulation program are from Nadel and Tress (1990).

(3) "Average Past Program" penetration is the average annual market penetration from a survey of 1980s weatherization programs by Berry (1990).

(4) The overall utility program average includes additional programs not shown in the table, such as the Energy Fitness program from Nadel and Tress (1990).

(5) RECO stands for residential energy conservation ordinance.

(6) RECO eligible stock is all pre-1990 homes in a given year.

(7) RECO penetration assumes $50 \%$ of cities adopt ordinances, $4 \%$ annual housing stock sales, and $50 \%$ enforcement. 
The second type of policy for improving thermal shells is the residential energy conservation ordinance (RECO). These ordinances require that all existing houses must be upgraded to a minimum thermal integrity level at the time of sale (another possibility is that all houses must meet this level by a certain date). Currently, RECOs have only been implemented in a very limited number of municipalities; San Francisco and Berkeley, CA are two frequently-cited examples. Moreover, the adoption of these ordinances is entirely at the volition of municipal governments, in contrast to new construction energy-efficiency codes that usually are based on a model code developed by a national organization such as ASHRAE or CABO. Thus, the diffusion of RECOs throughout the country may very well be a slow process, and probably will only happen as a result of coordinated action at the national level. On the other hand, home energy rating systems and energy-efficient mortgages may speed the adoption of RECOs by making the ordinance easier to implement and less burdensome for homeowners.

I assume that half the municipalities adopt RECOs between 1995 and 2000, and the other half will never adopt these ordinances. To be more precise, I assume that half the house sales in 2000 are subject to RECOs, implying that if the cities with the highest house sales rates were to adopt RECOs, my penetration assumptions could be achieved with only a minority of the US cities actually having adopted the ordinances. I further assume that $80 \%$ of the housing stock transfers ownership at some point during the 20 year study period, implying a constant annual sales rate of $4 \%$. Under these assumptions, RECOs will lead to the retrofit of $12 \%$ of the 2010 housing stock, as shown in Table 7.

\section{HVAC Equipment}

\section{a. Existing NAECA Standards}

NAECA standards became effective in 1990 for room air conditioners and in 1992 for heat pumps and central air conditioners. The assumptions about the existing NAECA standards are as follows: 1) $100 \%$ of the equipment sold in 1992 and later meets the standard. 2) Replacements assume that existing units are retired at a constant rate of 1/lifetime (in years). 3) New units begin to be retired after $3 / 4$ of their average lifetime. At 3/4 of the lifetime after the standard was passed, some of the first (1992) units will begin to be retired. The number of new units replacing non-standard units is reduced corresponding to the penetration of standard-meeting units in the previous year. An alternative method of calculating penetration is to assume that the stock eligible to be replaced by a standard unit (i.e., all non-standard units) is reduced according to the current penetration of standard units, starting immediately after the standard becomes effective. This assumption reduces the 2010 penetration of central air conditioners meeting the 1992 standard from $94 \%$ to $84 \%$. The

first method has more intuitive appeal and it is therefore adopted in calculating the remainder of the results presented in this paper.

\section{b. Advanced NAECA Standards}

I assume that subsequent NAECA standards are passed for HVAC equipment according to the schedule in Table 8. These standards are based strictly on judgment and do not represent official DOE policy. The 2010 market penetrations of these standards are calculated in the same way as the 1992 standards, assuming that units begin to be retired at 3/4 of their average lifetime. The cumulative penetrations shown are achieved by standards in isolation. 


\begin{tabular}{|c|c|c|c|c|c|}
\hline \multicolumn{6}{|c|}{ Table 8: HVAC Equipment Efficiency Standards } \\
\hline \multirow[t]{2}{*}{ Equipment Type } & \multirow{2}{*}{$\begin{array}{c}\text { Efficiency } \\
\text { Level }\end{array}$} & \multirow{2}{*}{$\begin{array}{l}\text { Start } \\
\text { Year }\end{array}$} & \multicolumn{3}{|c|}{2010 Cumulative Market Penetration } \\
\hline & & & Total Stock & New Construction & Replacement \\
\hline \multicolumn{6}{|l|}{ Heat Pump } \\
\hline - Current Standard & $\begin{array}{l}\mathrm{HSPF} \geq 7.46 \\
\mathrm{SEER} \geq 10.5\end{array}$ & 1992 & $89 \%$ & $88 \%$ & $90 \%$ \\
\hline - Future Standard & $\begin{array}{l}\mathrm{HSPF} \geq 9 \\
\mathrm{SEER} \geq 13\end{array}$ & 1999 & $68 \%$ & $49 \%$ & $77 \%$ \\
\hline \multicolumn{6}{|l|}{ Central A/C } \\
\hline - Current Standard & SEER $\geq 10.5$ & 1992 & $92 \%$ & $88 \%$ & $94 \%$ \\
\hline - Future Standard & SEER $\geq 14$ & 1999 & $72 \%$ & $49 \%$ & $82 \%$ \\
\hline Room A/C & & & & & \\
\hline - Current Standard & $E E R \geq 9$ & 1990 & $93 \%$ & $93 \%$ & $93 \%$ \\
\hline - Future Standard & $E E R \geq 10$ & 1995 & $80 \%$ & $71 \%$ & $84 \%$ \\
\hline
\end{tabular}

Notes:

(1) Current-standard efficiency levels and start-years are from Koomey et al. (1991).

(2) Future-standard start-years are based on judgment of LBL Energy Conservation Policy Group (1990).

(3) Future-standard efficiency levels are from Nadel and Tress (1990).

(4) Future standards are only for illustration and do not represent official DOE policy.

(5) New construction penetrations based on LBL-REM construction forecasts.

(6) New construction is considered a "lost opportunity." Equipment in houses built after 1990 is not replaced during the study period.

(7) HVAC equipment replacement penetration assumes that units are replaced at rate of 1/lifetime.

(Lifetimes from LBL-REM: Heat pump=14 yrs.; CAC=12 yrs.; RAC=15 yrs.).

(8) The 1999 air conditioner standards include variable-speed compressor drive.

\section{c. Utility Programs}

The impact of utility programs on the penetration of efficient HVAC equipment is shown in Table 9. The HVAC programs assumed in this study include rebates, where cost-effective, for conversion of electric resistance central furnaces to heat pumps, and rebates to upgrade to more efficient heat pumps, and central and room air conditioners. Both programs are for new and replacement applications. Assumptions about these programs are as follows: 1) New construction is targeted as part of the new construction program described previously under thermal shell measures. 2) Annual market penetration of the new construction program is assumed to be the same as previously calculated (see Table 4). 3) For replacement applications, because of the difficulty of recruiting individual customers at the time of replacement, the programs are run through equipment distributors, and HVAC engineers and contractors. 4) Penetrations shown in Table 9 for replacement applications are solely due to utility programs run from 1990 until new NAECA standards become effective in 1995 or 1999. 5) Utility programs give rebates on the same efficiency levels that will eventually be adopted as the advanced NAECA standard level.

The annual penetrations of HVAC equipment under these two policies (NAECA standards and utility programs) are shown in Table $\mathbf{1 0 .}$ 


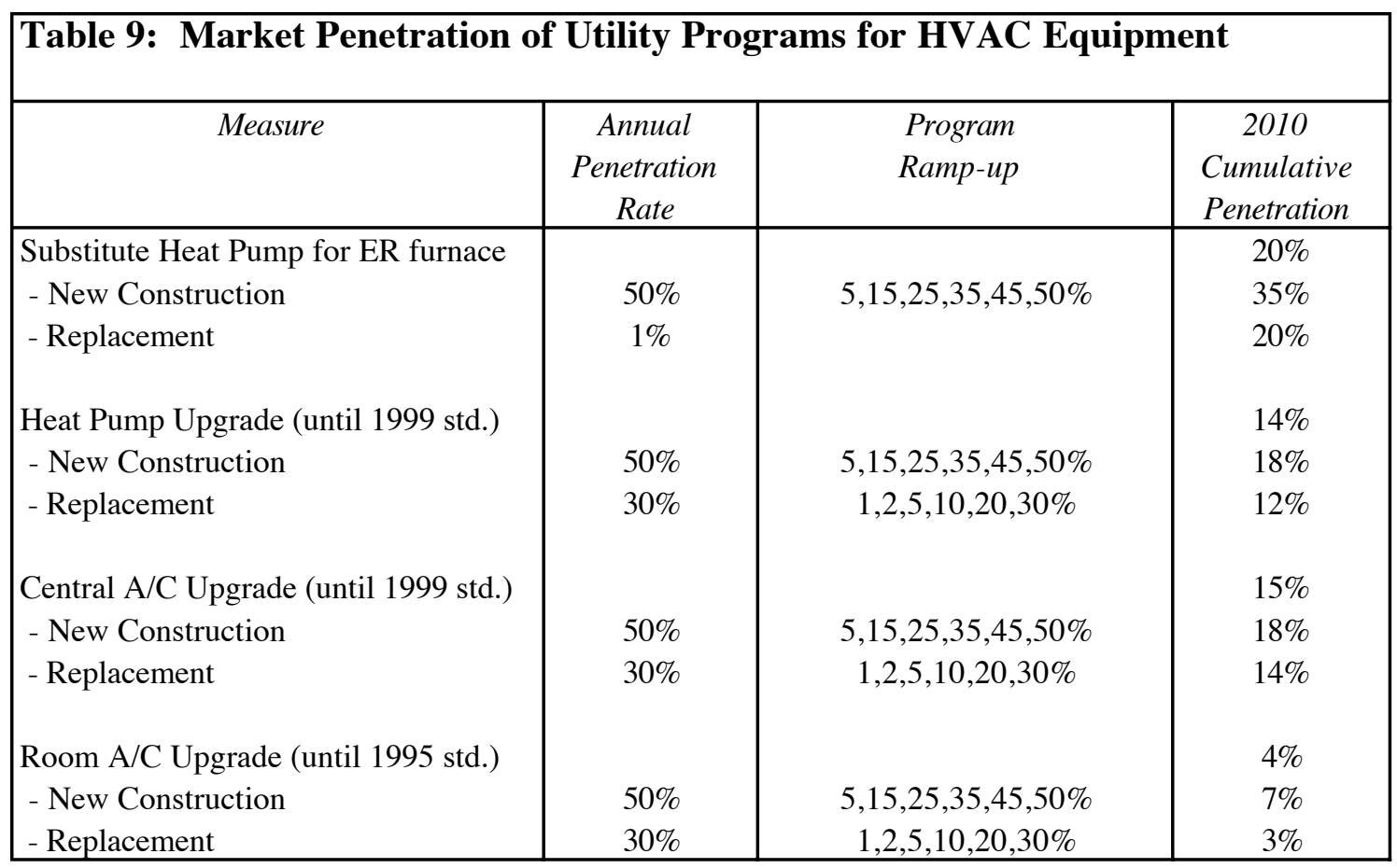

Notes:

(1) Penetrations are incremental to those achieved by appliance standards and building codes.

(2) HVAC equipment in new construction is targeted as part of the utilities' new construction programs. Annual penetration is from Nadel and Tress (1990).

(3) Replacement equipment penetrations are based on appliance rebate program described in Krause et al. (1988).

(4) I assume a low penetration of heat pumps replacing electric resistance furnaces due to consumer reluctance to switch product classes.

(5) Utility programs give rebates on the same efficiency levels that will eventually be adopted as the advanced NAECA standard level. 


\begin{tabular}{|c|c|c|c|c|c|c|}
\hline \multicolumn{7}{|c|}{$\begin{array}{l}\text { Table 10: Sample Penetration of Policies for Replacement HVAC Equipment } \\
\text { (\% of annual sales meeting the standard efficiency level) }\end{array}$} \\
\hline \multirow[b]{3}{*}{$\begin{array}{l}\text { Policy: } \\
\text { Year }\end{array}$} & \multicolumn{6}{|c|}{ Product / Efficiency Level } \\
\hline & \multicolumn{2}{|c|}{ CAC - 1999 Standard Efficiency } & \multicolumn{2}{|c|}{ RAC - 1995 Standard Efficiency } & \multicolumn{2}{|c|}{ Heat Pump - 1999 Standard Effic. } \\
\hline & $\begin{array}{c}\text { Utility } \\
\text { Programs }\end{array}$ & $\begin{array}{l}\text { NAECA } \\
\text { Standards }\end{array}$ & $\begin{array}{c}\text { Utility } \\
\text { Programs }\end{array}$ & $\begin{array}{l}\text { NAECA } \\
\text { Standards }\end{array}$ & $\begin{array}{c}\text { Utility } \\
\text { Programs }\end{array}$ & $\begin{array}{l}\text { NAECA } \\
\text { Standards }\end{array}$ \\
\hline 1990 & $1 \%$ & $0 \%$ & $1 \%$ & $0 \%$ & $1 \%$ & $0 \%$ \\
\hline 1991 & $2 \%$ & $0 \%$ & $2 \%$ & $0 \%$ & $2 \%$ & $0 \%$ \\
\hline 1992 & $5 \%$ & $0 \%$ & $5 \%$ & $0 \%$ & $5 \%$ & $0 \%$ \\
\hline 1993 & $10 \%$ & $0 \%$ & $10 \%$ & $0 \%$ & $10 \%$ & $0 \%$ \\
\hline 1994 & $20 \%$ & $0 \%$ & $20 \%$ & $0 \%$ & $20 \%$ & $0 \%$ \\
\hline 1995 & $30 \%$ & $0 \%$ & $0 \%$ & $100 \%$ & $30 \%$ & $0 \%$ \\
\hline 1996 & $30 \%$ & $0 \%$ & $0 \%$ & $100 \%$ & $30 \%$ & $0 \%$ \\
\hline 1997 & $30 \%$ & $0 \%$ & $0 \%$ & $100 \%$ & $30 \%$ & $0 \%$ \\
\hline 1998 & $30 \%$ & $0 \%$ & $0 \%$ & $100 \%$ & $30 \%$ & $0 \%$ \\
\hline 1999 & $0 \%$ & $100 \%$ & $0 \%$ & $100 \%$ & $0 \%$ & $100 \%$ \\
\hline 2000 & $0 \%$ & $100 \%$ & $0 \%$ & $100 \%$ & $0 \%$ & $100 \%$ \\
\hline 2001 & $0 \%$ & $100 \%$ & $0 \%$ & $100 \%$ & $0 \%$ & $100 \%$ \\
\hline 2002 & $0 \%$ & $100 \%$ & $0 \%$ & $100 \%$ & $0 \%$ & $100 \%$ \\
\hline 2003 & $0 \%$ & $100 \%$ & $0 \%$ & $100 \%$ & $0 \%$ & $100 \%$ \\
\hline 2004 & $0 \%$ & $100 \%$ & $0 \%$ & $100 \%$ & $0 \%$ & $100 \%$ \\
\hline 2005 & $0 \%$ & $100 \%$ & $0 \%$ & $100 \%$ & $0 \%$ & $100 \%$ \\
\hline 2006 & $0 \%$ & $100 \%$ & $0 \%$ & $100 \%$ & $0 \%$ & $100 \%$ \\
\hline 2007 & $0 \%$ & $100 \%$ & $0 \%$ & $100 \%$ & $0 \%$ & $100 \%$ \\
\hline 2008 & $0 \%$ & $100 \%$ & $0 \%$ & $100 \%$ & $0 \%$ & $100 \%$ \\
\hline 2009 & $0 \%$ & $100 \%$ & $0 \%$ & $100 \%$ & $0 \%$ & $100 \%$ \\
\hline 2010 & $0 \%$ & $100 \%$ & $0 \%$ & $100 \%$ & $0 \%$ & $100 \%$ \\
\hline $\begin{array}{l}2010 \text { Cumulative } \\
\text { Penetration: }\end{array}$ & $14 \%$ & $55 \%$ & $3 \%$ & $66 \%$ & $12 \%$ & $51 \%$ \\
\hline
\end{tabular}

Notes:

(1) Housing Stock decay rate and equipment lifetime are from LBL-REM.

(2) Program penetration adapted from MEOS (1988) appliance rebate program. 


\section{d. Building Standards}

In the past, building standards have not required efficient HVAC equipment beyond the efficiency level already required by appliance standards. I assume that this will continue to be the case in the future. However, building codes can have an effect on the relative market shares of alternative HVAC systems, by varying the difficulty and cost of installing certain systems. The primary example of this is electric resistance space heating. Building codes can be written so that the decision to build an electric-resistance heated house incurs a penalty in increased thermal integrity requirements for the thermal shell; the 1993 California energy-efficiency standards are written this way (CEC 1992). This penalty can serve as an incentive to install a heat pump rather than electric resistance heating (the technical potential measures in this end-use assume that any house with a natural gas hook-up will already use gas as its main heating fuel; thus conversion of electric resistance heating to gas is not considered to be technically feasible). The effectiveness of this incentive will depend on the magnitude of extra thermal integrity required with electric resistance heating. I assume that nationwide, half the homes install heat pumps as a result of this incentive, with no particular geographical distribution assumed. However, as calculated previously, utility new construction programs reach $35 \%$ of the 2010 new (post-1990) home stock, and I assume that electric-resistance heated homes are represented in these programs according to their saturation in the overall stock (i.e., 35\% of electric resistance homes are converted to heat pumps). These program-induced conversions are all included in the half of the stock converting to heat pumps, leaving $15 \%$ of the conversions attributable to the building code penalties alone.

\section{Appliances}

The assumed schedule of NAECA standards (both current and future) for all appliances are shown in Table 11.

\section{a. Refrigerators/Freezers}

This end-use includes both refrigerator/freezers and stand-alone freezers. Efficient refrigerators and freezers are promoted through efficiency standards and utility rebate programs. The first measure is the 1993 NAECA standard, which achieves an $86 \%$ market penetration by 2010 , in conjunction with utility programs run between 1990 and 1993.

Further measures are being developed through the Super Efficient Refrigerator Program (SERP). These advanced technologies will be promoted through utility rebates and eventually incorporated into a future NAECA standard. Table 12 summarizes the possible penetrations of these two policies, as a function of the effective date of the standard. There is some uncertainty as to exactly when the new technologies will be ready for inclusion in a standard; the main determinants will be the ability of manufacturers to mass-produce these technologies, and their cost-effectiveness. It is clear from Table 12, however, that earlier adoption of the standard leads to higher cumulative penetration of super-efficient models in 2010. Assumptions about refrigerator/freezer programs are as follows: 1) Utility program penetration is from Nadel and Tress (1990). The utility rebate program succeeds in shifting a significant portion of the annual refrigerator sales while it is run. The program ramp-up is shown in Table 13. 2) Nadel and Tress assume that the rebate program succeeds in accelerating the NAECA standard for these measures from 2003 to 1998. This study also makes that assumption (see Table 11). 


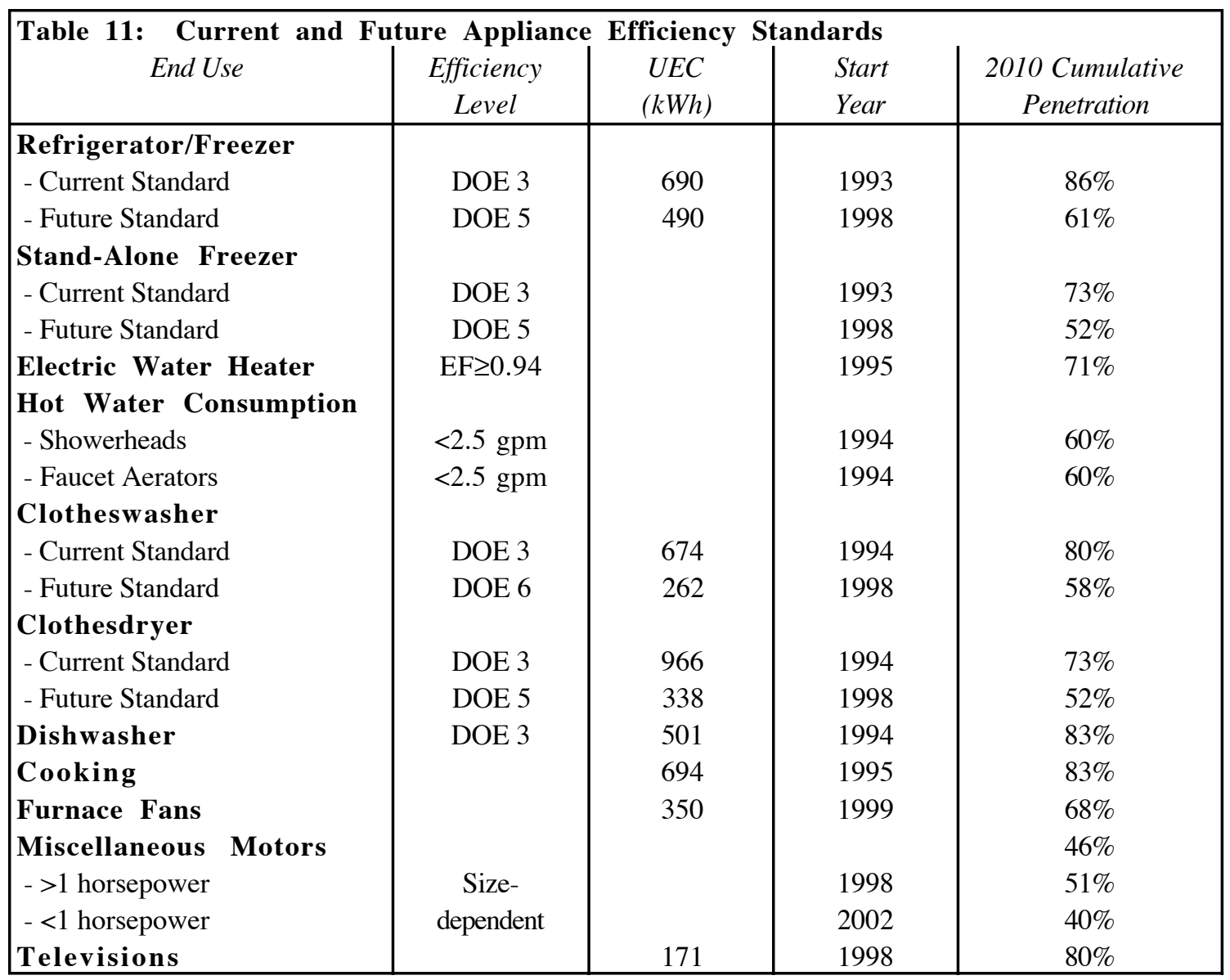

Notes:

(1) Current-standard efficiency levels and start-years are from Koomey et al. (1991).

(2) Future-standard start-years are from LBL Energy Conservation Policy Group (1990).

(3) Future-standard efficiency levels are based on advanced measures from Koomey et al. (1991).

(4) Standards are for illustration only and do not represent official DOE policy.

(5) Refrigerators/Freezers: UECs are based on $18 \mathrm{cu}$. ft. top-mount auto. defrost model. DOE Level 5 standard includes evacuated panels, twin 5.3 EER compressors, and adaptive defrost (U.S. DOE, Nov 89).

(6) Information on showerhead and aerator standards from Geller \& Nadel (1992); gpm=gallons/minute.

(7) Clotheswashers: DOE Level 6 standard is a horizontal-axis design.

UECs based on standard-capacity model (U.S. DOE, Dec 1990).

(8) Clothesdryers: DOE Level 5 standard is a heat pump design. UECs based on standard-size electric dryer (U.S. DOE, Dec 1990).

(9) Dishwashers: DOE Level 3 standard has booster heater and improved motor (U.S. DOE, Dec 1990).

(10) Cooking: Standard assumed to include induction cooktop and convection oven.

(11) Furnace Fans: Minimum efficiency is prescribed as part of 1999 heat pump standards.

(12) Motors: Energy Policy Act of 1992 prescribes minimum efficiencies for motors $>1 \mathrm{hp}$.

DOE must decide within 4 years whether to set standards on motors $<1$ hp (Geller \& Nadel 1992).

(13) TVs: 2010 penetration assumes constant linear stock turnover \& 15-yr life; UEC is for 21" color set. 
Table 12: Super-High Efficiency Refrigerator Penetration

(\% of 2010 Stock Converted as a Result of Programs)

\begin{tabular}{|l|c|c|c|}
\hline \multirow{2}{*}{ Program } & \multicolumn{3}{|c|}{ Year NAECA Standard Takes Effect } \\
\cline { 2 - 4 } & 1998 & 2003 & 2008 \\
\hline Utility Program Alone & $3 \%$ & $16 \%$ & $29 \%$ \\
Standard Alone & $61 \%$ & $34 \%$ & $9 \%$ \\
& & & \\
Total & $\mathbf{6 4 \%}$ & $\mathbf{5 0 \%}$ & $\mathbf{3 8 \%}$ \\
\hline
\end{tabular}

Notes:

(1) Utility program penetration based on Nadel \& Tress (1990) refrigerator rebate program. 
Table 13: Market Penetration of Utility Programs for Appliances

\begin{tabular}{|c|c|c|c|}
\hline Measure & \begin{tabular}{|c|} 
Annual \\
Penetration \\
Rate \\
\end{tabular} & $\begin{array}{l}\text { Program } \\
\text { Ramp-up }\end{array}$ & $\begin{array}{c}2010 \\
\text { Cumulative } \\
\text { Penetration } \\
\end{array}$ \\
\hline Refrigerator \& Freezer (till 2003 std.) & $50 \%$ & $1,5,15,30,50 \%$ & $16 \%$ \\
\hline Replace Elec. with Gas Water Heater & & & $18 \%$ \\
\hline - New Construction & $50 \%$ & $5,15,25,35,45,50 \%$ & $35 \%$ \\
\hline - Replacement & $10 \%$ & & $10 \%$ \\
\hline Replace Elec. with Heat Pump Water Heater & & & $31 \%$ \\
\hline - New Construction & $40 \%$ & $1,3,5,7,10,15,20,25,30,35,40 \%$ & $31 \%$ \\
\hline - Replacement & $40 \%$ & $1,3,5,7,10,15,20,25,30,35,40 \%$ & $31 \%$ \\
\hline Upgrade Elec. Water Heater (till 1995 std.) & & & $6 \%$ \\
\hline - New Construction & $50 \%$ & $5,15,25,35,45,50 \%$ & $7 \%$ \\
\hline - Replacement & $25 \%$ & $1,5,15,25 \%$ & $5 \%$ \\
\hline Reduce Hot Water Consumption & & & $29 \%$ \\
\hline - New Construction & $50 \%$ & $5,15,25,35,45,50 \%$ & $35 \%$ \\
\hline - Energy Fitness Retrofit & $4 \%$ & $2,2.5,3,4 \%$ & $27 \%$ \\
\hline Lighting & & & $36 \%$ \\
\hline - New Construction & $50 \%$ & $5,15,25,35,45,50 \%$ & $35 \%$ \\
\hline - Replacem't Light Coupons & $8 \%$ & $2,4,6,8 \%$ & $36 \%$ \\
\hline - Energy Fitness Retrofit & $4 \%$ & $2,2.5,3,4 \%$ & $38 \%$ \\
\hline Clotheswasher & & & $10 \%$ \\
\hline Clothesdryer & & & $10 \%$ \\
\hline Dishwasher & & & $0 \%$ \\
\hline Cooking & & & $10 \%$ \\
\hline
\end{tabular}

Notes:

(1) Penetration rates are from Nadel and Tress (1990).

(2) Penetrations are in addition to those achieved by appliance standards and building codes.

(3) Annual Rate is the market share of efficient models in each year.

(4) New construction is treated as a "lost opportunity." If efficiency measures are not implemented at time of construction, retrofit does not occur later.

(5) Cumulative penetration for Energy Fitness program from Nadel \& Tress (47.5\%) is reduced by $20 \%$ to account for rural customers unreachable by such programs (resulting in $38 \%$ nationwide penetration).

(6) Penetration of the hot water consumption portion of Energy Fitness program is further reduced by $30 \%$ to incorporate the effect of plumbing fixture standards. 


\section{b. Electric Water Heaters}

Several policies promote efficiency in electric water heating. First, two utility programs promote conversion of standard electric resistance water heaters to other technologies. For homes with gas hookups (or gas lines in the street) utilities give rebates to subsidize the cost of converting to gas water heating. In new construction, this fuel-switching program is part of the new construction program described previously. For replacement applications, the fuel switching measure must be installed at the time the existing electric water heater is replaced. The program is implemented through plumbers and contractors who install water heaters at the time of failure. For homes without a gas hookup, the water heater is converted to a heat pump water heater, as long as there is a location for the water heater that is warm enough throughout the year. This conversion is implemented in the same way as the gas conversion measure. For those houses with neither gas nor a proper location for a heat pump water heater, the standard electric water heater is upgraded to an efficient model at the time of replacement. Utility programs encourage this upgrade in the early phases of the study period, and in 1995 the NAECA water heater standard is upgraded so that all new electric water heaters are near the maximum thermal efficiency possible with electric resistance heating (Table 11). Finally, utilities run programs to reduce the use of hot water through low-flow shower heads and faucet aerators. In 1994, NAECA standards go into effect requiring that all plumbing fixtures be low flow, but the utilities continue their programs to speed the conversion of the existing stock.

Assumptions for electric water heater programs are as follows: 1) Gas fuel-switching is included in utilities' new construction efficiency programs. 2010 cumulative penetration is $35 \%$ of the eligible stock (eligibility for the measure is already included in the technical potential). 2) Krause and others (1988) found that $0.5 \%$ of existing homes convert to gas water heating each year. A utility program could significantly expand this rate. I assume a $10 \%$ annual and cumulative penetration for gas water heater conversion in existing homes. 3) Nadel and Tress (1990) assume that a utility program specifically targeted at conversion to heat pump water heaters could achieve a $40 \%$ annual penetration rate (after a long ramp-up period). This study also makes that assumption (see Table 13). 4) Utility programs for improving the efficiency of electric resistance water heaters have relatively little impact, primarily because the 1995 NAECA standard achieves most of the available savings. I assume the utility programs achieve $10 \%$ annual penetration for replacement applications, resulting in 5\% cumulative penetration in 2010. The new construction programs do little better than this, as shown in Table 13. The NAECA standard, however, achieves $71 \%$ penetration by 2010 , as shown in Table 11. 5) Through a combination of the 1994 NAECA plumbing fixture standard, and utility programs to promote conversion, approximately $80 \%$ of the 2010 stock has low-flow fixtures.

\section{c. Lighting}

The primary policy for promoting efficient lighting is utility programs. Advanced building codes may have some effect in this area, but it is hard to predict what their applicability to lighting will be. The assumptions for lighting programs are as follows: 1) Efficient lighting is promoted in new housing construction through the new construction program described previously. These programs require the installation of CFL fixtures at the time of construction, avoiding many of the problems encountered in later retrofits. 2) Utilities install compact fluorescents in high-usage sockets as part of their door-to-door energy fitness program. Additionally, the utilities run a lighting coupon program in order to ensure that CFLs installed in the energy fitness program are replaced by similar lights when they reach the end of their life. These replacement programs can convert approximately one-third of the stock of light sockets by 2010. The combined penetration of the new construction and replacement programs is $36 \%$. 3) Utility programs are needed throughout the study period in order to increase the penetration of CFLs. There are no significant breakthroughs in price or availability that would allow CFLs to become the standard lighting technology. 


\section{d. Other Appliances}

Table 11 shows the NAECA standards I assume for clothes washers, clothes dryers, dishwashers, and ranges. The 2010 penetrations shown in the table are for the standards in isolation from other policies. In addition, I assume that utilities make a limited effort to accelerate the replacement of the existing stock. These utility programs would take the form of information campaigns (possibly as part of the energy fitness program) and a rebate for incentive. These programs are able to convert an additional $10 \%$ of the 2010 stock (except for dishwashers, which are completely converted by the standard).

\section{Policy Enforcement}

Building standards are the most difficult to implement of the three policies considered in this study. There are many reasons for this, but the fundamental difficulty is that building standards are implemented at the local level. The codes are therefore subject to great variation in: the content of the ordinances, the competence and motivation of building officials, and the materials and design of new houses. These factors mean that in practice building officials are given substantial discretion to determine code compliance. Complicating this situation is the tendency for energy-efficiency standards to require complex calculations and numerous trade-offs to arrive at a design that complies with the code yet still meets the other requirements of the building (aesthetic, budget, etc.). A plausible assumption is that more complex standards will have lower compliance because builders have a larger incentive to evade the standards (higher construction and transaction costs to avoid) and it is more difficult for building officials to verify compliance. To my knowledge, no studies have quantified the level of compliance with building standards. As a representative figure, I assume that current advanced building codes (such as California's Title 24) have an $80 \%$ compliance rate. This rate applies also to the new ASHRAE 90.2 standard. For advanced standards to be instituted in the future, I assume a slightly lower, $70 \%$ compliance rate. These figures apply to new construction. For retrofits and renovations, the compliance rates are much lower because much of this work is done without building permits. Therefore, for RECOs, I assume that the compliance rate is $50 \%$ (that is, $50 \%$ of all homes that are legally required to install energy-efficiency improvements actually do so).

\section{Program Costs}

Program costs are the "overhead" costs to administer programs, set energy-efficiency levels for standards, select technologies eligible for rebates, find participants for DSM programs, and conduct all the other administrative activities that ensure a successful policy. I do not include any transaction or information costs these policies may impose; for example, the costs a home builder might incur to learn about new building codes or DSM programs. On the other hand, program costs can themselves be considered "revealed" transaction and information costs. ${ }^{9}$ One of the effects of policies is to internalize (put a monetary value on) costs that were originally not valued by markets. In this way, private costs borne by individuals are assumed by society (or disappear altogether). For instance, if a policy makes energy-efficient lighting products commonplace, then individual consumers can avoid many of the transaction costs they originally would have incurred to purchase those products. Moreover, it is possible for the government to achieve economies of scale in information gathering, thereby reducing the aggregate information costs in society.

\footnotetext{
${ }^{9}$ An example of a transaction cost in the energy services market is the process of finding stores that sell energyefficient lighting products. An example of an information cost is the process of collecting technical data on alternative products in order to compare their energy-efficiency.
} 
The program costs used in this study are summarized in Table 14.

\begin{tabular}{|c|c|}
\hline \multicolumn{2}{|c|}{ Table 14: Summary of Program Costs } \\
\hline Policy & $\begin{array}{c}\text { Average Program Cost } \\
(\phi / k W h)\end{array}$ \\
\hline Appliance Standards & 0.25 \\
\hline Utility Programs & 0.68 \\
\hline Building Standards & 0.33 \\
\hline Overall Average & 0.41 \\
\hline
\end{tabular}

\section{A. Appliance Standards}

For appliance standards, program costs are incurred by government agencies to set and enforce standards. Determining these costs is difficult because they are buried in the budget of the government agency that is responsible for the standards. In addition, there may be indirect costs due to the standards (such as costs for appliance manufacturers to adapt to the standards), which are not considered in this study. For appliance standards I assume a levelized program cost of 0.25 cents/kWh, derived from Krause and others (1992). The costs of setting appliance standards and enforcing their compliance are largely fixed costs (irrespective of measure capital cost or energy savings), so a levelized cost is the appropriate method to account for program costs.

\section{B. Utility Programs}

The program costs for utility DSM programs are estimated on a program-by-program basis because they vary considerably with the type of measure and design of the program. Generally, these costs are publicly known because utilities are required to keep track of them for cost accounting purposes (although there are many discrepancies in the accounting formats used by different utilities to report costs). Table 15 shows the program costs assumed for each utility program included in this study. When applied to each measure and averaged according to the savings achieved by the programs, the average utility program costs approximately $0.7 \mathrm{cents} / \mathrm{kWh}$ (Table 14). These costs are approximately $20 \%$ of the average technical potential measure CCE (3.5 cents/kWh), which agrees well with the findings of Berry (1991) in a review of DSM program administrative costs.

Another component of utility program costs are "free riders" - people who would have adopted the technology without the program, but took advantage of the program to subsidize their investment. Free riders increase program costs per TWh of energy savings because the total program cost is allocated over a smaller amount of savings directly attributable to the program. The free ridership level for each of these programs is also presented in Table 15. One potential problem with free ridership estimates is that the estimation techniques can be inaccurate. The most common method is to survey program participants to find out if they would have purchased the measure without the program. Depending on how the survey questions are asked, these surveys can be biased (Vine 1992a).

The concept of free riders does not apply to either of the standards programs because people who would have adopted the technology without the standard do not impose a "cost" on the program or displace other program participants. Free ridership levels can be reduced by specifically designing the program to minimize free riders or giving rebates on very high efficiency equipment that would not normally be purchased without incentives. 


\begin{tabular}{|c|c|c|}
\hline Table 15: Utility Program Costs ar & Free Rider L & \\
\hline Program & $\begin{array}{c}\text { Program Cost } \\
\text { (\% of CCE) }\end{array}$ & $\begin{array}{c}\text { Free Rider } \\
\text { Fraction }\end{array}$ \\
\hline - Building Shell & & \\
\hline - New Construction & $10 \%$ & $0 \%$ \\
\hline - Existing Houses & $31 \%$ & $10 \%$ \\
\hline - Weatherstripping Measures & $13 \%$ & $10 \%$ \\
\hline - Home Insulation & $39 \%$ & $10 \%$ \\
\hline - Window Rebates & $10 \%$ & $21 \%$ \\
\hline - HVAC Equipment & & \\
\hline Substitute Heat Pump for ER furnace & & \\
\hline - New Construction & $10 \%$ & $5 \%$ \\
\hline - Replacement & $20 \%$ & $5 \%$ \\
\hline Heat Pump Upgrade (until 1999 std.) & & \\
\hline - New Construction & $10 \%$ & $10 \%$ \\
\hline - Replacement & $9 \%$ & $10 \%$ \\
\hline Central A/C Upgrade (until 1999 std.) & & \\
\hline - New Construction & $10 \%$ & $10 \%$ \\
\hline - Replacement & $9 \%$ & $10 \%$ \\
\hline Room A/C Upgrade (until 1995 std.) & & \\
\hline - New Construction & $10 \%$ & $10 \%$ \\
\hline - Replacement & $9 \%$ & $10 \%$ \\
\hline - Appliances & & \\
\hline Refrigerator \& Freezer (Until 2003 std.) & $7 \%$ & $0 \%$ \\
\hline Replace Elec. with Gas Water Heater & $23 \%$ & $5 \%$ \\
\hline Replace Elec. with Heat Pump Water Heater & $7 \%$ & $0 \%$ \\
\hline Upgrade Elec. Water Heater (Until 1995 std.) & $10 \%$ & $0 \%$ \\
\hline Reduce Hot Water Consumption & $41 \%$ & $30 \%$ \\
\hline Lighting & $13 \%$ & $10 \%$ \\
\hline
\end{tabular}




\section{Building Standards}

The costs of energy-efficiency building codes are similar to appliance standards. They are even more difficult to quantify, however, because energy efficiency is only a portion of existing building codes and building standards are implemented at the local level, so the entire cost to the government is spread over many local jurisdictions. Due to the larger burden of implementing a decentralized policy, the program costs for building standards are assumed to be higher than appliance standards costs. The value used in this study is $0.3 \notin / \mathrm{kWh}$, which is also derived from Krause and others (1992). The rationale for a levelized program cost is the same as for appliance standards.

\section{Adjustments to Technical Potential}

This section describes how the technical potential estimates of energy savings were adjusted to more closely predict the energy savings that might actually be realized by the measures. Several factors are of interest: calibrations of engineering estimates to measured data, the takeback effect, and savings persistence. Engineering estimate adjustments calibrate the estimates of energy savings to account for inaccurate assumptions or analysis methods. The takeback effect is a phenomenon in which increasing the efficiency of energy-using capital equipment saves less energy than expected because consumers simply use the equipment more intensively, thereby "taking back" the energy savings in the form of increased energy services. Savings persistence accounts for the fact that the efficiency of physical devices degrades over time, or in some cases may be rendered inoperable by the building occupants.

Nadel and Keating (1991) have made the only attempt to systematically address these issues by comparing the evaluation results of DSM programs to the engineering calculations of savings originally used to design those same programs. Their results suffer two shortcomings. First, for most end-uses the results are based on a very limited sample of programs, and are thus not necessarily representative of the majority of past or future DSM programs. Second, the program evaluations on which they rely generally include several different factors that could be causing the engineering calculations to over-predict program impact. These effects include: "market" savings achieved by the non-participant control group, free riders, takeback, measure persistence, quality control problems with measure installation, use of secondary fuels, and poor assumptions used in the engineering calculations. The current study uses separate parameters to address most of these effects, making the Nadel and Keating results inapplicable as presented. Moreover, the effects for which a DSM program is evaluated are by no means standard. For example, some studies attempt to account for measure persistence, while others do not. Further complicating this process is the fact that these effects are very difficult to isolate; the most reliable adjustment would be an aggregate measure that lumps all effects together (as the Nadel and Keating study does). However, for the purposes of this study (in which the adjustment factors are estimated separately), the empirical results from Nadel and Keating provide a rough guideline as to the magnitude of adjustment required.

The values assumed for these factors are shown in Table 16. The effects vary by end-use because the equipment, operating conditions, and behavioral effects are different for each end-use. 


\begin{tabular}{|c|c|c|c|}
\hline \multicolumn{4}{|c|}{$\begin{array}{l}\text { Table 16: Summary of Technical Potential Adjustment Factors } \\
\text { (\% of original savings estimate not realized) }\end{array}$} \\
\hline \multirow[b]{2}{*}{ Efficiency Measure } & \multicolumn{3}{|c|}{ Factor } \\
\hline & Takeback & $\begin{array}{c}\text { Measured-Savings } \\
\text { Adjustment }\end{array}$ & Persistence \\
\hline Thermal Shell Retrofits & $15 \%$ & $15 \%$ & $10 \%$ \\
\hline New Thermal Shells & $5 \%$ & $5 \%$ & $5 \%$ \\
\hline New-home HVAC Equipment & & & \\
\hline - Heat Pumps & $5 \%$ & $10 \%$ & $5 \%$ \\
\hline - Air Conditioning & $5 \%$ & $15 \%$ & $5 \%$ \\
\hline Replacement HVAC Equipment & & & \\
\hline - Heat Pumps & $10 \%$ & $10 \%$ & $10 \%$ \\
\hline - Air Conditioning & $10 \%$ & $15 \%$ & $5 \%$ \\
\hline Refrigerators / Freezers & $0 \%$ & $5 \%$ & $5 \%$ \\
\hline Water Heating & & & \\
\hline - Efficient New Water Heater & $10 \%$ & $5 \%$ & $5 \%$ \\
\hline - Showerheads \& Aerators & $15 \%$ & $5 \%$ & $10 \%$ \\
\hline Lighting & $10 \%$ & $10 \%$ & $10 \%$ \\
\hline Clotheswasher & $5 \%$ & $5 \%$ & $0 \%$ \\
\hline Clothesdryer & $0 \%$ & $5 \%$ & $0 \%$ \\
\hline Dishwasher & $0 \%$ & $5 \%$ & $0 \%$ \\
\hline
\end{tabular}

Notes:

(1) Takeback is the reduction in energy savings due to increased use after measure installation.

(2) The measured-savings adjustment accounts for inaccuracies in the original estimates of technical potential energy savings.

(3) Persistence accounts for the performance degradation that the energy efficiency measure will suffer over its lifetime, over and above the expected performance degradation of the baseline device. 


\section{A. Engineering Estimate Adjustments}

The need to calibrate engineering estimates seems quite obvious, and has been demonstrated by the observation that DSM programs typically do not achieve the level of energy savings estimated $a$ priori through engineering calculations. Part of this may be due to the takeback effect, but part might simply be due to inaccuracies in the engineering estimates (equipment not working as well as expected in the field, etc.). Each end-use in the technical potential was estimated using different techniques and thus is subject to different adjustments. The detailed discussion of each is treated separately here.

\section{Space Conditioning}

The technical potential estimates of space conditioning energy savings are based on PEAR building simulations (Huang et al. 1987). This program assumes that thermal shells are 1980s-style construction, the entire conditioned floor area is conditioned at all times, the central heating and cooling systems are used to meet the entire space conditioning load, and the thermostat is set at a constant temperature with a 10 degree heating setback at night. These assumptions are more representative of new construction and I therefore assume that the savings estimates are more accurate for the new construction vintage houses. In general, the space conditioning end-use (particularly air conditioning) is the most prone to estimation errors because of the large number of variables that influence energy use and the importance of usage patterns (such as thermostat setpoint, door and window opening schedules, zoning of conditioned spaces, etc.) in determining the resultant energy consumption. For new houses I assume that measured energy consumption is actually $5 \%$ less than the PEAR estimates. For existing houses, I assume the correction is 15\%, because usage plays an even larger role in houses with less thermal integrity and the PEAR database was developed to model new, rather than existing, house construction practices.

\section{HVAC Equipment}

HVAC equipment is subject to many of the same influences that thermal shells are. In particular, air conditioners are subject to significant variation in usage patterns and are therefore difficult to estimate with building simulations. Heat pump savings estimates tend to be more accurate because a greater fraction of their consumption is for winter heating, which can be modeled more accurately. I assume that the quality of estimates does not vary between replacement equipment and equipment installed in new homes. The engineering adjustment factors for HVAC equipment are shown in Table 16.

\section{Appliances}

Appliances have been modeled differently for each end-use. The most common problems with these savings estimates are the operating conditions (such as kitchen temperature, for refrigerators) and usage level (such as the amount of hot water used per day, for water heaters). I assume that the engineering estimates for appliances are accurate to within 5-10\% because there are fewer factors that influence consumption (compared to space conditioning) and they are therefore easier to model. The engineering adjustment factors for appliances are shown in Table 16.

\section{B. Takeback Effect}

The takeback effect is a phenomenon in which increasing the efficiency of energy-using capital equipment saves less energy than expected because consumers simply use the equipment more intensively, thereby "taking back" the energy savings in the form of increased energy services. The best example of takeback is turning the thermostat up after insulating a home's thermal shell. This is fundamentally an economic concept because it assumes that a change in the price signal leads to a change in the equilibrium quantity demanded. In this case, the demand is for energy services, and 
increases in equipment efficiency serve to lower the relative monetary cost of a "unit" of energy service. The existence of takeback rests on two further assumptions: a) consumers are cognizant of the prices they pay for energy services, and b) their desire for energy services is not fully satisfied at the original level of consumption. These assumptions are valid to differing degrees for different end-uses. For instance, end-uses that have a latent demand for energy services and a "visible" energy price should experience relatively more takeback. Private autos are probably the best example of these conditions. In residences, however, conditions are much different. First, the electricity price signal is not clearly transmitted to the consumer because all end-uses are combined into one monthly utility bill and it is therefore difficult for the consumer to determine the effect of any particular usage change. Residents often are not even aware of the price they pay for electricity, let alone the price of the services delivered by that electricity. If, on the other hand, consumers are aware of efficiency improvements in new equipment they purchase, it is possible they will use this information as a proxy for operating cost and adjust their usage accordingly. This theory is intuitively logical, but may not prove true in many cases because few people actually know the efficiency of the products they use (Davis [1982] as cited in CEC (1983)). Second, the benefits of energy services decrease with increasing consumption levels. In other words, at some point the demand for energy services is saturated and people will not consume more. For instance, the human body is comfortable in only a relatively small temperature range, thus one would expect thermostat adjustments to be limited to this range. Similarly, a given size family can only wash a certain number of laundry loads each year or use a certain volume of refrigerated space. While these saturation consumption levels vary for individual households, and the absolute level at which saturation is reached is open to debate, a strong case can be made that current consumption levels in U.S. residences are close to these saturation levels. In other words, latent demand for energy services is small in most residential end-uses.

Nevertheless, certain end-uses $d o$ hold the potential for takeback. For instance, air conditioning is generally thought to be subject to takeback because the usage level is typically determined by the operator's discretion rather than automatic controls. Although one can qualitatively describe tendencies for takeback, there are no models to accurately estimate its effects. For the purposes of this study, takeback is quantified by making subjective estimates of the importance of behavioral influences in an end-use's energy consumption. These quantified factors are shown in Table 16. In estimating achievable potential, takeback reduces the total energy savings but is assumed not to affect the CCE of a measure because the "cost" to the consumer is reduced due to added value from increased energy services. Whether or not this added consumer value is equivalent to the reduced energy savings will be highly dependent on the situation. Including consumer value in evaluations of cost-effectiveness is a relatively new concept. See Chamberlain (1993) and Brathwait (1993) for more details.

\section{Savings Persistence}

Savings persistence accounts for the fact that the energy-efficiency of physical devices degrades over time, or in some cases may be rendered inoperable by the building occupants. Because energy savings are measured incrementally to the baseline, performance degradation is only important in this situation when it is greater than what the baseline device would suffer. Savings persistence is an increasingly important issue in the evaluation of DSM programs. In some cases, however, the definition of persistence in a program evaluation may include other factors that this study treats elsewhere. For instance, Vine (1992b) summarizes the empirical data on DSM savings persistence by pointing out that savings can decrease over time, not because the consumption for the participant group increases, but because the consumption for the control group decreases (ostensibly because of market-induced adoption of energy efficiency). Because the current study uses a frozen efficiency baseline, which explicitly excludes market-induced energy efficiency, the persistence effect cited by Vine does not apply here. On the other hand, empirical evidence suggests that the energy-efficiency performance of measures degrades over time, particularly because measures installed through DSM programs are sometimes removed by building occupants. 
At this point there are no comprehensive studies of savings persistence. Values for performance degradation by 2010 have been qualitatively assessed based on the potential that measures will physically degrade over time (e.g., vacuum panel insulation) or are easily removed/disabled (e.g., shower heads or compact fluorescent lamps). The assumed values are presented in Table 16.

\section{Results}

The achievable potential measures are listed in Table 17. The detailed inputs for each measure are shown in Table 18. The resulting supply curve is presented graphically in Figure 5, incorporating all the adjustment factors described previously. These results show that approximately $185 \mathrm{TWh}$ of annual electricity savings can be achieved by 2010 , which is $45 \%$ of the technical potential and $18 \%$ of the frozen efficiency baseline consumption forecast for that year.

To investigate the role that each factor plays in achievable potential, Figure 6 shows the supply curve when each factor is sequentially added to the calculation. The order in which factors are applied (progressing from the right to the left in the diagram) are: technical potential, market penetration, program costs, engineering estimate adjustment, savings takeback, and measure persistence. Two observations can be made from these curves. First, approximately two-thirds of the difference between the technical and achievable potential is due to market penetration alone. This implies that the principal barrier to achieving savings is getting people to adopt the new technologies. The second observation is that program costs (the smallest dotted line) has essentially no effect on achievable potential, and is a smaller effect than the technical potential adjustment factors. This occurs because most measures cost much less than the electricity price, so an increase in their cost of 10-20\% (due to program costs) still does not push them above the electricity line.

The achievable potential also shows some interesting trends when aggregated by end-use. Table 19 shows the achievable potential energy savings by end-use and also the fraction of savings due to each type of policy. The breakdown of savings for the various policies is: $60 \%$ of the achievable potential is due to appliance standards, $33 \%$ due to utility programs, and $7 \%$ due to building standards. Figure 7 shows both the technical and achievable potential for all measures costing less than the electricity price $(7.8 \phi / \mathrm{kWh})$. The end-uses corresponding to these supply curves are in Table 20. The end-uses are ordered differently in the achievable potential (relative to the technical potential) because different end-uses have differing program costs (due to differing policies) and the mix of high and low-cost measures varies between the two curves (high cost measures tend to be implemented less, therefore in the achievable potential the weighted average cost can be lower than expected). 


\begin{tabular}{|c|c|c|c|c|c|c|}
\hline \multicolumn{7}{|c|}{$\begin{array}{l}\text { Table 17: Achievable Potential with All Adjustment Factors } \\
\text { (Annual Residential Savings in 2010) }\end{array}$} \\
\hline $\begin{array}{c}\text { Ach'v. } \\
\text { Pot. } \\
\text { Meas. } \\
\text { \# } \\
\end{array}$ & $\begin{array}{c}\text { Tech. } \\
\text { Pot. } \\
\text { Meas. } \\
\#\end{array}$ & \begin{tabular}{|} 
Meas- \\
ure \\
Code
\end{tabular} & Measure Name & \begin{tabular}{|l} 
Measure \\
Energy \\
Savings \\
$(T W h)$ \\
\end{tabular} & $\begin{array}{c}\text { Cum. } \\
\text { Energy } \\
\text { Savings } \\
(T W h) \\
\end{array}$ & $\begin{array}{c}A v g . \\
C C E \\
(\phi / k W h) \\
\end{array}$ \\
\hline 1 & 1 & 55 & 1994 NAECA Standard Clotheswasher & 1.74 & 1.74 & 0.4 \\
\hline 2 & 2 & 34 & Switch ER furnace to 9.5 HSPF HP in NSF homes & 5.95 & 7.69 & 1.1 \\
\hline 3 & 3 & 49 & EWH: Aerators, Showerheads & 27.21 & 34.90 & 1.3 \\
\hline 4 & 4 & 17 & Switch ER furnace to 9.5 HSPF HP in ESF \& EMH homes & 2.76 & 37.66 & 2.0 \\
\hline 5 & 5 & 40 & 9.5 HSPF HP in NSF \& NMH homes & 3.61 & 41.27 & 2.4 \\
\hline 6 & 6 & 23 & 9.5 HSPF HP in ESF \& EMH HP-conditioned homes & 3.26 & 44.53 & 2.6 \\
\hline 7 & 8 & 13 & 9.43 HSPF HP in EMF homes & 0.40 & 44.93 & 2.7 \\
\hline 8 & 7 & 53 & Compact Fluorescents; Outdoor Timer and Photocell & 15.30 & 60.23 & 2.9 \\
\hline 9 & 9 & 61 & 1994 NAECA Standard Dishwasher & 2.76 & 62.99 & 3.4 \\
\hline 10 & 10 & 66 & TV sets: efficiency improvements & 2.76 & 65.75 & 3.7 \\
\hline 11 & 16 & 64 & Upgrade Furnace Fan Efficiency & 4.13 & 69.88 & 3.9 \\
\hline 12 & 11 & 22 & 1992 Std. HP: ESF \& EMH HP-heated homes (7.46 HSPF) & 0.77 & 70.65 & 4.0 \\
\hline 13 & 14 & 50 & EWH: Reduce Standby Losses & 12.73 & 83.38 & 4.1 \\
\hline 14 & 17 & 44 & 1993 NAECA Standard Refrigerator & 22.68 & 106.06 & 4.2 \\
\hline 15 & 15 & 39 & 1992 Std. HP: NSF \& NMH HP-heated homes (7.46 HSPF) & 0.98 & 107.04 & 4.3 \\
\hline 16 & 13 & 25 & 9.42 EER RAC in ESF \& EMH homes & 0.23 & 107.27 & 4.5 \\
\hline 17 & 19 & 5 & Insulation \& W'strip. in NSF homes (I) & 4.13 & 111.41 & 4.6 \\
\hline 18 & 18 & 31 & 9.06 HSPF HP in NMF homes & 0.14 & 111.55 & 4.8 \\
\hline 19 & 20 & 12 & 1992 Std HP in EMF homes (7.46 HSPF) & 0.08 & 111.63 & 5.0 \\
\hline 20 & 22 & 58 & 1994 NAECA Standard Clothes Dryer & 4.02 & 115.65 & 5.1 \\
\hline 21 & 24 & 47 & 1993 NAECA Standard Freezer & 2.82 & 118.46 & 5.2 \\
\hline 22 & 12 & 1 & Insulation \& W'strip. in ESF homes (I) & 4.47 & 122.94 & 5.5 \\
\hline 23 & 21 & 7 & Windows in NSF homes (I) & 3.46 & 126.40 & 5.5 \\
\hline 24 & 25 & 42 & 9.42 EER, Var. Spd. RAC in NSF \& NMH homes & 0.17 & 126.57 & 6.0 \\
\hline 25 & 27 & 19 & 1992 Std. CAC in ESF \& EMH homes (10.5 SEER) & 1.26 & 127.83 & 6.2 \\
\hline 26 & 31 & 56 & Horizontal Axis Clotheswasher (I) & 1.47 & 129.30 & 6.4 \\
\hline 27 & 28 & 27 & Var. spd. RAC in ESF \& EMH homes (post-2000) & 0.64 & 129.94 & 6.5 \\
\hline 28 & 32 & 52 & Replace electric water heater with HP water heater & 6.71 & 136.65 & 6.6 \\
\hline 29 & 26 & 51 & Replace electric water heater with gas & 2.41 & 139.06 & 6.7 \\
\hline 30 & 29 & 20 & 13.3 SEER CAC in ESF \& EMH homes & 3.83 & 142.88 & 6.7 \\
\hline 31 & 30 & 36 & 1992 Std. CAC in NSF \& NMH homes (10.5 SEER) & 0.54 & 143.42 & 6.9 \\
\hline 32 & 35 & 48 & Freezer: 5.3 EER, Evac. Panels, Recycle Heat (post-2000) & 2.67 & 146.09 & 7.1 \\
\hline 33 & 36 & 60 & Heat Pump Clothes Dryer & 8.77 & 154.87 & 7.1 \\
\hline 34 & 38 & 45 & Refrig.: Evac. Panels, Recycle Condenser Heat (post-2000) & 11.42 & 166.28 & 7.5 \\
\hline 35 & 23 & 3 & Window Retrofits in ESF homes (I) & 0.69 & 166.97 & 7.5 \\
\hline 36 & 34 & 59 & Switch Electric Clothes Dryer to Gas & 9.64 & 176.61 & 7.6 \\
\hline 37 & 37 & 62 & Switch from electric to gas range & 8.28 & 184.89 & 7.7 \\
\hline 38 & 33 & 37 & 13.3 SEER CAC in NSF \& NMH homes & 1.17 & 186.06 & 7.9 \\
\hline 39 & 39 & 30 & 1992 Std. HP in NMF homes (7.46 HSPF) & 0.04 & 186.11 & 8.2 \\
\hline 40 & 40 & 63 & Induction cooktop and improved oven (post-1995) & 9.05 & 195.15 & 8.2 \\
\hline 41 & 41 & 15 & 9.42 SEER RAC in EMF homes & 0.02 & 195.17 & 9.5 \\
\hline 42 & 42 & 11 & Var. spd. CAC compressor in EMF homes & 0.26 & 195.43 & 9.8 \\
\hline
\end{tabular}




\begin{tabular}{|c|c|c|c|c|c|c|}
\hline \multicolumn{7}{|c|}{$\begin{array}{l}\text { Table 17: Achievable Potential with All Adjustment Factors (continued) } \\
\text { (Annual Residential Savings in 2010) }\end{array}$} \\
\hline $\begin{array}{c}\text { Ach'v. } \\
\text { Pot. } \\
\text { Meas. } \\
\#\end{array}$ & $\begin{array}{c}\text { Tech. } \\
\text { Pot. } \\
\text { Meas. } \\
\#\end{array}$ & $\begin{array}{c}\text { Meas- } \\
\text { ure } \\
\text { Code }\end{array}$ & Measure Name & $\begin{array}{l}\text { Measure } \\
\text { Energy } \\
\text { Savings } \\
\text { (TWh) }\end{array}$ & $\begin{array}{c}\text { Cum. } \\
\text { Energy } \\
\text { Savings } \\
(T W h)\end{array}$ & $\begin{array}{c}\text { Avg. } \\
C C E \\
(\phi / k W h)\end{array}$ \\
\hline 48 & 52 & 65 & Appliance Motors: misc. efficiency improvements & 8.71 & 208.20 & 13.1 \\
\hline 49 & 49 & 8 & Windows in NSF homes (II) & 2.03 & 210.23 & 13.2 \\
\hline 50 & 45 & 4 & Window Retrofits in ESF homes (II) & 1.14 & 211.37 & 14.0 \\
\hline 51 & 50 & 29 & 13.3 SEER, Variable Speed CAC in NMF homes & 0.19 & 211.57 & 14.1 \\
\hline 52 & 54 & 43 & 9.42 EER RAC in NSF homes & 0.02 & 211.58 & 14.3 \\
\hline 53 & 56 & 35 & 9.93 HSPF HP in NSF homes & 0.18 & 211.76 & 14.9 \\
\hline 54 & 51 & 18 & Switch ER furnace to $9.93 \mathrm{HSPF}$ HP in ESF \& EMH homes & 0.11 & 211.87 & 15.6 \\
\hline 55 & 53 & 54 & Compact Fluorescent Fixtures & 9.09 & 220.96 & 16.2 \\
\hline 56 & 57 & 24 & 9.93 HSPF HP in ESF \& EMH HP-conditioned homes & 0.14 & 221.11 & 16.3 \\
\hline 57 & 60 & 33 & 9.42 EER, Var. Spd. RAC in NMF homes & 0.01 & 221.12 & 17.5 \\
\hline 58 & 64 & 46 & Refrigerator: 5.3 EER \& Two Compressors (post-2000) & 4.66 & 225.78 & 18.0 \\
\hline 59 & 63 & 26 & 10.08 EER RAC in ESF \& EMH homes & 0.16 & 225.94 & 18.7 \\
\hline 60 & 58 & 14 & 9.93 HSPF HP in EMF homes & 0.02 & 225.96 & 18.7 \\
\hline 61 & 55 & 2 & Insulation \& W'strip. in ESF homes (II) & 0.55 & 226.51 & 19.1 \\
\hline 62 & 59 & 16 & Var. spd. RAC compressor in EMF homes (post-2000) & 0.01 & 226.52 & 20.0 \\
\hline 63 & 61 & 21 & 14.9 SEER CAC in ESF \& EMH homes & 0.43 & 226.96 & 20.0 \\
\hline 64 & 62 & 41 & 9.93 HSPF HP in NSF \& NMH homes & 0.25 & 227.21 & 21.2 \\
\hline 65 & 65 & 38 & 14.9 SEER CAC in NSF \& NMH homes & 0.18 & 227.39 & 22.6 \\
\hline 66 & 66 & 32 & 9.43 HSPF HP in NMF homes & 0.02 & 227.41 & 24.2 \\
\hline
\end{tabular}

Notes:

(1) The techno-economic potential of these measures in 2010 is $410 \mathrm{TWh}$ based on a 1990 residential electricity price of $7.8 \notin / \mathrm{kWh}$.

(2) Frozen efficiency baseline consumption in 2010 is 1019 TWh.

(3) CCEs are calculated in base year 1990 dollars, using a 7\% real discount rate.

(4) "Measure Code" is the measure identifier from Table 18.

(5) "Technical Potential Measure \#" is the order of the measures according to technical potential CCE. 
Table 18: Measures Sorted by Enduse

\begin{tabular}{|c|c|c|c|c|c|c|c|c|c|c|c|c|c|}
\hline \multicolumn{14}{|c|}{ Table 18: Measures Sorted by Enduse } \\
\hline \multirow{5}{*}{$\begin{array}{c}\text { Meas- } \\
\text { ure } \\
\text { Code }\end{array}$} & \multirow{5}{*}{ Measure Name } & \multicolumn{2}{|c|}{ Technical Potential } & \multicolumn{10}{|c|}{$\begin{array}{r}\text { Achievable Potential } \\
\end{array}$} \\
\hline & & \multirow{4}{*}{$\begin{array}{l}\text { Measure } \\
\text { Energy } \\
\text { Savings } \\
\\
(T W h)\end{array}$} & \multirow{4}{*}{$\begin{array}{l}\text { Avg. } \\
\text { CCE } \\
\\
(c / k W h)\end{array}$} & \multirow{2}{*}{\multicolumn{3}{|c|}{$\begin{array}{l}\text { Cumulative 2010 Market } \\
\text { Penetration }\end{array}$}} & \multirow{4}{*}{\begin{tabular}{|c|}
\multicolumn{2}{|c}{ Technice } \\
Engineering \\
Estimate \\
Adjustment \\
$(\%$ Reduction)
\end{tabular}} & \multirow{4}{*}{$\begin{array}{c}\text { Potential A } \\
\text { Savings } \\
\text { Takeback } \\
(\%)\end{array}$} & tments & Progrt & Costs & & Avg. \\
\hline & & & & & & & & & & Program & Free & Energy & $C C E$ \\
\hline & & & & $\begin{array}{l}\text { Appliance } \\
\text { Standards }\end{array}$ & $\begin{array}{c}\text { Utility } \\
\text { Programs }\end{array}$ & $\begin{array}{l}\text { Building } \\
\text { Standards }\end{array}$ & & & $\begin{array}{l}\text { ence } \\
(\%\end{array}$ & Costs & $\begin{array}{l}\text { Rider } \\
\text { Fraction }\end{array}$ & Savings & \\
\hline & & & & & & & & & & & & & $(c / k W h)$ \\
\hline & $\begin{array}{l}\text { nieasures } \\
\text { Insulation \& W'strin in ESF homes }(\mathrm{D})\end{array}$ & 2075 & 34 & $0 \%$ & $26 \%$ & $7 \%$ & $15 \%$ & 1509 & $10 \%$ & $26 \%$ & $10 \%$ & 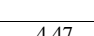 & 55 \\
\hline & Insulation \& W'strip. in ESF homes (II) & $\frac{0.13}{4.05}$ & $\frac{5.4}{12.2}$ & $0 \%$ & $20 \%$ & $5 \%$ & $15 \%$ & $15 \%$ & $10 \%$ & $23 \%$ & $10 \%$ & 0.55 & $\frac{5.9}{191}$ \\
\hline$\frac{2}{3}$ & Window Retrofits in ESF homes (I) & 5.70 & $\frac{12.2}{4.6}$ & $0 \%$ & $18 \%$ & $1 \%$ & $15 \%$ & $15 \%$ & $10 \%$ & $10 \%$ & $21 \%$ & 0.69 & 7.5 \\
\hline 4 & Window Retrofits in ESF homes (II) & 7.06 & 9.6 & $0 \%$ & $16 \%$ & $9 \%$ & $15 \%$ & $15 \%$ & $10 \%$ & $8 \%$ & $21 \%$ & 1.14 & 14.0 \\
\hline 5 & Insulation \& W'strip. in NSF homes (I) & 12.38 & 4.0 & $0 \%$ & $30 \%$ & $9 \%$ & $5 \%$ & $5 \%$ & $5 \%$ & $10 \%$ & $0 \%$ & 4.13 & 4.6 \\
\hline & Insulation \& W'strip. in NSF homes (II) & 2.46 & 10.7 & $0 \%$ & $23 \%$ & $6 \%$ & $5 \%$ & $5 \%$ & $5 \%$ & $9 \%$ & $0 \%$ & 0.61 & 12.2 \\
\hline 7 & Windows in NSF homes (I) & 5.66 & 4.4 & $0 \%$ & $31 \%$ & $40 \%$ & $5 \%$ & $5 \%$ & $5 \%$ & $9 \%$ & $21 \%$ & 3.46 & 5.5 \\
\hline HVAC & Equipment Measures & & & & & & & & & & & & \\
\hline$\frac{- \text { Exis }}{9}$ & $\begin{array}{l}\text { ting Multifamily Equipment } \\
1992 \text { Std. CAC (10 } 5 \text { SEFR) in EMF homes }\end{array}$ & 020 & 82 & $94 \%$ & $0 \%$ & $0 \%$ & & $10 \%$ & $5 \%$ & $3 \%$ & & 0.14 & \\
\hline 10 & 13.3 SEER CAC in EMF homes & 0.54 & 9.6 & $82 \%$ & $14 \%$ & $0 \%$ & $15 \%$ & $10 \%$ & $5 \%$ & $4 \%$ & $10 \%$ & 0.14 & 11.9 \\
\hline 11 & Var. spd. CAC compressor in EMF homes & 0.38 & 7.9 & $82 \%$ & $14 \%$ & $0 \%$ & $15 \%$ & $10 \%$ & $5 \%$ & $4 \%$ & $10 \%$ & 0.26 & 9.8 \\
\hline 12 & 1992 Std HP in EMF homes (7.46 HSPF) & 0.12 & 4.2 & $90 \%$ & $0 \%$ & $0 \%$ & $10 \%$ & $10 \%$ & $10 \%$ & $6 \%$ & $0 \%$ & 0.08 & 5.0 \\
\hline 13 & 9.43 HSPF HP in EMF homes & 0.62 & 2.1 & $77 \%$ & $12 \%$ & $0 \%$ & $10 \%$ & $10 \%$ & $10 \%$ & $11 \%$ & $10 \%$ & 0.40 & 2.7 \\
\hline 14 & 9.93 HSPF HP in EMF homes & 0.21 & 13.9 & $0 \%$ & $12 \%$ & $0 \%$ & $10 \%$ & $10 \%$ & $10 \%$ & $9 \%$ & $10 \%$ & 0.02 & 18.7 \\
\hline 15 & 9.42 SEER RAC in EMF homes & 0.03 & 7.8 & $84 \%$ & $3 \%$ & $0 \%$ & $15 \%$ & $10 \%$ & $5 \%$ & $3 \%$ & $10 \%$ & 0.02 & 9.5 \\
\hline 16 & Var. spd. RAC compressor in EMF homes (post-2000) & 0.07 & 14.0 & $0 \%$ & $20 \%$ & $0 \%$ & $15 \%$ & $10 \%$ & $5 \%$ & $9 \%$ & $10 \%$ & 0.01 & 20.0 \\
\hline -Exis & ting Single-Family \& Mobile Home Equipment & & & & & & & & & & & & \\
\hline 17 & Switch ER furnace to 9.5 HSPF HP in ESF \& EMH homes & 18.94 & 1.4 & $0 \%$ & $20 \%$ & $0 \%$ & $10 \%$ & $10 \%$ & $10 \%$ & $20 \%$ & $5 \%$ & 2.76 & 2.0 \\
\hline 18 & Switch ER furnace to $9.93 \mathrm{HSPF}$ HP in ESF \& EMH homes & 0.72 & 11.4 & $0 \%$ & $20 \%$ & $0 \%$ & $10 \%$ & $10 \%$ & $10 \%$ & $20 \%$ & $3 \%$ & 0.11 & 15.6 \\
\hline 21 & 14.9 SEER CAC in ESF \& EMH homes & 4.33 & 15.3 & $0 \%$ & $14 \%$ & $0 \%$ & $15 \%$ & $10 \%$ & $5 \%$ & $9 \%$ & $2 \%$ & 0.43 & 20.0 \\
\hline 22 & 1992 Std. HP: ESF \& EMH HP-heated homes ( $7.46 \mathrm{HSPF})$ & 1.17 & 3.3 & $90 \%$ & $0 \%$ & $0 \%$ & $10 \%$ & $10 \%$ & $10 \%$ & $8 \%$ & $0 \%$ & 0.77 & 4.0 \\
\hline 23 & 9.5 HSPF HP in ESF \& EMH HP-conditioned homes & 5.02 & 2.0 & $77 \%$ & $12 \%$ & $0 \%$ & $10 \%$ & $10 \%$ & $10 \%$ & $12 \%$ & $10 \%$ & 3.26 & 2.6 \\
\hline 24 & 9.93 HSPF HP in ESF \& EMH HP-conditioned homes & 1.65 & 12.7 & $0 \%$ & $12 \%$ & $0 \%$ & $10 \%$ & $10 \%$ & $10 \%$ & $9 \%$ & $5 \%$ & 0.14 & 16.3 \\
\hline 25 & 9.42 EER RAC in ESF \& EMH homes & 0.37 & 3.5 & $84 \%$ & $3 \%$ & $0 \%$ & $15 \%$ & $10 \%$ & $5 \%$ & $7 \%$ & $10 \%$ & 0.23 & 4.5 \\
\hline 26 & 10.08 EER RAC in ESF \& EMH homes & 0.26 & 15.6 & $84 \%$ & $3 \%$ & $0 \%$ & $15 \%$ & $10 \%$ & $5 \%$ & $2 \%$ & $0 \%$ & 0.16 & 18.7 \\
\hline 27 & Var. spd. RAC in ESF \& EMH homes (post-2000) & 1.01 & 5.3 & $84 \%$ & $3 \%$ & $0 \%$ & $15 \%$ & $10 \%$ & $5 \%$ & $5 \%$ & $0 \%$ & 0.64 & 6.5 \\
\hline- New & Multifamily Equipment & & & & & & & & & & & & \\
\hline 28 & 1992 Std. CAC in NMF homes (10.5 SEER) & 0.15 & 10.0 & $88 \%$ & $0 \%$ & $0 \%$ & $15 \%$ & $5 \%$ & $5 \%$ & $2 \%$ & $0 \%$ & 0.10 & 12.1 \\
\hline 29 & 13.3 SEER, Variable Speed CAC in NMF homes & 0.38 & 11.2 & $49 \%$ & $18 \%$ & $0 \%$ & $15 \%$ & $5 \%$ & $5 \%$ & $4 \%$ & $10 \%$ & 0.19 & 14.1 \\
\hline 30 & 1992 Std. HP in NMF homes (7.46 HSPF) & 0.06 & 7.1 & $88 \%$ & $1 \%$ & $0 \%$ & $10 \%$ & $5 \%$ & $5 \%$ & $4 \%$ & $0 \%$ & 0.04 & 8.2 \\
\hline 31 & 9.06 HSPF HP in NMF homes & 0.26 & 3.9 & $49 \%$ & $18 \%$ & $0 \%$ & $10 \%$ & $5 \%$ & $5 \%$ & $7 \%$ & $10 \%$ & 0.14 & 4.8 \\
\hline 32 & 9.43 HSPF HP in NMF homes & 0.04 & 20.7 & $49 \%$ & $18 \%$ & $0 \%$ & $10 \%$ & $5 \%$ & $5 \%$ & $4 \%$ & $5 \%$ & 0.02 & 24.2 \\
\hline 33 & 9.42 EER, Var. Spd. RAC in NMF homes & 0.01 & 14.3 & $71 \%$ & $7 \%$ & $0 \%$ & $15 \%$ & $5 \%$ & $5 \%$ & $3 \%$ & $10 \%$ & 0.01 & 17.5 \\
\hline- New & Single-Family \& Mobile Home Equipment & & & & & & & & & & & & \\
\hline 34 & Switch ER furnace to $9.5 \mathrm{HSPF}$ HP in NSF homes & 14.78 & 0.8 & $0 \%$ & $35 \%$ & $15 \%$ & $10 \%$ & $5 \%$ & $5 \%$ & $19 \%$ & $5 \%$ & 5.95 & 1.1 \\
\hline 35 & 9.93 HSPF HP in NSF homes & 0.45 & 12.2 & $0 \%$ & $35 \%$ & $15 \%$ & $10 \%$ & $5 \%$ & $5 \%$ & $8 \%$ & $3 \%$ & 0.18 & 14.9 \\
\hline 36 & 1992 Std. CAC in NSF \& NMH homes (10.5 SEER) & 0.80 & 5.6 & $88 \%$ & $0 \%$ & $0 \%$ & $15 \%$ & $5 \%$ & $5 \%$ & $4 \%$ & $0 \%$ & 0.54 & 6.9 \\
\hline 37 & 13.3 SEER CAC in NSF \& NMH homes & 2.27 & 6.2 & $49 \%$ & $18 \%$ & $0 \%$ & $15 \%$ & $5 \%$ & $5 \%$ & $6 \%$ & $10 \%$ & 1.17 & 7.9 \\
\hline 38 & 14.9 SEER CAC in NSF \& NMH homes & 1.26 & 17.4 & $0 \%$ & $18 \%$ & $0 \%$ & $15 \%$ & $5 \%$ & $5 \%$ & $10 \%$ & $0 \%$ & 0.18 & 22.6 \\
\hline 39 & 1992 Std. HP: NSF \& NMH HP-heated homes (7.46 HSPF) & 1.37 & 3.6 & $88 \%$ & $0 \%$ & $0 \%$ & $10 \%$ & $5 \%$ & $5 \%$ & $7 \%$ & $0 \%$ & 0.98 & 4.3 \\
\hline 40 & 9.5 HSPF HP in NSF \& NMH homes & 6.59 & 1.9 & $49 \%$ & $18 \%$ & $0 \%$ & $10 \%$ & $5 \%$ & $5 \%$ & $12 \%$ & 0 & 3.61 & 2.4 \\
\hline 41 & 9.93 HSPF HP in NSF \& NMH homes & 1.73 & 15.5 & $0 \%$ & $18 \%$ & $0 \%$ & $10 \%$ & $5 \%$ & $5 \%$ & $10 \%$ & $10 \%$ & 0.25 & 21.2 \\
\hline 42 & 9.42 EER, Var. Spd. RAC in NSF \& NMH homes & 0.28 & 4.8 & $71 \%$ & $7 \%$ & $0 \%$ & $15 \%$ & $5 \%$ & $5 \%$ & $6 \%$ & $10 \%$ & 0.17 & 6.0 \\
\hline & 9.42 EER RAC in NSF homes & 0.02 & 11.7 & $71 \%$ & $7 \%$ & $0 \%$ & $15 \%$ & $5 \%$ & $5 \%$ & $3 \%$ & $10 \%$ & 0.02 & 14.3 \\
\hline Applia & & & & & & & & & & & & & \\
\hline 44 & 1993 NAECA Standard Refrigerator & 27.61 & 3.7 & $86 \%$ & $5 \%$ & $0 \%$ & $5 \%$ & $0 \%$ & $5 \%$ & $7 \%$ & $10 \%$ & 22.68 & 4.2 \\
\hline 45 & Refrig.: Evac. Panels, Recycle Condenser Heat (post-2000) & 16.43 & 6.8 & $61 \%$ & $16 \%$ & $0 \%$ & $5 \%$ & $0 \%$ & $5 \%$ & $4 \%$ & $0 \%$ & 11.42 & 7.5 \\
\hline \begin{tabular}{|r|r}
49 \\
49
\end{tabular} & EWH: Aerators, Showerheads & $\frac{3.04}{42.02}$ & 0.9 & $60 \%$ & $29 \%$ & $0 \%$ & $5 \%$ & $15 \%$ & $10 \%$ & $33 \%$ & $30 \%$ & 27.21 & 1.3 \\
\hline 50 & EWH: Reduce Standby Losses & 20.45 & 3.6 & $71 \%$ & $6 \%$ & $0 \%$ & $5 \%$ & $10 \%$ & $5 \%$ & $7 \%$ & $12 \%$ & 12.73 & 4.1 \\
\hline 51 & Replace electric water heater with gas & 16.66 & 4.9 & $0 \%$ & $18 \%$ & $0 \%$ & $5 \%$ & $10 \%$ & $5 \%$ & $23 \%$ & $5 \%$ & 2.41 & 6.7 \\
\hline 52 & Replace electric water heater with HP & 26.66 & 5.9 & $0 \%$ & $31 \%$ & $0 \%$ & $5 \%$ & $10 \%$ & $5 \%$ & $7 \%$ & $0 \%$ & 6.71 & 6.6 \\
\hline 53 & Compact Fluorescents: Outdoor Timer and Photocel & 57.96 & 2.1 & $0 \%$ & $36 \%$ & $0 \%$ & $10 \%$ & $10 \%$ & $10 \%$ & $13 \%$ & $10 \%$ & 15.30 & 2.9 \\
\hline
\end{tabular}


Table 18: Measures Sorted by Enduse

\begin{tabular}{|c|c|c|c|c|c|c|c|c|c|c|c|c|c|}
\hline \multirow{4}{*}{$\begin{array}{c}\text { Meas- } \\
\text { ure } \\
\text { Code }\end{array}$} & \multirow{4}{*}{ Measure Name } & \multicolumn{2}{|c|}{ Technical Potential } & \multicolumn{10}{|c|}{ Achievable Potential } \\
\hline & & \multirow{3}{*}{$\begin{array}{l}\text { Measure } \\
\text { Energy } \\
\text { Savings } \\
(T W h)\end{array}$} & \multirow{3}{*}{$\begin{array}{l}\text { Avg. } \\
\text { CCE } \\
(c / k W h)\end{array}$} & \multicolumn{3}{|c|}{$\begin{array}{l}\text { Cumulative } 2010 \text { Market } \\
\text { Penetration }\end{array}$} & \multicolumn{3}{|c|}{ Technical Potential Adjustments } & \multicolumn{2}{|c|}{ Program Costs } & \multirow{2}{*}{$\begin{array}{l}\text { Measure } \\
\text { Energy } \\
\text { Savings }\end{array}$} & \multirow{2}{*}{$\begin{array}{l}\text { Avg. } \\
C C E\end{array}$} \\
\hline & & & & $\begin{array}{l}\text { Appliance } \\
\text { Standards }\end{array}$ & $\begin{array}{c}\text { Penetration } \\
\text { Utility } \\
\text { Programs }\end{array}$ & $\begin{array}{c}\text { Building } \\
\text { Standards }\end{array}$ & $\begin{array}{l}\text { Engineering } \\
\text { Estimate } \\
\text { Adjustment }\end{array}$ & $\begin{array}{c}\text { Savings } \\
\text { Takeback }\end{array}$ & $\begin{array}{l}\text { Persist- } \\
\text { ence } \\
\%\end{array}$ & $\begin{array}{l}\text { Program } \\
\text { Costs }\end{array}$ & $\begin{array}{c}\text { Free } \\
\text { Rider } \\
\text { Fraction }\end{array}$ & & \\
\hline & & & & & & & (\% Reduction) & & (decline) & $(\%)$ & $(\%)$ & $(T W h)$ & $(c / k W h)$ \\
\hline 54 & Compact Fluorescent Fixtures & 34.44 & 11.7 & $0 \%$ & $36 \%$ & $0 \%$ & $10 \%$ & $10 \%$ & $10 \%$ & $13 \%$ & $10 \%$ & 9.09 & 16.2 \\
\hline 56 & Horizontal Axis Clotheswasher (I) & 3.36 & 5.8 & $46 \%$ & $2 \%$ & $0 \%$ & $5 \%$ & $5 \%$ & $0 \%$ & $4 \%$ & $0 \%$ & 1.47 & 6.4 \\
\hline 57 & Horizontal Axis Clotheswasher (II) & 9.79 & 9.8 & $27 \%$ & $5 \%$ & $0 \%$ & $5 \%$ & $5 \%$ & $0 \%$ & $3 \%$ & $0 \%$ & 2.83 & 10.6 \\
\hline 58 & 1994 NAECA Standard Clothes Dryer & 5.10 & 4.5 & $73 \%$ & $10 \%$ & $0 \%$ & $5 \%$ & $0 \%$ & $0 \%$ & $6 \%$ & $15 \%$ & 4.02 & 5.1 \\
\hline 59 & Switch Electric Clothes Dryer to Gas & 20.29 & 6.4 & $0 \%$ & $20 \%$ & $30 \%$ & $5 \%$ & $0 \%$ & $0 \%$ & $12 \%$ & $0 \%$ & 9.64 & 7.6 \\
\hline 60 & Heat Pump Clothes Dryer & 14.89 & 6.5 & $52 \%$ & $10 \%$ & $0 \%$ & $5 \%$ & $0 \%$ & $0 \%$ & $4 \%$ & $0 \%$ & 8.77 & 7.1 \\
\hline 61 & 1994 NAECA Standard Dishwasher & 3.40 & 2.9 & $83 \%$ & $3 \%$ & $0 \%$ & $5 \%$ & $0 \%$ & $0 \%$ & $8 \%$ & $15 \%$ & 2.76 & 3.1 \\
\hline 62 & Switch from electric to gas range & $\frac{3.40}{18.35}$ & 6.6 & $0 \%$ & $20 \%$ & $30 \%$ & $5 \%$ & $5 \%$ & $0 \%$ & $12 \%$ & $0 \%$ & 8.28 & $\frac{3.4}{7.7}$ \\
\hline 64 & Upgrade Furnace Fan Efficiency & 5.29 & 3.7 & $68 \%$ & $14 \%$ & $0 \%$ & $0 \%$ & $0 \%$ & $5 \%$ & $7 \%$ & $0 \%$ & 4.13 & 3.9 \\
\hline 65 & Appliance Motors: misc. efficiency improvements & 22.34 & 11.6 & $46 \%$ & $0 \%$ & $0 \%$ & $10 \%$ & $0 \%$ & $5 \%$ & $2 \%$ & $0 \%$ & 8.71 & 13.1 \\
\hline 66 & TV sets: efficiency improvements & 3.83 & 3.3 & $80 \%$ & $0 \%$ & $0 \%$ & $5 \%$ & $5 \%$ & $0 \%$ & $8 \%$ & $0 \%$ & 2.76 & 3.7 \\
\hline
\end{tabular}


Figure 5: Potential for Electricity-Efficiency Improvements in 2010

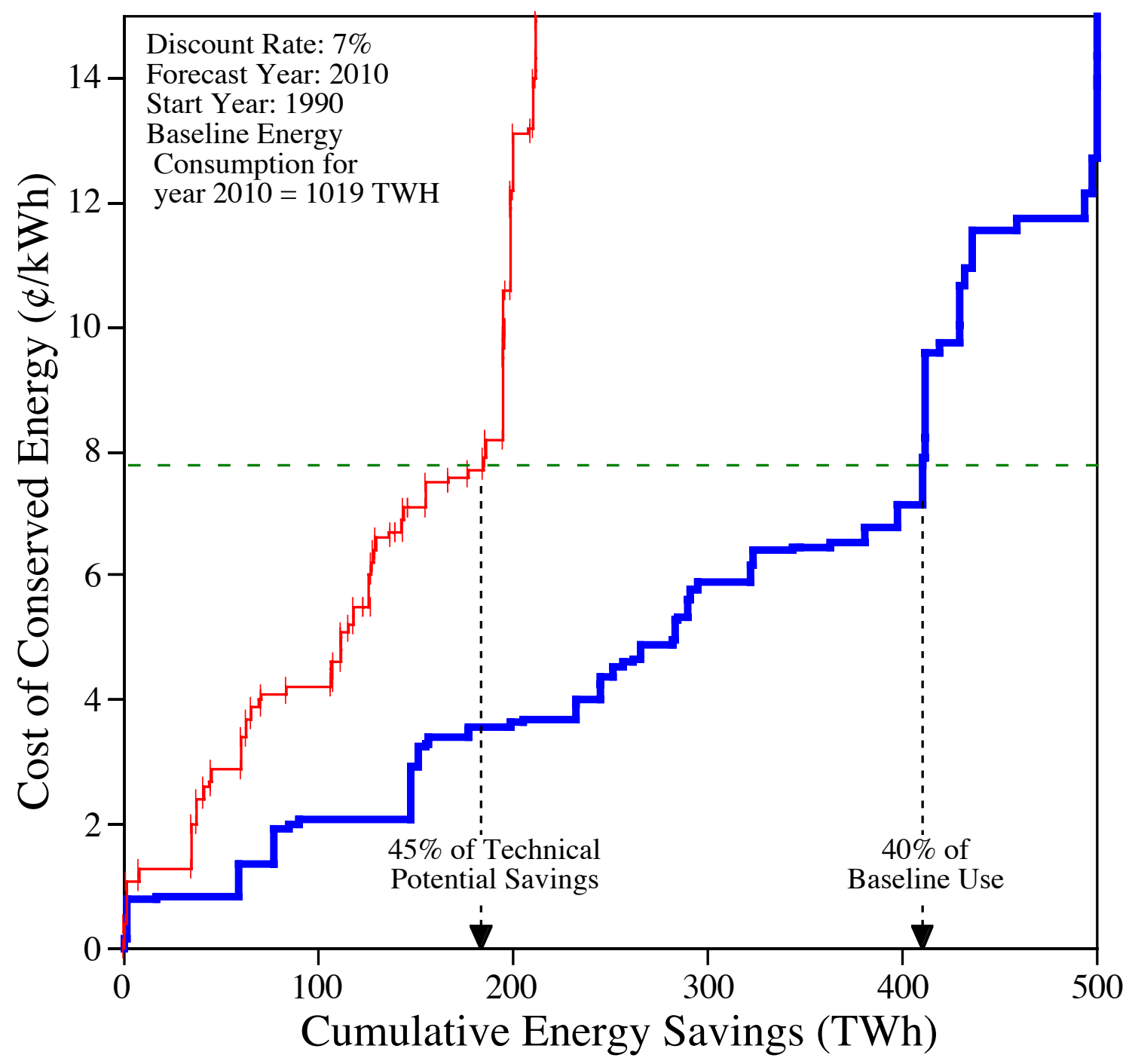

Technical Potential

- - 1990 Electricity Price $(7.8 ф / \mathrm{kWh})$

Achievable Potential- Best Estimate

The policies described in this study lead to an achievable potential of approximately 185 TWh of annual electricity savings in the year 2010, which is $18 \%$ of the frozen efficiency baseline consumption forecast for that year. This potential includes all technical potential adjustment factors: market penetration of policies, program costs, engineering estimate adjustment, savings takeback, and measure persistence. The technical potential is based on Koomey et al. (1991). 
Figure 6: Impact of Technical Potential Adjustment Factors

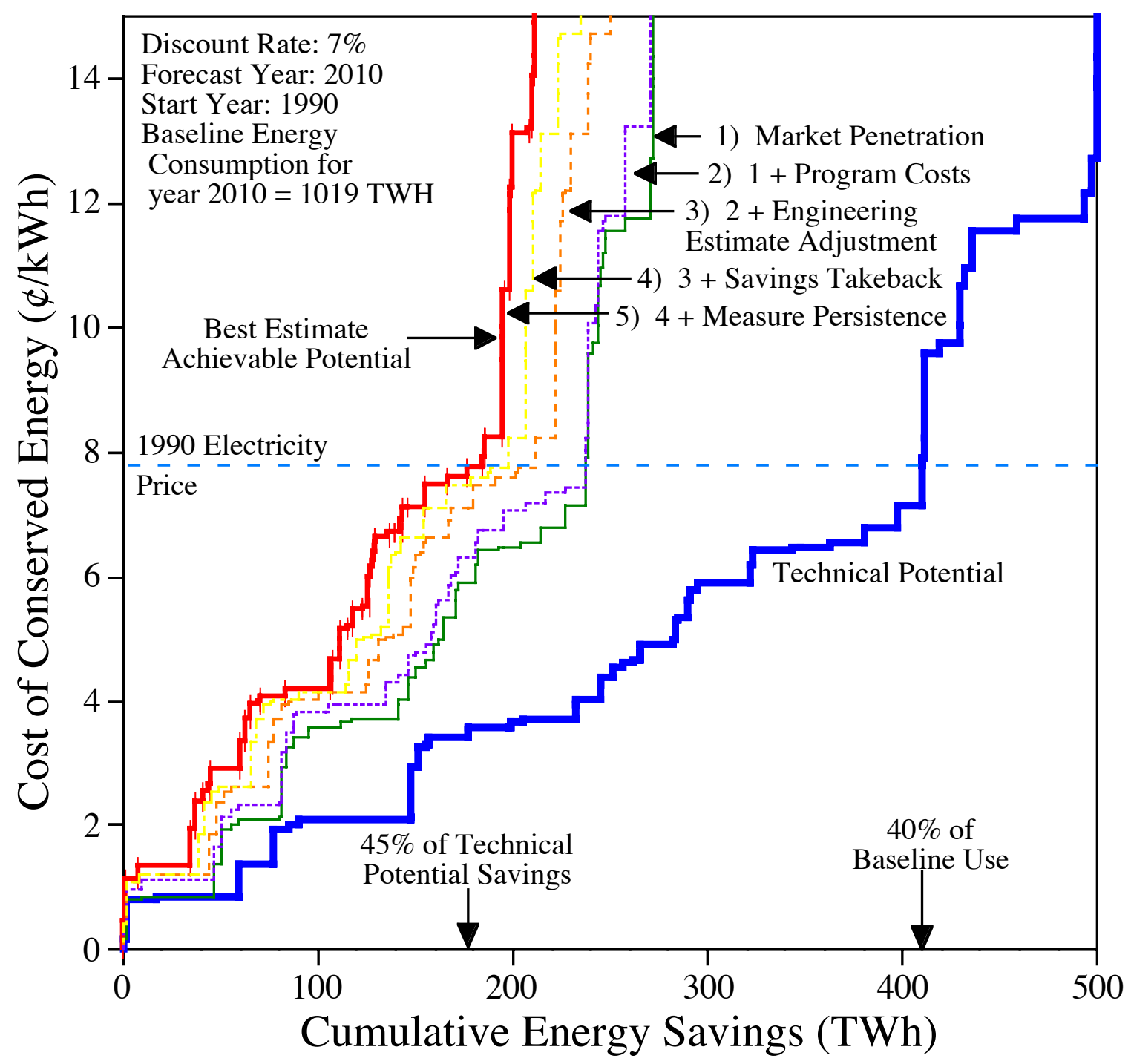

This figure illustrates how achievable potential changes with the sequential addition of technical potential adjustment factors. The order in which factors are applied (progressing from right to left in the diagram) are: technical potential, market penetration, program costs, engineering estimate adjustments, savings takeback, and measure persistence. The left-most achievable potential curve is the "best-estimate" potential shown in Figure 5. 


\begin{tabular}{|c|c|c|c|c|c|c|c|c|}
\hline \multicolumn{9}{|c|}{$\begin{array}{l}\text { Table 19: Summary of Achievable Electricity-Efficiency Potential in 2010, Using All Adjustment Factors } \\
\text { (For measures costing less than } 7.8 \varnothing / \mathrm{kWh} \text { ) }\end{array}$} \\
\hline \multirow[b]{2}{*}{ End-use } & \multicolumn{2}{|c|}{ Technical Potential } & \multicolumn{3}{|c|}{ Achievable Potential } & \multicolumn{3}{|c|}{ \% of Achievable Savings Due to: } \\
\hline & $\begin{array}{c}\text { Enduse } \\
\text { Energy } \\
\text { Savings } \\
(T W h) \\
\end{array}$ & $\begin{array}{c}A v g . \\
C C E \\
(\phi / k W h)\end{array}$ & $\begin{array}{l}\text { Enduse } \\
\text { Energy } \\
\text { Savings } \\
(T W h) \\
\end{array}$ & $\begin{array}{c}\text { Enduse } \\
\text { Tech. Pot. } \\
\text { Achieved } \\
(\%)\end{array}$ & $\begin{array}{c}A v g . \\
C C E \\
(\phi / k W h)\end{array}$ & $\begin{array}{l}\text { Appliance } \\
\text { Standards }\end{array}$ & $\begin{array}{c}\text { Utility } \\
\text { Programs }\end{array}$ & $\begin{array}{l}\text { Building } \\
\text { Standards }\end{array}$ \\
\hline Shell Measures & 44.49 & 3.9 & 12.76 & $29 \%$ & 5.3 & $0 \%$ & $66 \%$ & $34 \%$ \\
\hline - Existing House Retrofits & 26.45 & 3.7 & 5.16 & $20 \%$ & 5.7 & $0 \%$ & $79 \%$ & $21 \%$ \\
\hline - New Construction & 18.04 & 4.1 & 7.60 & $42 \%$ & 5.0 & $0 \%$ & $57 \%$ & $43 \%$ \\
\hline HVAC Equipment Measures & 61.03 & 2.3 & 24.61 & $40 \%$ & 3.3 & $68 \%$ & $26 \%$ & $6 \%$ \\
\hline - Existing Multifamily Equipment & 0.77 & 2.7 & 0.48 & $62 \%$ & 3.1 & $89 \%$ & $11 \%$ & $0 \%$ \\
\hline - Existing Single-Family \& Mobile Home Equipment & 33.85 & 2.5 & 12.74 & $38 \%$ & 4.3 & $85 \%$ & $15 \%$ & $0 \%$ \\
\hline - New Multifamily Equipment & 0.31 & 4.5 & 0.14 & $45 \%$ & 4.8 & $73 \%$ & $27 \%$ & $0 \%$ \\
\hline - New Single-Family \& Mobile Home Equipment & 26.09 & 1.9 & 11.25 & $43 \%$ & 2.2 & $47 \%$ & $40 \%$ & $13 \%$ \\
\hline Appliances & 249.78 & 3.7 & 127.20 & $50.92 \%$ & 4.1 & $72 \%$ & $28 \%$ & $0 \%$ \\
\hline - Refrigerators/Freezers & 51.32 & 4.9 & 39.59 & $77 \%$ & 5.4 & $90 \%$ & $10 \%$ & $0 \%$ \\
\hline - Water Heating & 89.13 & 3.0 & 46.66 & $52 \%$ & 2.8 & $70 \%$ & $30 \%$ & $0 \%$ \\
\hline - Lighting & 57.96 & 2.1 & 15.30 & $26 \%$ & 2.9 & $0 \%$ & $100 \%$ & $0 \%$ \\
\hline - Clotheswashers & 5.51 & 3.6 & 3.21 & $58 \%$ & 3.1 & $91 \%$ & $9 \%$ & $0 \%$ \\
\hline - Clothesdryers & 19.99 & 6.0 & 12.79 & $64 \%$ & 6.5 & $85 \%$ & $15 \%$ & $0 \%$ \\
\hline - Dishwashers & 3.40 & 2.9 & 2.76 & $81 \%$ & 3.4 & $96 \%$ & $4 \%$ & $0 \%$ \\
\hline - Cooking & 13.37 & 7.2 & 0.00 & $0 \%$ & 8.2 & $0 \%$ & $0 \%$ & $0 \%$ \\
\hline - Miscellaneous & 9.12 & 3.5 & 6.89 & $76 \%$ & 3.8 & $90 \%$ & $10 \%$ & $0 \%$ \\
\hline Fuel Switching Measures & 55.30 & 6.0 & 20.32 & $36.75 \%$ & 7.5 & $0 \%$ & $47 \%$ & $53 \%$ \\
\hline - Water Heating & 16.66 & 4.9 & 2.41 & $14 \%$ & 6.7 & $0 \%$ & $100 \%$ & $0 \%$ \\
\hline - Clothesdryers & 20.29 & 6.4 & 9.64 & $48 \%$ & 7.6 & $0 \%$ & $40 \%$ & $60 \%$ \\
\hline - Cooking & 18.35 & 6.6 & 8.28 & $45 \%$ & 7.7 & $0 \%$ & $40 \%$ & $60 \%$ \\
\hline NAECA Standard Measures w/ CCEs above elec. price & $\mathrm{n} / \mathrm{a}$ & $\mathrm{n} / \mathrm{a}$ & 0.29 & & 10.5 & & & \\
\hline Total (excluding previous line) & 410.60 & 3.8 & 184.89 & $45 \%$ & 4.4 & $58 \%$ & $33 \%$ & $9 \%$ \\
\hline
\end{tabular}

Notes:

(1) Frozen efficiency baseline electricity consumption in 2010 is $1019 \mathrm{TWh}$. The technical potential shown above is $40 \%$ of this baseline.

(2) Clotheswasher and dishwasher savings include reduced hot water consumption measures for those enduses.

(3) Achievable potential includes all adjustment factors: program penetration and costs, engineering estimate adjustment, savings takeback, measure persistence, and DSM program free riders.

(4) Three CAC measures, which are part of the existing NAECA standards, have CCEs greater than the price of electricity.

(5) Fuel switching potential includes only those housing units that have gas service but use electric equipment.

(6) For the clotheswasher enduse, the achievable potential CCE is less than the technical potential CCE because relatively fewer of the high-cost measures are implemented in the achievable potential (the CCE is an average over all measures within the enduse). 
Figure 7: Electricity-Efficiency Potential By End-Use
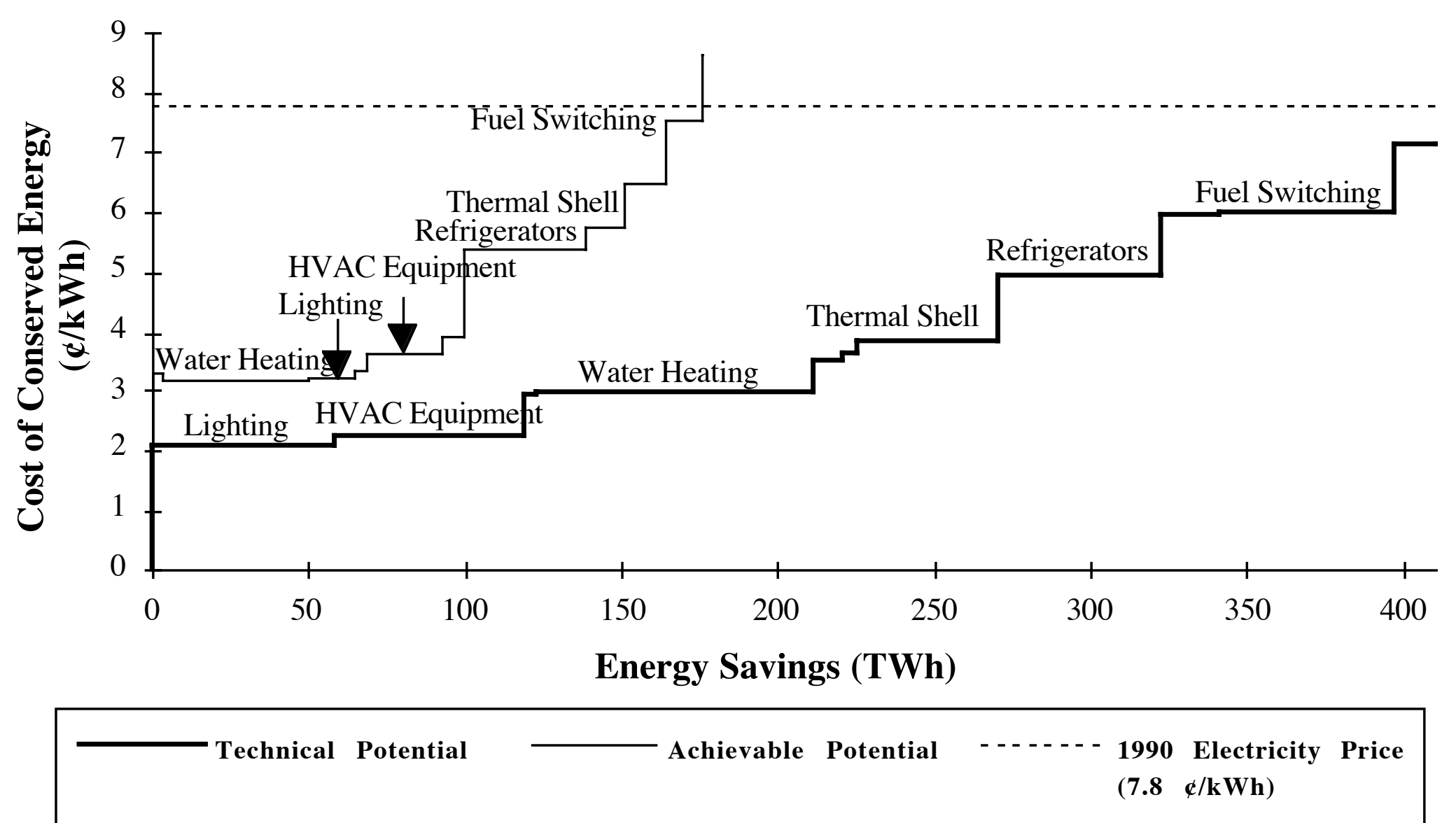

Energy savings are aggregated over all measures costing less than the 1990 electricity price $(7.8 \notin / \mathrm{kWh})$ within each end-use. CCE for each end-use is the average for these measures below the electricity price, weighted according to the energy savings for each measure. In comparing the technical and achievable potentials, the order of certain end-uses changes because they have differing program costs, and the achievable potential includes fewer high-cost measures (some measures in the technical potential are not cost-effective in the achievable potential). 


\begin{tabular}{|c|c|c|c|c|c|c|}
\hline \multirow[b]{2}{*}{ Enduse } & \multicolumn{3}{|c|}{ Technical Potential } & \multicolumn{3}{|c|}{ Achievable Potential } \\
\hline & $\begin{array}{c}\text { Total } \\
\text { Energy } \\
\text { Savings } \\
(T W h) \\
\end{array}$ & $\begin{array}{c}\text { Cum. } \\
\text { Energy } \\
\text { Savings } \\
(T W h) \\
\end{array}$ & $\begin{array}{c}A v g . \\
C C E \\
(\phi / k W h)\end{array}$ & $\begin{array}{c}\text { Total } \\
\text { Energy } \\
\text { Savings } \\
(T W h) \\
\end{array}$ & $\begin{array}{c}\text { Cum. } \\
\text { Energy } \\
\text { Savings } \\
(T W h) \\
\end{array}$ & $\begin{array}{c}\text { Avg. } \\
C C E \\
(\phi / k W h)\end{array}$ \\
\hline Clotheswashers & 5.51 & 5.51 & 3.6 & 3.21 & 3.21 & 3.1 \\
\hline Water Heating & 89.13 & 94.64 & 3.0 & 46.66 & 49.87 & 2.8 \\
\hline Lighting & 57.96 & 152.59 & 2.1 & 15.30 & 65.17 & 2.9 \\
\hline Dishwashers & 3.40 & 155.99 & 2.9 & 2.76 & 67.93 & 3.4 \\
\hline HVAC Equipment & 61.03 & 217.02 & 2.3 & 24.61 & 92.54 & 3.3 \\
\hline Miscellaneous & 9.12 & 226.13 & 3.5 & 6.89 & 99.43 & 3.8 \\
\hline Refrigerators/Freezers & 51.32 & 277.45 & 4.9 & 39.59 & 139.02 & 5.4 \\
\hline Thermal Shell & 44.49 & 321.94 & 3.9 & 12.76 & 151.78 & 5.3 \\
\hline Clothesdryers & 19.99 & 341.93 & 6.0 & 12.79 & 164.57 & 6.5 \\
\hline Fuel Switching & 55.30 & 397.23 & 6.0 & 20.32 & 184.89 & 7.5 \\
\hline Cooking & 13.37 & 410.60 & 7.2 & 0.00 & 184.89 & 8.2 \\
\hline $\begin{array}{r}\% \text { of Frozen Eff. Baseline Saved: } \\
\% \text { of Technical Potential: }\end{array}$ & & $\begin{array}{l}40 \% \\
100 \%\end{array}$ & & & $\begin{array}{l}18 \% \\
45 \%\end{array}$ & \\
\hline
\end{tabular}

Notes:

(1) Frozen efficiency baseline electricity consumption in 2010 is $1019 \mathrm{TWh}$

The technical potential shown above is $40 \%$ of this baseline.

(2) Clotheswasher and dishwasher savings include reduced hot water consumption measures for those enduses.

(3) Achievable potential includes all adjustment factors: engineering estimate adjustment, savings takeback,

measure persistence, program costs, and DSM program free riders.

(4) Fuel switching technical potential includes only those housing units that have gas service but use electric equipment.

(5) For the clotheswasher enduse, the achievable potential CCE is less than the technical potential CCE because

relatively fewer of the high-cost measures are implemented in the achievable potential (the CCE is an average over

all measures within the enduse). 


\section{Uncertainty Analysis}

\section{A. Factors Contributing to Uncertainty}

Many of the inputs and assumptions used to estimate achievable potential are uncertain. While it is difficult to quantify the uncertainty in an aggregate estimate such as achievable potential, the task is made easier by assessing the level of uncertainty in each of the individual factors which makes up the achievable potential. Some of the sources of uncertainty in these parameters are as follows. First, inherent in the supply curve methodology is the assumption that it is possible to adequately describe a heterogeneous system (i.e., the stock of energy-using equipment) by means of average values. In other words, this analysis assumes that the law of large numbers holds for the populations under consideration. The magnitude of uncertainty introduced by this assumption is not easily known, but one should bear in mind that this premise underlies the entire analysis. Another similar uncertainty is the assumption that tastes, preferences, and behaviors exhibited in the past will continue unchanged in the future.

The principal sources of uncertainty that directly impact the results of this analysis have to do with energy-efficiency policies. Depending on the policy, the very existence of the policy may be in question (or its date of enactment), as well as its method of implementation, its reception by consumers, and its overall effectiveness in transforming the market. In addition, the cost of implementing programs can vary substantially, as demonstrated by past policies. These are the main types of uncertainty considered here.

\section{B. Scenarios}

This study analyzes two scenarios, besides the "best estimate" scenario already presented. The first is a "Higher Penetration, Lower Cost" scenario, which is meant to be an upper-bound on achievable potential. This scenario is founded on the assumption that the experience with implementing policies in the past makes the future policies more successful and less expensive than expected. The second scenario represents a "Lower Penetration, Higher Cost" situation, and is intended to be a lower-bound on achievable potential. This scenario assumes that the policy successes to date have simply exploited the "easy" savings, implying that future programs will be less successful.

In order to estimate the uncertainty contained in the best estimate of achievable potential, I have constructed supply curves using modified estimates of market penetration and program costs. The resulting scenarios include all adjustment factors discussed earlier. The values of these factors did not change in the scenarios, except for free riders, which decreased by $50 \%$ in the low-cost scenario and increased by $20 \%$ in the high-cost scenario. The results of changing the scenario inputs are shown in Figure 8. They indicate that between 36 and $58 \%$ of the technical potential is achievable. It is interesting to note that even with this uncertainty range, the achievable potential is still significantly less than the technical potential. 
Figure 8: Achievable Potential Scenarios

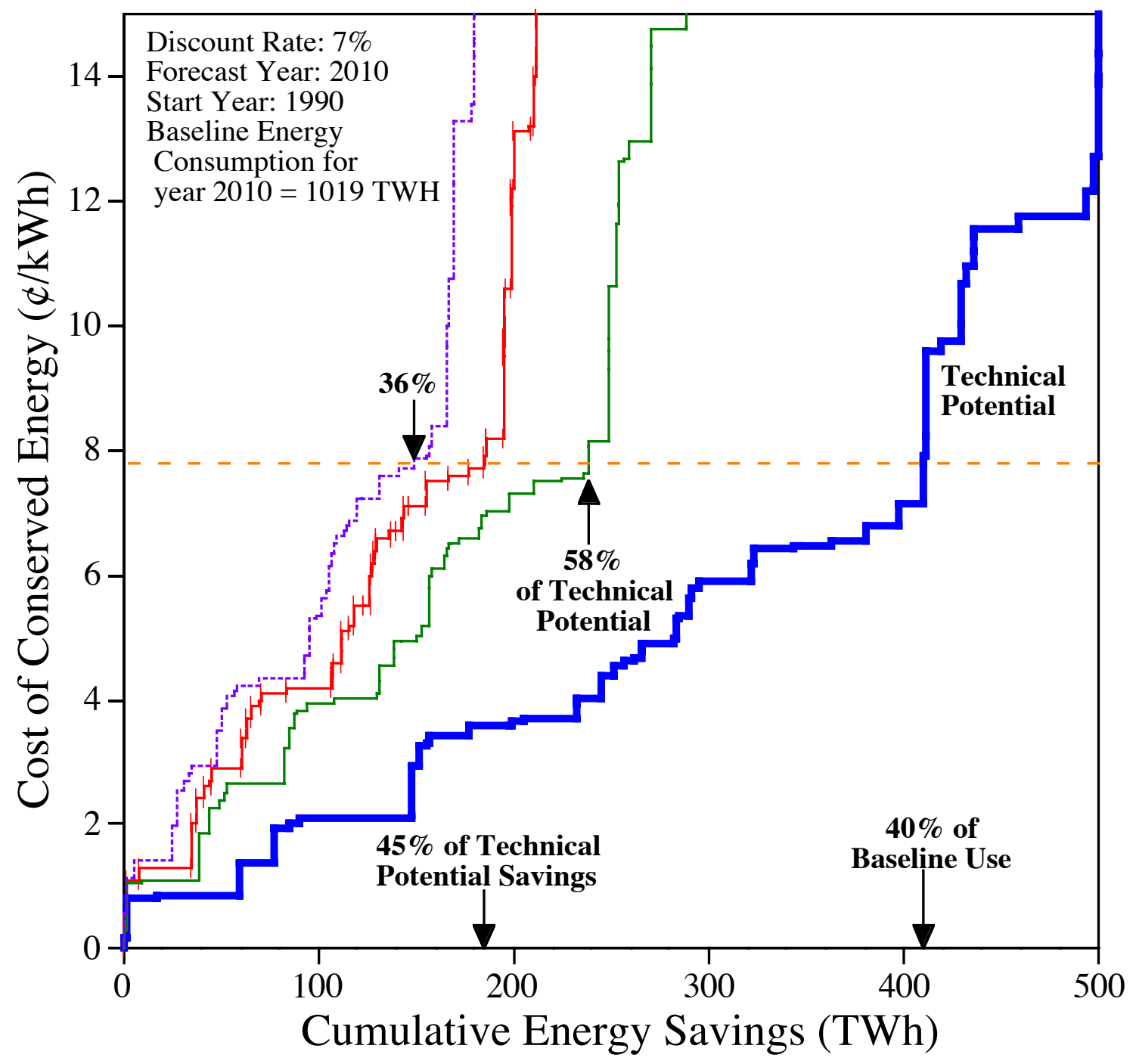

Two scenarios have been constructed to investigate the possible range of achievable potential. The "optimistic" scenario assumes higher market penetration and lower program costs for policies. The "pessimistic" scenario assumes lower market penetration and higher program costs. The full range of energy savings is approximately $50 \%$ of the best estimate (22\% range from high to low, compared to a best estimate of $45 \%$ ), while the range of CCEs is approximately $100 \%$ of the best estimate on the upper side and only about $10 \%$ on the lower side (the range is defined at the best-estimate savings level, compared to a best-estimate CCE of $7.8 \phi / \mathrm{kWh})$. 


\section{Conclusions}

\section{A. Limitations}

As a preliminary attempt to quantify achievable potential, this study suffers from several limitations. First, all of the limitations outlined in the original technical potential study also apply to this effort, because the efficiency measures are drawn directly from that study. Second, the technical potential adjustment factors used in this study are a crude attempt to incorporate dynamic effects which can be important in determining the ultimate energy savings. Empirical evidence suggests that these dynamic effects exist, but quantifying them more precisely will require more data and more sophisticated models. Third, the uncertainty in the achievable potential estimate should be examined in more detail, preferably using a probabilistic uncertainty method. Scenario analysis such as used in this study tends to identify the most extreme possible outcomes, with little regard for the probability that those outcomes will actually occur. A probabilistic analysis can help to identify the range of savings potentials which are likely to be achieved. Finally, assessing achievable potential more accurately will require more comprehensive empirical data on the effects and costs of policies. In particular, the costs of standards and the market penetration of utility programs are two areas in which generalized empirical results are needed.

\section{B. Summary}

This paper has developed estimates of the achievable potential for electricity efficiency improvements in the U.S. residential sector. The work builds upon a previous technical potential study that used the supply curves of conserved energy method. This study adjusted the technical potential in three ways to estimate achievable potential: 1) derived market penetrations for energyefficient technologies as a result of policies; 2) added program administration costs to the technology costs of the technical potential; and 3) adjusted the technical potential energy savings to account for deviations between engineering estimates and observed energy savings. Three policies were considered: appliance standards, utility DSM programs, and building standards. The results show that by 2010 these policies can achieve approximately $40 \%$ of the technical potential, or 180 TWh of electricity savings out of a frozen efficiency baseline consumption of $1019 \mathrm{TWh}(17 \%)$. This savings potential includes all measures costing less than the 1990 national average retail electricity price $(7.8 \propto / \mathrm{kWh})$. Approximately $60 \%$ of these savings were due to appliance standards, $33 \%$ due to DSM programs, and $7 \%$ due to building standards.

Two caveats apply to these results. First, the achievable potential is not the likely level of energyefficiency improvements, but rather the savings we can achieve through a concerted effort to institute energy-efficiency policies. Second, the savings potential presented here includes all of the technical potential adjustment factors, which some readers may feel over-compensates for empirically-observed shortfalls in the performance and cost of energy-efficient technologies. 


\section{References}

Berry, Linda. 1990. The Market Penetration of Energy-Efficiency Programs. Oak Ridge National Laboratory. ORNL/CON-299. April.

Berry, Linda. 1991. "The Administrative Costs of Energy Conservation Programs." Energy Systems and Policy. vol. 15, no. 1. p. 1.

Brathwait, Steven D., Douglas W. Caves and Philip Hanser. 1993. "The Complete and Unabridged Measure of DSM Net Benefits: What We've Been Missing". Presented at 6th National DemandSide Management Conference: Making a Difference in Published by Electric Power Research Institute.

CEC. 1983. California's Appliance Standards: An Historical Review, Analysis, and Recommendations. California Energy Commission. P400-83-020. July, 1983.

CEC. 1992. Energy Efficiency Standards for Residential and Nonresidential Buildings. California Energy Commission. P400-92-001. July.

Chamberlin, John N. and Patricia N. Herman. 1993. "Why All "Good" Economists Reject the RIM Test". Presented at 6th National Demand-Side Management Conference: Making a Difference in Published by Electric Power Research Institute.

EPACT. 1992. Energy Policy Act of 1992. House of Representatives. 102-1018. October 5th.

Huang, Y.J., R. Ritschard, J. Bull, S. Byrne, I. Turiel, D. Wilson, C. Hsui and D. Foley. 1987. Methodology and Assumptions for Evaluating Heating and Cooling Energy Requirements in New Single-Family Residential Buildings. Technical Support Document for the PEAR Microcomputer Program. Lawrence Berkeley Laboratory. LBL-19128. January.

Kendall, D.L. and S.C. Cates. 1991. Market Penetration of New Technologies, Programs, and Services. Electric Power Research Institute. CU-7011. February.

Koomey, Jonathan, Celina Atkinson, Alan Meier, James E. McMahon, Stan Boghosian, Barbara Atkinson, Isaac Turiel, Mark D. Levine, Bruce Nordman and Peter Chan. 1991. The Potential for Electricity Efficiency Improvements in the U.S. Residential Sector. Lawrence Berkeley Laboratory. LBL-30477. July 1991.

Krause, Florentin, John Brown, Deborah Connell, Peter DuPont, Kathy Greely, Margaret Meal, Alan Meier, Evan Mills and Bruce Nordman. 1988. Analysis of Michigan's Demand-Side Electric Resources in the Residential Sector (Prepared for the Michigan Electricity Options Study). Lawrence Berkeley Laboratory. LBL-23025 (Vol. I-Executive Summary); LBL-23026 (Vol. IIMethodology and Results); LBL-23027 (Vol. III-End-use studies). April.

Krause, Florentin, John F. Busch and Jonathan G. Koomey. 1992. Incorporating Global Warming Risks in Power Sector Planning: A Case Study of the New England Region. Lawrence Berkeley Laboratory. LBL-30797 (vols I and II). November 1992. 
Krause, Florentin and Joseph Eto. 1988. Least-Cost Utility Planning: A Handbook for Public Utility Commissioners (v.2): The Demand Side: Conceptual and Methodological Issues. National Association of Regulatory Utility Commissioners, Washington, DC. December.

Meier, Alan, Jan Wright and Arthur H. Rosenfeld. 1983. Supplying Energy Through Greater Efficiency. Berkeley, CA: University of California Press.

Morrill, John. 1993. "New Standards Begin, But Will Rebates Continue?". Home Energy. January/February. p. 34.

Nadel, Steven. 1990. Lessons Learned: A Review of Utility Experience with Conservation and Load Management Programs for Commercial and Industrial Customers. New York State Energy Research and Development Authority. March.

Nadel, Steven. 1991. "Electric Utility Conservation Programs: A Review of the Lessons Taught by a Decade of Program Experience." In State of the Art of Energy Efficiency: Future Directions. Edited by E. Vine and D. Crawley. Washington, D.C.: American Council for an Energy-Efficient Economy.

Nadel, Steven M. and Kenneth M. Keating. 1991. "Engineering Estimates Vs. Impact Evaluation Results: How Do They Compare and Why?". Presented at International Energy Program Evaluation Conference in Chicago. Published by Argonne National Laboratory.

Nadel, Steven M. and Harvey B. Tress. 1990. The Achievable Conservation Potential in New York State from Utility Demand-Side Management Programs. New York State Energy Research and Development Authority. 90-18. November.

NAHB. 1990. Consumer Survey of Additions and Alterations. National Association of Home Builders. March.

Rosenfeld, Arthur, Celina Atkinson, Jonathan Koomey, Alan Meier, Robert Mowris and Lynn Price. 1993. "Conserved Energy Supply Curves." Contemporary Policy Issues. vol. XI, no. 1. p. 45.

Rubin, Edward S., Richard N. Cooper, Robert A. Frosch, Thomas H. Lee, Gregg Marland, Arthur H. Rosenfeld and Deborah D. Stine. 1992. "Realistic Mitigation Options for Global Warming." Science. vol. 257, no. p. 148.

US DOE, U.S. Department of Energy. 1991. Electric Power Annual 1989. Energy Information Administration. DOE/EIA-0348(89). January.

Vine, Edward L. 1992a. "Free Rider Estimation: Refining the Use of Surveys." Energy -- The International Journal. vol. 17, no. 10. p. 919.

Vine, Edward L. 1992b. "Persistence of Energy Savings: What Do We Know and How Can It Be Ensured?" Energy: The International Journal. vol. 17, no. 11. p. 1073. 


\section{Appendix A: Aggregation of Technical Potential Measures}

Table A-1 shows the correspondence between the aggregated measures and the measures from the original LBL technical potential study (Koomey et al. 1991). Measures are grouped according to similar end-uses, cost-effectiveness, and efficiency level. The columns labeled "RECO \& Basic Code" and "Program" are used for thermal shell measures to distinguish which specific technical potential measures are promoted by these policies. Table A-2 summarizes the final aggregated measures and ranks them by CCE. 
Table A-1: Technical Potential Measure Aggregation

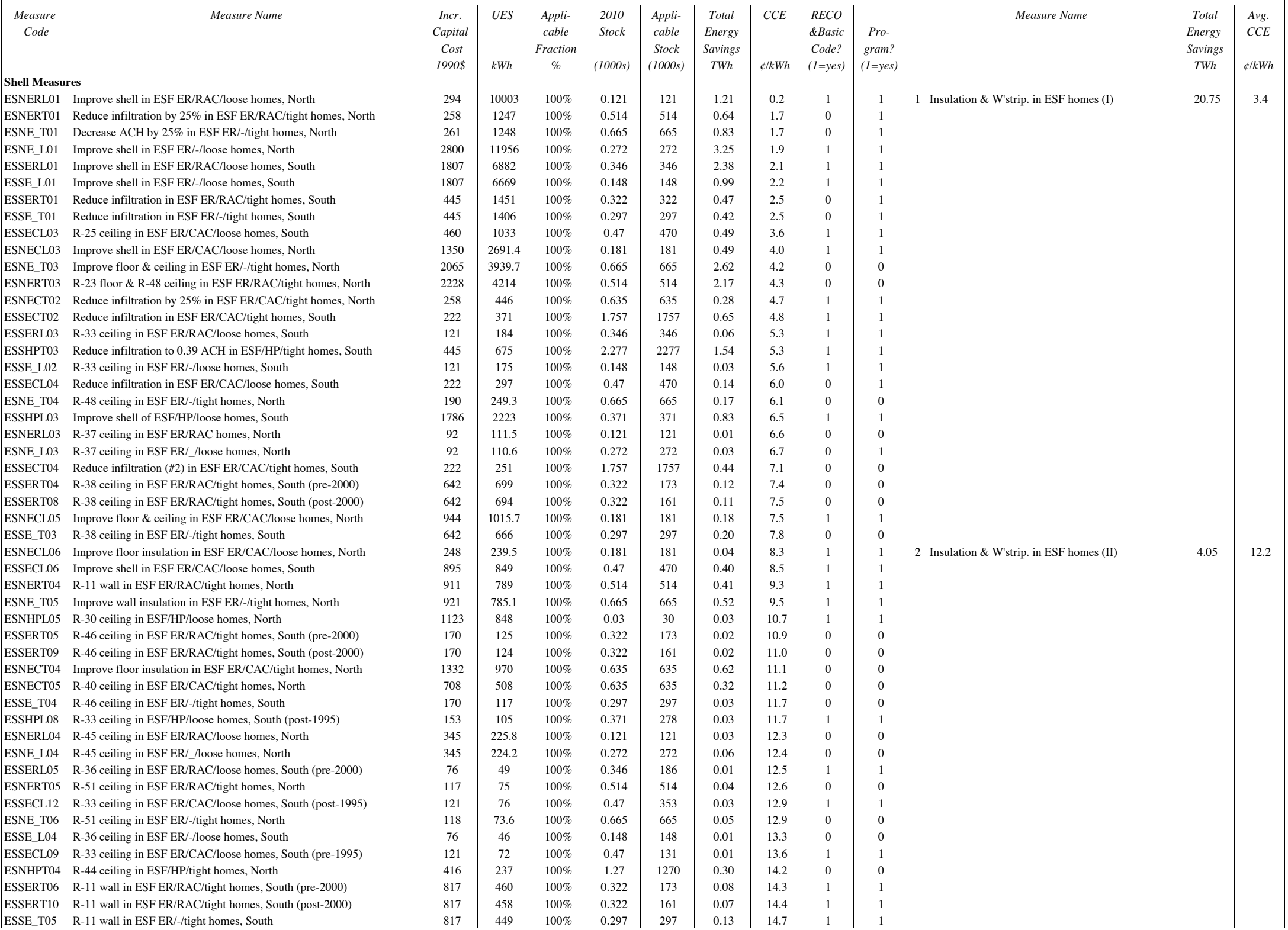


Table A-1: Technical Potential Measure Aggregation

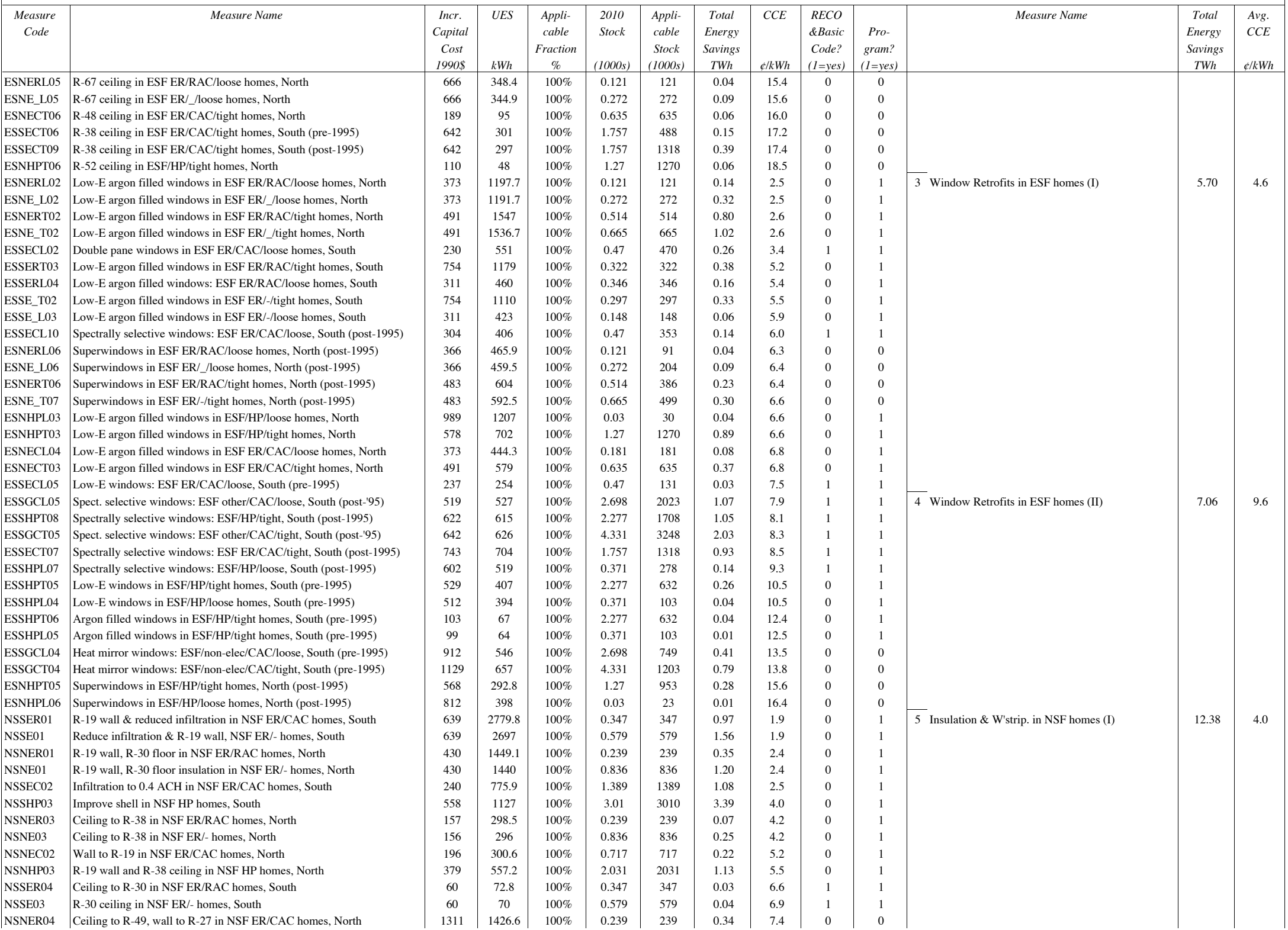


Table A-1: Technical Potential Measure Aggregation

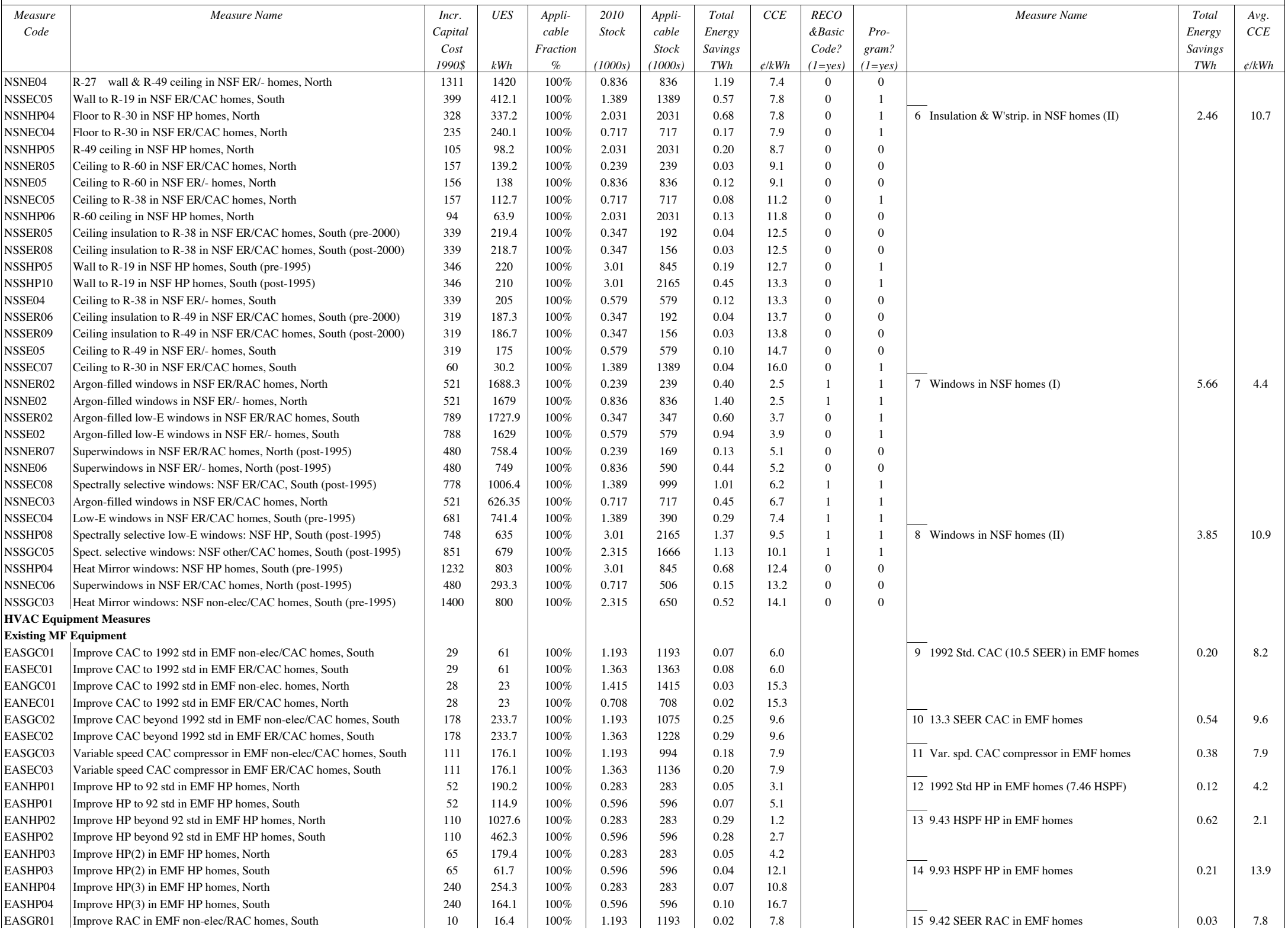




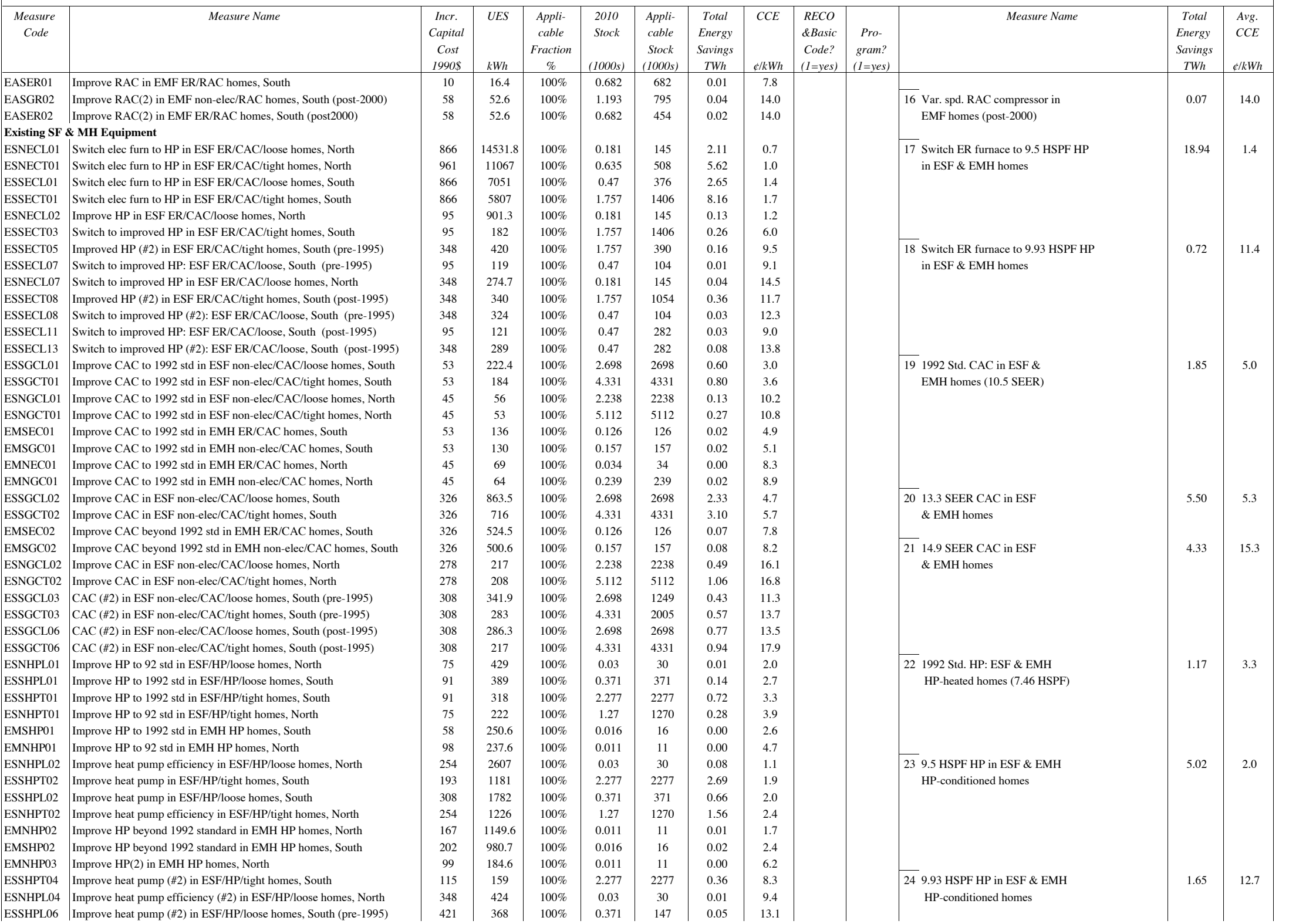


Table A-1: Technical Potential Measure Aggregation

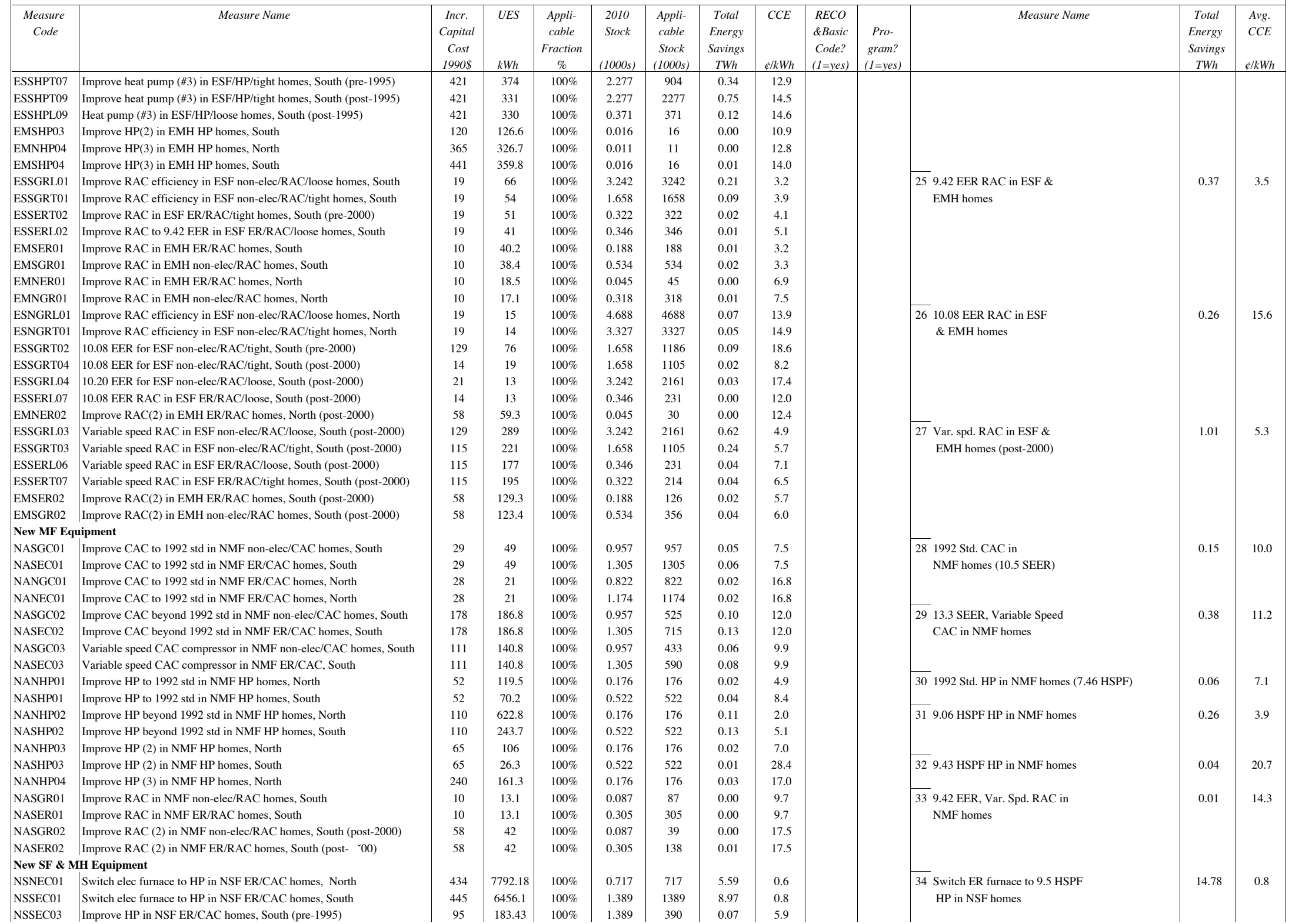


Table A-1: Technical Potential Measure Aggregation

\begin{tabular}{|c|c|c|c|c|c|c|c|c|c|c|c|c|c|}
\hline $\begin{array}{c}\text { Measure } \\
\text { Code }\end{array}$ & Measure Name & $\begin{array}{c}\text { Incr. } \\
\text { Capital } \\
\text { Cost } \\
1990 \$\end{array}$ & $k W h$ & $\begin{array}{c}\text { Appli- } \\
\text { cable } \\
\text { Fraction } \\
\%\end{array}$ & $\begin{array}{l}2010 \\
\text { Stock } \\
(1000 s)\end{array}$ & $\begin{array}{l}\text { Appli- } \\
\text { cable } \\
\text { Stock } \\
(1000 s)\end{array}$ & $\begin{array}{c}\text { Total } \\
\text { Energy } \\
\text { Savings } \\
\text { TWh }\end{array}$ & CCE & $\begin{array}{l}\text { RECO } \\
\& \text { Basic } \\
\text { Code? } \\
(1=y e s)\end{array}$ & $\begin{array}{c}\text { Pro- } \\
\text { gram? } \\
(1=y e s)\end{array}$ & Measure Name & $\begin{array}{c}\text { Total } \\
\text { Energy } \\
\text { Savings } \\
\text { TWh } \\
\end{array}$ & $\begin{array}{l}\text { Avg. } \\
C C E \\
\epsilon / k W h\end{array}$ \\
\hline NSSEC09 & Improve HP in NSF ER/CAC homes, South (post-1995) & 95 & 155.6 & $100 \%$ & 1.389 & 999 & 0.16 & 7.0 & & & & & \\
\hline NSSEC06 & Improve HP in NSF ER/CAC homes, South (pre-1995) & 348 & 359.4 & $100 \%$ & 1.389 & 390 & 0.14 & 11.1 & & & 359.93 HSPF HP in NSF homes & 0.45 & 12.2 \\
\hline NSSEC10 & Improve HP in NSF ER/CAC homes, South (post-1995) & 348 & 313.8 & $100 \%$ & 1.389 & 999 & 0.31 & 12.7 & & & & & \\
\hline NSSGC01 & Improve CAC to 1992 std in NSF non-elec/CAC homes, South & 53 & 186.59 & $100 \%$ & 2.315 & 2315 & 0.43 & 3.6 & & & 361992 Std. CAC in NSF \& & 0.80 & 5.6 \\
\hline NSNGC01 & Improve CAC to 1992 std in NSF non-elec/CAC homes, North & 45 & 54 & $100 \%$ & 3.704 & 3704 & 0.20 & 10.6 & & & NMH homes (10.5 SEER) & & \\
\hline NMSGC01 & Improve CAC to 1992 std in NMH non-elec/CAC homes, South & 53 & 140 & $100 \%$ & 0.424 & 424 & 0.06 & 4.7 & & & & & \\
\hline NMSEC01 & Improve CAC to 1992 std in NMH ER/CAC homes, South & 53 & 140 & $100 \%$ & 0.679 & 679 & 0.10 & 4.7 & & & & & \\
\hline NMNGC01 & Improve CAC to 1992 std in NMH non-elec/CAC homes, North & 45 & 67 & $100 \%$ & 0.147 & 147 & 0.01 & 8.5 & & & & & \\
\hline NMNEC01 & Improve CAC to 1992 std in NMH ER/CAC homes, North & 45 & 67 & $100 \%$ & 0.031 & 31 & 0.00 & 8.5 & & & & & \\
\hline NSSGC02 & Improve CAC in NSF non-elec/CAC homes, South & 326 & 724.54 & $100 \%$ & 2.315 & 2315 & 1.68 & 5.7 & & & 37 13.3 SEER CAC in NSF & 2.27 & 6.2 \\
\hline NMSGC02 & Improve CAC beyond 1992 std in NMH non-elec/CAC homes, South & 326 & 536.9 & $100 \%$ & 0.424 & 424 & 0.23 & 7.6 & & & \& NMH homes & & \\
\hline NMSEC02 & Improve CAC beyond 1992 std in NMH ER/CAC homes, South & 326 & 536.9 & $100 \%$ & 0.679 & 679 & 0.36 & 7.6 & & & & & \\
\hline NSNGC02 & Improve CAC to $13.3 \mathrm{SEER}$ in NSF non-elec/CAC homes, North & 278 & 208 & $100 \%$ & 3.704 & 3704 & 0.77 & 16.8 & & & 3814.9 SEER CAC in NSF & 1.26 & 17.4 \\
\hline NSSGC04 & CAC to 14.87 SEER: NSF non-elec/CAC homes, South (pre-1995) & 308 & 202.4 & $100 \%$ & 2.315 & 650 & 0.13 & 19.2 & & & \& NMH homes & & \\
\hline NSSGC06 & CAC to 14.87 SEER: NSF non-elec/CAC homes, South (post-1995) & 308 & 215.2 & $100 \%$ & 2.315 & 1666 & 0.36 & 18.0 & & & & & \\
\hline NSNHP01 & Improve HP to 1992 standard in NSF HP homes, North & 75 & 242.9 & $100 \%$ & 2.031 & 2031 & 0.49 & 3.5 & & & 391992 Std. HP: NSF \& NMH & 1.37 & 3.6 \\
\hline NSSHP01 & Improve HP to 1992 standard in NSF HP homes, South & 91 & 285.4 & $100 \%$ & 3.01 & 3010 & 0.86 & 3.6 & & & HP-heated homes (7.46 HSPF) & & \\
\hline NMSHP01 & Improve HP to 1992 std in NMH HP homes, South & 60 & 238.8 & $100 \%$ & 0.057 & 57 & 0.01 & 2.9 & & & & & \\
\hline NSNHP02 & Improve HP beyond 1992 standard in NSF HP homes, North & 254 & 1557.4 & $100 \%$ & 2.031 & 2031 & 3.16 & 1.9 & & & $409.5 \mathrm{HSPF}$ HP in NSF \& & 6.59 & 1.9 \\
\hline NSSHP02 & Improve HP beyond 1992 standard in NSF HP homes, South & 193 & 1122 & $100 \%$ & 3.01 & 3010 & 3.38 & 2.0 & & & NMH homes & & \\
\hline NMSHP02 & Improve HP beyond 1992 standard in NMH HP homes, South & 202 & 916.8 & $100 \%$ & 0.057 & 57 & 0.05 & 2.5 & & & & & \\
\hline NSSHPO6 & Improve HP in NSF HP homes, South (pre-1995) & 115 & 99 & $100 \%$ & 3.01 & 845 & 0.08 & 13.3 & & & $419.93 \mathrm{HSPF}$ HP in NSF \& & 1.73 & 15.5 \\
\hline NSNHP07 & Improve HP to $9.93 \mathrm{HSPF} / 15.14$ SEER in NSF HP homes, North & 348 & 282 & $100 \%$ & 2.031 & 2031 & 0.57 & 14.1 & & & NMH homes & & \\
\hline NSSHP07 & Improve HP (\#2) in NSF HP homes, South (pre-1995) & 421 & 255 & $100 \%$ & 3.01 & 845 & 0.22 & 18.9 & & & & & \\
\hline NSSHP09 & Improve HP in NSF HP homes, South (post-1995) & 115 & 113.4 & $100 \%$ & 3.01 & 2165 & 0.25 & 11.6 & & & & & \\
\hline NSSHP11 & Improve HP (\#2) in NSF HP homes, South (post-1995) & 421 & 272 & $100 \%$ & 3.01 & 2165 & 0.59 & 17.7 & & & & & \\
\hline NMSHP03 & Improve HP (2) in NMH HP homes, South & 120 & 115.3 & $100 \%$ & 0.057 & 57 & 0.01 & 11.9 & & & & & \\
\hline NMSHP04 & Improve HP (3) in NMH HP homes, South & 441 & 326.7 & $100 \%$ & 0.057 & 57 & 0.02 & 15.4 & & & & & \\
\hline NSSGR01 & Increase RAC condenser rows in NSF non-elec/RAC, South & 19 & 55 & $100 \%$ & 0.81 & 810 & 0.04 & 3.8 & & & 429.42 EER, Var. Spd. RAC in & 0.28 & 4.8 \\
\hline NSSER03 & Increase RAC condenser rows in NSF ER/RAC homes, South & 19 & 46.2 & $100 \%$ & 0.347 & 347 & 0.02 & 4.5 & & & NSF \& NMH homes & & \\
\hline NSSGR02 & Variable speed RAC in NSF non-elec/RAC, South (post-2000) & 115 & 261.8 & $100 \%$ & 0.81 & 363 & 0.10 & 4.8 & & & & & \\
\hline NSSER07 & Variable speed RAC in NSF ER/RAC homes, South (post-2000) & 115 & 187.2 & $100 \%$ & 0.347 & 156 & 0.03 & 6.7 & & & & & \\
\hline NMSGR01 & Improve RAC in NMH non-elec/RAC homes, South & 10 & 41.2 & $100 \%$ & 0.424 & 424 & 0.02 & 3.1 & & & & & \\
\hline NMSER01 & Improve RAC in NMH ER/RAC homes, South & 10 & 41.2 & $100 \%$ & 0.538 & 538 & 0.02 & 3.1 & & & & & \\
\hline NMNGR01 & Improve RAC in NMH non-elec/RAC homes, North & 10 & 18.1 & $100 \%$ & 0.165 & 165 & 0.00 & 7.0 & & & & & \\
\hline NMNER01 & Improve RAC in NMH ER/RAC homes, North & 10 & 18.1 & $100 \%$ & 0.037 & 37 & 0.00 & 7.0 & & & & & \\
\hline NMSGR02 & Improve RAC (2) in NMH non-elec/RAC homes, South (post-2000) & 58 & 132.3 & $100 \%$ & 0.424 & 188 & 0.02 & 5.6 & & & & & \\
\hline NMSER02 & Improve RAC (2) in NMH ER/RAC homes, South (post-2000) & 58 & 132.3 & $100 \%$ & 0.538 & 239 & 0.03 & 5.6 & & & & & \\
\hline NSSGR03 & Incr. RAC evaporator area: NSF non-elec/RAC, South (post-2000) & 14 & 18.2 & $100 \%$ & 0.81 & 363 & 0.01 & 8.6 & & & 439.42 EER RAC in NSF homes & 0.02 & 11.7 \\
\hline NSNGR01 & Increase RAC condenser rows in NSF non-elec/RAC homes, North & 16 & 14.4 & $100 \%$ & 1.075 & 1075 & 0.02 & 12.1 & & & & & \\
\hline NSNER06 & Improve room AC efficiency in NSF ER/CAC homes, North & 19 & 12 & $100 \%$ & 0.239 & 239 & 0.00 & 17.4 & & & & & \\
\hline \multicolumn{14}{|c|}{ Appliance Measures } \\
\hline REF01 & Improve refrigerator to 1993 standard & 78 & 203.2 & $100 \%$ & 135.898 & 135898 & 27.61 & 3.7 & & & 44 1993 NAECA Standard Refrigerator & 27.61 & 3.7 \\
\hline REF04 & Recycle refrigerator condenser heat (post-2000) & 58 & 100 & $100 \%$ & 135.898 & 77135 & 7.71 & 5.6 & & & 45 Refrig.: Evac. Panels, Recycle & 16.43 & 6.8 \\
\hline REF02 & Evacuated Panels for refrigerator (post-2000) & 91 & 113 & $100 \%$ & 135.898 & 77135 & 8.72 & 7.8 & & & _Condenser Heat (post-2000) & & \\
\hline REF05 & Raise refrigerator compressor EER to 5.3 (post-2000) & 15 & 18 & $100 \%$ & 135.898 & 77135 & 1.39 & 8.0 & & & 46 Refrigerator: 5.3 EER \& Two & 6.71 & 16.7 \\
\hline REF03 & Two-Compressor System for refrigerator (post-2000) & 135 & 69 & $100 \%$ & 135.898 & 77135 & 5.32 & 18.9 & & & Compressors (post-2000) & & \\
\hline FRZR01 & Improve freezer to $1993 \mathrm{DOE}$ standard & 50 & 99.8 & $100 \%$ & 35.973 & 34372 & 3.43 & 4.6 & & & 47 1993 NAECA Standard Freezer & 3.43 & 4.6 \\
\hline FRZR03 & 5.3 EER compressor for freezer (post-2000) & 11 & 25 & $100 \%$ & 35.973 & 18569 & 0.46 & 4.1 & & & 48 Freezer: 5.3 EER, Evac. Panels, & 3.84 & 6.4 \\
\hline FRZR04 & Recycle freezer condenser heat (post-2000) & 33 & 50 & $100 \%$ & 35.973 & 18569 & 0.93 & 6.1 & & & Recycle Heat (post-2000) & & \\
\hline FRZR02 & Evacuated panels for freezer (post-2000) & 101 & 132 & $100 \%$ & 35.973 & 18569 & 2.45 & 7.0 & & & & & \\
\hline
\end{tabular}


Table A-1: Technical Potential Measure Aggregation

\begin{tabular}{|c|c|c|c|c|c|c|c|c|c|c|c|c|c|}
\hline $\begin{array}{c}\text { Measure } \\
\text { Code }\end{array}$ & Measure Name & $\begin{array}{c}\text { Incr. } \\
\text { Capital } \\
\text { Cost } \\
1990 \$ \\
\end{array}$ & UES & $\begin{array}{c}\text { Appli- } \\
\text { cable } \\
\text { Fraction } \\
\%\end{array}$ & $\begin{array}{l}2010 \\
\text { Stock } \\
(1000 s)\end{array}$ & $\begin{array}{c}\text { Appli- } \\
\text { cable } \\
\text { Stock } \\
(1000 \text { s })\end{array}$ & $\begin{array}{c}\text { Total } \\
\text { Energy } \\
\text { Savings } \\
\text { TWh } \\
\end{array}$ & $C C E$ & $\begin{array}{c}\text { RECO } \\
\& \text { Basic } \\
\text { Code? } \\
(1=y e s)\end{array}$ & $\begin{array}{c}\text { Pro- } \\
\text { gram? } \\
(1=y e s)\end{array}$ & Measure Name & $\begin{array}{c}\text { Total } \\
\text { Energy } \\
\text { Savings } \\
\text { TWh } \\
\end{array}$ & $\begin{array}{l}\text { Avg. } \\
C C E \\
4 / k W h\end{array}$ \\
\hline EWH02 & Reduce hot water consumption with aerators \& showerheads & 53 & 873 & $92 \%$ & 52.314 & 48129 & 42.02 & 0.9 & & & 49 EWH: Aerators, Showerheads & 42.02 & 0.9 \\
\hline EWH04 & Reduce water heater standby losses & 126 & 425 & $92 \%$ & 52.314 & 48129 & 20.45 & 3.6 & & & 50 EWH: Reduce Standby Losses & 20.45 & 3.6 \\
\hline EWH08 & Heat pump water heater (post-2000) & 530 & 1076 & $48 \%$ & 52.314 & 20044 & 21.57 & 5.9 & & & 52 Replace electric water heater with & 26.66 & 5.9 \\
\hline EWH05 & Heat pump water heater (1995-2000) & 530 & 1076 & $24 \%$ & 52.314 & 4730 & 5.09 & 5.9 & & & HP water heater & & \\
\hline LTG02 & Compact Fluorescent Lamps & 65 & 342 & $100 \%$ & 117.559 & 117559 & 40.21 & 2.1 & & & 53 Compact Fluorescents; Outdoor & 57.96 & 2.1 \\
\hline LTG01 & Timer \& photocell for outdoor lighting & 29 & 151 & $100 \%$ & 117.559 & 117559 & 17.75 & 2.1 & & & L Timer and Photocell & & \\
\hline LTG03 & Compact Fluorescent Fixtures & 313 & 293 & $100 \%$ & 117.559 & 117559 & 34.44 & 11.7 & & & 54 Compact Fluorescent Fixtures & 34.44 & 11.7 \\
\hline EWH07 & Horizontal axis clotheswasher w/ EWH (1995-2000) & 144 & 285 & $27 \%$ & 52.314 & 5321 & 1.52 & 5.7 & & & 56 Horizontal Axis Clotheswasher (I) & 3.36 & 5.8 \\
\hline MISE06 & Horizontal axis clotheswasher w/EWH (motor svgs) post-2000 & 33 & 64.6 & $35 \%$ & 117.559 & 28560 & 1.85 & 5.8 & & & & & \\
\hline EWH10 & Horizontal axis clotheswasher w/ EWH (post-2000) & 197 & 285 & $35 \%$ & 52.314 & 14616 & 4.17 & 7.9 & & & 57 Horizontal Axis Clotheswasher (II) & 9.79 & 9.8 \\
\hline MISE04 & Horizontal axis clotheswasher w/EWH (motor svgs) 1995-2000 & 45 & 64.6 & $27 \%$ & 117.559 & 10911 & 0.70 & 8.0 & & & & & \\
\hline EWHO6 & Horizontal axis clotheswasher w/ HPWH (1995-2000) & 122 & 142.5 & $10 \%$ & 52.314 & 1971 & 0.28 & 9.7 & & & & & \\
\hline MISE07 & Horizontal axis clotheswasher w/HPWH (motor svgs) post-2000 & 55 & 64.6 & $39 \%$ & 117.559 & 31824 & 2.06 & 9.7 & & & & & \\
\hline EWHO9 & Horizontal axis clotheswasher w/HPWH (post-2000) & 166 & 142.5 & $39 \%$ & 52.314 & 16286 & 2.32 & 13.3 & & & & & \\
\hline MISE05 & Horizontal axis clotheswasher w/HPWH (motor svgs) 1995-2000 & 76 & 64.6 & $10 \%$ & 117.559 & 4041 & 0.26 & 13.3 & & & & & \\
\hline CD-E01 & Improve clothes dryer to 1994 NAECA standard & 32 & 73 & $100 \%$ & 69.83 & 69830 & 5.10 & 4.5 & & & 581994 NAECA Standard Clothes Dryer & 5.10 & 4.5 \\
\hline CD-E02 & Switch electric clothes dryer to gas & 506 & 807 & $36 \%$ & 69.83 & 25139 & 20.29 & 6.4 & & & 59 Switch Electric Clothes Dryer to Gas & 20.29 & 6.4 \\
\hline CD-E03 & Heat pump clothes dryer & 331 & 524.9 & $64 \%$ & 69.83 & 28374 & 14.89 & 6.5 & & & 60 Heat Pump Clothes Dryer & 14.89 & 6.5 \\
\hline MISE03 & Improve dishwasher motor to 1994 standard & 5 & 23.4 & $45 \%$ & 117.559 & 52666 & 1.23 & 2.7 & & & 611994 NAECA Standard Dishwasher & 3.40 & 2.9 \\
\hline ERNG01 & Switch from electric to gas range & 622 & 943.5 & $22 \%$ & 88.404 & 19449 & 18.35 & 6.6 & & & 62 Switch from electric to gas range & 18.35 & 6.6 \\
\hline ERNG02 & Induction cooktop and improved oven (post-1995) & 180 & 250 & $70 \%$ & 88.404 & 53465 & 13.37 & 7.2 & & & 63 Induction cooktop and improved oven (post-1995) & 13.37 & 7.2 \\
\hline MISE02 & Upgrade furnace fan efficiency & 50 & 150 & $30 \%$ & 117.559 & 35268 & 5.29 & 3.7 & & & 64 Upgrade Furnace Fan Efficiency & 5.29 & 3.7 \\
\hline MISE01 & Improve miscellaneous appliance motor efficiency & 200 & 190 & $100 \%$ & 117.559 & 117559 & 22.34 & 11.6 & & & 65 Appliance Motors: misc. efficiency improvements & 22.34 & 11.6 \\
\hline TV-C01 & Efficient color TV set & 8 & 34 & $100 \%$ & 109.33 & 109330 & 3.72 & 3.2 & & & $66 \mathrm{TV}$ sets: efficiency improvements & 3.83 & 3.3 \\
\hline TV-BW01 & Efficient black and white TV set & 1 & 2.5 & $100 \%$ & 43.497 & 43497 & 0.11 & 5.2 & & & & & \\
\hline
\end{tabular}

Source: Koomey et al. 1991.

Notes: (1) UES is the Unit Energy Savings of the measure.

(2) The "RECO \& Basic Code" colunn whicues which specific thermal shell measures are included in the ASHRAE 90.2 standard.

(3) The "Program" column indicates which specific thermal shell measures are promoted by utility DSM programs. 


\begin{tabular}{|c|c|c|c|c|c|}
\hline \multicolumn{6}{|c|}{$\begin{array}{l}\text { Table A-2: Technical Potential Aggregated Measures, Sorted by CCE } \\
\text { (Annual Residential Savings in 2010) }\end{array}$} \\
\hline $\begin{array}{c}\text { Tech. } \\
\text { Pot. } \\
\text { Meas. } \\
\text { \# }\end{array}$ & $\begin{array}{c}\text { Meas- } \\
\text { ure } \\
\text { Code }\end{array}$ & Measure Name & $\begin{array}{l}\text { Measure } \\
\text { Energy } \\
\text { Savings } \\
(T W h) \\
\end{array}$ & $\begin{array}{c}\text { Cum. } \\
\text { Energy } \\
\text { Savings } \\
(T W h) \\
\end{array}$ & $\begin{array}{c}\text { Avg. } \\
C C E \\
(\phi / k W h) \\
\end{array}$ \\
\hline 1 & 55 & 1994 NAECA Standard Clotheswasher & 2.15 & 2.15 & 0.2 \\
\hline 2 & 34 & Switch ER furnace to 9.5 HSPF HP in NSF homes & 14.78 & 16.93 & 0.8 \\
\hline 3 & 49 & EWH: Aerators, Showerheads & 42.02 & 58.94 & 0.9 \\
\hline 4 & 17 & Switch ER furnace to 9.5 HSPF HP in ESF \& EMH homes & 18.94 & 77.88 & 1.4 \\
\hline 5 & 40 & 9.5 HSPF HP in NSF \& NMH homes & 6.59 & 84.47 & 1.9 \\
\hline 6 & 23 & 9.5 HSPF HP in ESF \& EMH HP-conditioned homes & 5.02 & 89.49 & 2.0 \\
\hline 7 & 53 & Compact Fluorescents; Outdoor Timer and Photocell & 57.96 & 147.45 & 2.1 \\
\hline 8 & 13 & 9.43 HSPF HP in EMF homes & 0.62 & 148.06 & 2.1 \\
\hline 9 & 61 & 1994 NAECA Standard Dishwasher & 3.40 & 151.46 & 2.9 \\
\hline 10 & 66 & TV sets: efficiency improvements & 3.83 & 155.29 & 3.3 \\
\hline 11 & 22 & 1992 Std. HP: ESF \& EMH HP-heated homes (7.46 HSPF) & 1.17 & 156.46 & 3.3 \\
\hline 12 & 1 & Insulation \& W'strip. in ESF homes (I) & 20.75 & 177.21 & 3.4 \\
\hline 13 & 25 & 9.42 EER RAC in ESF \& EMH homes & 0.37 & 177.58 & 3.5 \\
\hline 14 & 50 & EWH: Reduce Standby Losses & 20.45 & 198.03 & 3.6 \\
\hline 15 & 39 & 1992 Std. HP: NSF \& NMH HP-heated homes (7.46 HSPF) & 1.37 & 199.40 & 3.6 \\
\hline 16 & 64 & Upgrade Furnace Fan Efficiency & 5.29 & 204.69 & 3.7 \\
\hline 17 & 44 & 1993 NAECA Standard Refrigerator & 27.61 & 232.30 & 3.7 \\
\hline 18 & 31 & 9.06 HSPF HP in NMF homes & 0.26 & 232.56 & 3.9 \\
\hline 19 & 5 & Insulation \& W'strip. in NSF homes (I) & 12.38 & 244.94 & 4.0 \\
\hline 20 & 12 & 1992 Std HP in EMF homes (7.46 HSPF) & 0.12 & 245.06 & 4.2 \\
\hline 21 & 7 & Windows in NSF homes (I) & 5.66 & 250.73 & 4.4 \\
\hline 22 & 58 & 1994 NAECA Standard Clothes Dryer & 5.10 & 255.82 & 4.5 \\
\hline 23 & 3 & Window Retrofits in ESF homes (I) & 5.70 & 261.52 & 4.6 \\
\hline 24 & 47 & 1993 NAECA Standard Freezer & 3.43 & 264.95 & 4.6 \\
\hline 25 & 42 & 9.42 EER, Var. Spd. RAC in NSF \& NMH homes & 0.28 & 265.23 & 4.8 \\
\hline 26 & 51 & Replace electric water heater with gas & 16.66 & 281.90 & 4.9 \\
\hline 27 & 19 & 1992 Std. CAC in ESF \& EMH homes (10.5 SEER) & 1.85 & 283.74 & 5.0 \\
\hline 28 & 27 & Var. spd. RAC in ESF \& EMH homes (post-2000) & 1.01 & 284.76 & 5.3 \\
\hline 29 & 20 & 13.3 SEER CAC in ESF \& EMH homes & 5.50 & 290.25 & 5.3 \\
\hline 30 & 36 & 1992 Std. CAC in NSF \& NMH homes (10.5 SEER) & 0.80 & 291.05 & 5.6 \\
\hline 31 & 56 & Horizontal Axis Clotheswasher (I) & 3.36 & 294.41 & 5.8 \\
\hline 32 & 52 & Replace electric water heater with HP water heater & 26.66 & 321.07 & 5.9 \\
\hline 33 & 37 & 13.3 SEER CAC in NSF \& NMH homes & 2.27 & 323.34 & 6.2 \\
\hline 34 & 59 & Switch Electric Clothes Dryer to Gas & 20.29 & 343.63 & 6.4 \\
\hline 35 & 48 & Freezer: 5.3 EER, Evac. Panels, Recycle Heat (post-2000) & 3.84 & 347.47 & 6.4 \\
\hline 36 & 60 & Heat Pump Clothes Dryer & 14.89 & 362.36 & 6.5 \\
\hline 37 & 62 & Switch from electric to gas range & 18.35 & 380.71 & 6.6 \\
\hline 38 & 45 & Refrig.: Evac. Panels, Recycle Condenser Heat (post-2000) & 16.43 & 397.14 & 6.8 \\
\hline 39 & 30 & 1992 Std. HP in NMF homes (7.46 HSPF) & 0.06 & 397.20 & 7.1 \\
\hline 40 & 63 & Induction cooktop and improved oven (post-1995) & 13.37 & 410.57 & 7.2 \\
\hline 41 & 15 & 9.42 SEER RAC in EMF homes & 0.03 & 410.60 & 7.8 \\
\hline 42 & 11 & Var. spd. CAC compressor in EMF homes & 0.38 & 410.97 & 7.9 \\
\hline
\end{tabular}




\begin{tabular}{|c|c|c|c|c|c|}
\hline \multicolumn{6}{|c|}{$\begin{array}{l}\text { Table A-2: Technical Potential Aggregated Measures, Sorted by CCE } \\
\text { (Annual Residential Savings in 2010) }\end{array}$} \\
\hline $\begin{array}{c}\text { Tech. } \\
\text { Pot. } \\
\text { Meas. } \\
\quad \#\end{array}$ & $\begin{array}{c}\text { Meas- } \\
\text { ure } \\
\text { Code }\end{array}$ & Measure Name & $\begin{array}{l}\text { Measure } \\
\text { Energy } \\
\text { Savings } \\
(T W h) \\
\end{array}$ & $\begin{array}{c}\text { Cum. } \\
\text { Energy } \\
\text { Savings } \\
(T W h) \\
\end{array}$ & $\begin{array}{c}\text { Avg. } \\
C C E \\
(\phi / k W h) \\
\end{array}$ \\
\hline 43 & 9 & 1992 Std. CAC (10.5 SEER) in EMF homes & 0.20 & 411.18 & 8.2 \\
\hline 44 & 10 & 13.3 SEER CAC in EMF homes & 0.54 & 411.72 & 9.6 \\
\hline 45 & 4 & Window Retrofits in ESF homes (II) & 7.06 & 418.77 & 9.6 \\
\hline 46 & 57 & Horizontal Axis Clotheswasher (II) & 9.79 & 428.56 & 9.8 \\
\hline 47 & 28 & 1992 Std. CAC in NMF homes (10.5 SEER) & 0.15 & 428.71 & 10.0 \\
\hline 48 & 6 & Insulation \& W'strip. in NSF homes (II) & 2.46 & 431.17 & 10.7 \\
\hline 49 & 8 & Windows in NSF homes (II) & 3.85 & 435.03 & 10.9 \\
\hline 50 & 29 & 13.3 SEER, Variable Speed CAC in NMF homes & 0.38 & 435.40 & 11.2 \\
\hline 51 & 18 & Switch ER furnace to $9.93 \mathrm{HSPF}$ HP in ESF \& EMH homes & 0.72 & 436.13 & 11.4 \\
\hline 52 & 65 & Appliance Motors: misc. efficiency improvements & 22.34 & 458.46 & 11.6 \\
\hline 53 & 54 & Compact Fluorescent Fixtures & 34.44 & 492.91 & 11.7 \\
\hline 54 & 43 & 9.42 EER RAC in NSF homes & 0.02 & 492.93 & 11.7 \\
\hline 55 & 2 & Insulation \& W'strip. in ESF homes (II) & 4.05 & 496.98 & 12.2 \\
\hline 56 & 35 & 9.93 HSPF HP in NSF homes & 0.45 & 497.44 & 12.2 \\
\hline 57 & 24 & 9.93 HSPF HP in ESF \& EMH HP-conditioned homes & 1.65 & 499.09 & 12.7 \\
\hline 58 & 14 & 9.93 HSPF HP in EMF homes & 0.21 & 499.30 & 13.9 \\
\hline 59 & 16 & Var. spd. RAC compressor in EMF homes (post-2000) & 0.07 & 499.36 & 14.0 \\
\hline 60 & 33 & 9.42 EER, Var. Spd. RAC in NMF homes & 0.01 & 499.38 & 14.3 \\
\hline 61 & 21 & 14.9 SEER CAC in ESF \& EMH homes & 4.33 & 503.71 & 15.3 \\
\hline 62 & 41 & 9.93 HSPF HP in NSF \& NMH homes & 1.73 & 505.44 & 15.5 \\
\hline 63 & 26 & 10.08 EER RAC in ESF \& EMH homes & 0.26 & 505.70 & 15.6 \\
\hline 64 & 46 & Refrigerator: 5.3 EER \& Two Compressors (post-2000) & 6.71 & 512.41 & 16.7 \\
\hline 65 & 38 & 14.9 SEER CAC in NSF \& NMH homes & 1.26 & 513.68 & 17.4 \\
\hline 66 & 32 & 9.43 HSPF HP in NMF homes & 0.04 & 513.72 & 20.7 \\
\hline
\end{tabular}

Notes:

(1) Measures are from Koomey et al. (1991), aggregated within enduses.

(2) Koomey et al. found a techno-economic potential of 404 TWh by 2010. The aggregated measures used in this study contain a techno-economic potential of $410 \mathrm{TWh}$ (using the 1990 residential electricity price; $7.8 \not / \mathrm{kWh}$ ). The difference is due to updates in the measure database since the 1991 report was published, updating to 1990 base year dollars and electricity prices, and some savings due to existing NAECA standards have been "aggregated into" the techno-economic potential.

(3) Frozen efficiency baseline consumption in 2010 is 1019 TWh.

(4) CCEs are calculated in base year 1990 dollars, using a 7\% real discount rate.

(5) "Measure Code" is the number in the "Aggregated Measure Name" column from Table A-1. 